\title{
LA IMAGEN DE LA CIRUGÍA ESTÉTICA Y SU PRESENCIA EN LOS MEDIOS DE COMUNICACIÓN
}

\section{THE IMAGE OF COSMETIC SURGERY AND HER PRESENCE IN THE MEDIA}

\author{
AUTOR \\ David Caldevilla Domínguez \\ Profesor en la Facultad de CC.II. de la Universidad Complutense de Madrid (España) \\ davidcaldevilla@ccinf.ucm.es
}

\section{RESUMEN}

Como tema recurrente en la comunicación persuasiva de nuestros días, el Grupo Concilium decidió llevar a cabo un análisis de las tendencias publicitarias que hacen que la Cirugía Estética sea considerada como la panacea antiedad actual.

Bombardeados por campañas que prometen adelgazar de años nuestro DNI, las clínicas estéticas se lanzan a la búsqueda de mercados y nuevos clientes al albur de las modas (más o menos pasajeras). Ante ellas sus detractores que prometen similares resultados sin el recurso al bisturí: las empresas cosméticas, quienes también inundan los medios de comunicación para masas con sus promesas de un Shangri-La eterno. Esta lucha por el público supone un mercado millonario ante el que nadie se muestra renuente.

Para analizar esta 'guerra' encubierta, se estudió la publicidad impresa y emitida en los diversos medios nacionales durante el periodo octubre de 2005-febrero de 2006. 
Tras la recolección de datos, se procedió a plasmar las diversas campañas en un libro-vídeo digital en el que hallan cabida la mayoría de las existentes y en el que se propuso, a modo de ejercicio de estilo una campaña de imagen en pro y otra en contra de dichos usos quirúrgicos, constituyendo una imagen fiel de los hilos que configuran este tipo de controversias en un mercado publicitario que mueve en su entorno millones de euros.

\section{PALABRAS CLAVE}

Cirugía estética - Cosmética - Moda - Operaciones quirúrgicas

\section{ABSTRACT}

As Plastic Surgery is a trending topic in the persuasive communication of these days, the Concilium Group decided to analyze the advertising trends that make Plastic Surgery be considered as the current anti-age panacea.

We are assailed by advertising campaigns that promise to make our identity cards thinner, and plastic surgery clinics are looking for new markets and customers, depending on the ongoing tendencies. There are also those who despise these practises and who promise similar results without resorting to the scalpel: cosmetic enterprises, which are also prominently present on the mass media with their promises of an eternal Shangri-La. This fight for an audience is for a billion-dollar market no one can escape from.

In order to analyze this covert 'war', we studied advertisements published in the press in the various national mass media between October 2005 and February 2006. After the recollection of data, the diverse campaigns were published on a digital video-book in which most of the advertising strategies are present, and in which, as an exercise on style, both a campaign in favour of and another against surgical practises are included, in a faithful image of the pulling of strings behind an advertising market which involves millions of euros. 


\section{KEY WORDS}

Cosmetic Surgery - Cosmetics - Fashion - Surgical operations

\section{ÍNDICE}

\section{Introducción}

2. Objetivos

3. Trabajo de campo

4. Documentación empleada

5. Historia de una 'necesidad social'

5.1. Procedimientos y técnicas de la cirugía estética:

5.2. Paso a paso de una intervención

6. Cuestión de imagen

7. Bibliografía

\section{Introducción}

La cirugía plástica no es un tipo de operación que se haya puesto de moda hoy día, sino que ya se realizaba en la antigüedad, concretamente en India hacia el 1500 a. C. para mejorar el aspecto, transformar y modificar el cuerpo humano; aunque antiguamente sólo se operaban la nariz y las orejas.

Como toda actividad humana (en este caso propia del último estadio de la pirámide de Maslow) posee aspectos positivos, neutros y negativos. En estás páginas, vamos a detenernos más específicamente en el recurso a este tipo de cirugía por deseo de 


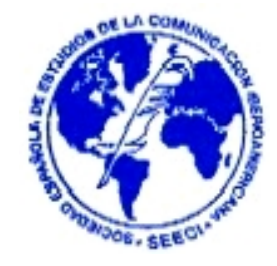

mejora física y moda que por necesidad biológica (sea médica por enfermedad, sea reconstructiva, por deficiencias naturales de la persona, incluyendo accidentes).

En cuanto a aspectos positivos a relucir podemos decir que este proceso lleva a cabo intervenciones que consiguen que las personas se sientan a gusto consigo mismas. Hay personas para las cuales la apariencia física es más importante de lo que parece, y si no se sienten a gusto con alguna parte de su cuerpo les puede acarrear un conflicto psicológico muy duro. Ellos deciden someterse a este tipo de intervenciones quirúrgicas acarreando todo tipo de riesgos, aunque también puede darse el caso que sean los propios padres quienes toman la decisión de someter a sus hijos a alguna operación de estética para evitar problemas en un futuro.

Como muchos profesionales han afirmado, en ocasiones estas operaciones están ligadas a la salud, como son aquellas mujeres que al tener demasiado pecho acarrean problemas de espalda, o casos graves de Blefarochalasis (caída de los párpados que impide la visión).

Las clínicas de cirugía estética, que se anuncian con el principal propósito de hacer la vida más agradable a aquellas personas que no estén felices con su apariencia, en todo momento se comprometen con ofrecer la máxima calidad de los tratamientos y toda la seguridad posible. Se presentan como un equipo de cualificados profesionales médicos para así aportar la mayor confianza posible, y asegurar a los pacientes que serán intervenidos en las mejores y más modernas instalaciones. Estos mensajes que dan las clínicas son muy positivos puesto que ayudan a las personas que necesitan estos tratamientos a hacerles más llevadero el procedimiento. Ofrecen la posibilidad de ver fotografías de personas que anteriormente han pasado por esas intervenciones y les explican paso a paso y con todo tipo de detalles las operaciones. Esto les genera una confianza que les permite eliminar toda clase de miedos. Es más, antes de someterse a estas técnicas todos los equipos médicos ponen al tanto a sus pacientes de los posibles riesgos y de la posibilidad de que no se consiga el 
aspecto deseado. A pesar de que en su mayoría si se consiga nunca hay que descartar la posibilidad de que surjan complicaciones.

También se puede considerar como aspecto positivo, que en la mayoría de los procedimientos no se necesita un ingreso del paciente, todo depende de la operación, de las partes y de la cantidad que se quiera reducir, etc.

\section{En cuanto a los aspectos neutros, es decir, tanto positivos como negativos,} se observa como con el paso de los años, sobre todo una vez superadas las dos guerras mundiales, la Cirugía Plástica se dividió en dos ramas:

- La Cirugía Reconstructiva o reparadora y

- La Cirugía Estética, al dictado de la moda.

Esta división fue promovida por los seguros y los servicios de Salud pública y privada, ya que éstos sólo van a cubrir aquellas operaciones relacionadas con enfermedades congénitas $\mathrm{o}$ adquiridas y con accidentes. Esto puede ser considerado un aspecto positivo, debido a que muchas personas se operan por puro placer y no por necesidad. Pero también puede ser considerado como un punto negativo porque resulta un obstáculo para aquellas personas que sí que lo necesiten, pero que no cumplan los requisitos necesarios para que la operación la cubra el seguro y no tenga medios para llevarla a cabo.

Al investigar en estos temas relacionados con la cirugía estética ha salido a relucir que la sociedad actual está muy determinada por lo que los demás piensen u opinen de uno mismo. Por ello este tipo de operaciones pueden ser positivas porque sirven para mantener contenta a la sociedad, cómoda y conforme consigo misma y que pueda alcanzar su ideal de cuerpo deseado. Por otro lado, puede ser muy negativo porque puede producir la unión de la sociedad, acarrear la pérdida de la 
personalidad y, además, una obsesión por el cambio, aunque éste no fuera necesario.

Y como aspectos negativos se podrían recalcar la falta de seriedad con que la gente se somete a estas intervenciones quirúrgicas. Tras la lectura de numerosos comentarios ha quedado demostrado que un gran número de personas que se han sometido a estas intervenciones hablan de ellas como si se tratara de un simple tratamiento de belleza, sin dar importancia a las complicaciones y los riegos que tiene cualquier operación.

Siempre hay que tener en cuenta que entrar en quirófano ya significa una intervención delicada que puede complicarse en cualquier momento y no dar los resultados esperados.

Otro aspecto negativo son lo cirujanos, muchos de ellos se hacen llamar profesionales por el hecho de llevar un título "bajo el brazo", cuando en realidad lo único que consiguen es poner en riesgo la salud de las personas que tienen pocos conocimientos en la materia. Por ello, una persona no se puede fiar de cualquiera que se haga llamar profesional en este tipo de procedimientos, sino que debe acudir a sociedades, asociaciones, personas que ya hayan pasado por estas intervenciones y clínicas que se hagan responsables, que tengan un nombre y que les aporte todo lo necesario, tanto si sale bien como si sale mal. Un caso destacado es la Sociedad Española de Sociedad Española de Cirugía Plástica (SECPRE), en donde ofrecen un listado por provincias de cirujanos que se han ganado un respeto y valoración en su trabajo por otros profesionales, y que, por ello, gozan de todas las prescripciones.

Un aspecto negativo más leve, podrían ser todas la molestias postoperatorias que implican una visita al cirujano cada cierto tiempo. 


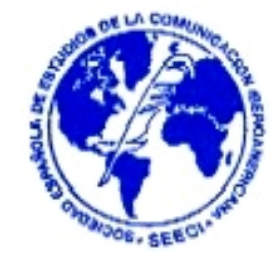

\section{Objetivos}

Durante el estudio se han ido descubriendo todas las técnicas y procedimientos posibles para realizar una transformación en la parte del cuerpo que desee la persona. Así, poco a poco nos vamos sumergiendo en el conocimiento del mundo de la cirugía estética, y vamos encontrando los consejos de los profesionales, los pasos que debe seguir un paciente, los riesgos que se corren en cada una de las operaciones y todo lo que conlleva un procedimiento de este estilo.

Así llegamos al meollo de la cuestión: ¿Qué fibras de la consciencia del público se ven afectadas en esta Comunicación Persuasiva para convertirlos en clientes?. Dicho de otro modo: ¿Cómo afecta todo esto a la sociedad en la que vivimos, qué es lo que hace que una serie de personas decidan operarse para cambiar su cuerpo?. A partir de este punto se podrá conocer cuál es el público más propicio para cada oferta de operación, la época en el año en que este tipo de cirugía está en auge, qué características comunes presentan todos aquellos que van a una clínica para transformar su cuerpo. Conociendo los intervinientes analizaremos mejor los resultados.

Para dar forma a este estudio, hemos tenido que utilizar y consultar diversas fuentes de información, las más importantes conseguidas a través de la autopista de la información: Internet. Esto es posible gracias a que la mayoría de las clínicas facilitan toda clase de información necesaria a través de sus páginas Web, al igual que los cirujanos.

Una de las páginas en que más nos hemos apoyado es www.secpre.org, página oficial de la Sociedad Española de Cirugía Plástica Reparadora y Estética, donde se facilita datos básicos de los profesionales en la materia según la operación deseada, repartidos por provincias; se desarrollan las operaciones más usuales; facilitan información para realizar cursos, conferencias, etc. 
A parte de Internet hemos encontrado otras fuentes de información, como los periódicos, Diario Médico y Correo Farmacéutico, que aparece este tema reflejado en varios números relacionados con la sanidad, si aumenta o disminuye, información de otros países, etc. Además en la página del doctor Alberto Abufalia te facilitan un número de libros escritos por el mismo sobre este tipo de procedimientos.

\section{Trabajo de campo}

Para recoger la información necesaria de primera de mano, hemos entrado en contacto con los profesionales que se dedican a la cirugía estética. La mejor forma fue acceder a la Sociedad Española de Cirugía Plástica, Reparadora y Estética (SECPRE), y una vez en la página, participamos en el foro, introduciendo comentarios y preguntas que fueron contestadas por varios especialistas.

También se recurrió a entrevistas ya realizadas y publicadas en los medioos ya que esta es una forma muy común de hacer publicity por parte de este tipo de clínicas, como fue la que realizó el periódico La Voz de Galicia al Presidente de SECARE.

Con este mismo método, quisimos contactar con diferentes medios de información nacionales, para obtener así noticias que se hubieran publicado relacionadas con las Cirugía Estética.

Visitamos algunas de las clínicas de cirugía estética más conocidas y populares en Madrid para ver las instalaciones y los medios de los que disponen y entablar un diálogo directo con los implicados.

Estuvimos en la calle Menorca donde se ubica el Centro Clínico Menorca. Allí pudimos conocer sus instalaciones y sus salas, y además comprobamos que disponen de la más moderna tecnología. Hablamos con el personal de atención al cliente y nos 
explicaron los sistemas con los que contaban, la frecuencia con la que se realizaban intervenciones y cuales eran las más solicitadas.

También acudimos a la clínica de Corporación Dermoestética situada en la calle Hermosilla. Nos garantizaron que su compromiso diario es ofrecer una respuesta satisfactoria a sus clientes, a través de la máxima calidad de los tratamientos y de la seguridad que les proporciona estar en manos de cualificados profesionales médicos en las más modernas instalaciones.

Y por último, visitamos dos de las clínicas con más prestigio en Madrid (y con sedes en otras provincias españolas), la Clínica Barragán sita en la avenida Moscatelar y la Policlínica Londres de la calle Zurbano. Allí, su personal nos explicó que llevan veinte años 'creando belleza' (lema recurrente en este tipo de clínicas), intentado aportar los mejores servicios a sus clientes. Han renovado sus instalaciones en Madrid y mantienen labores de investigación y desarrollo para la implantación de los últimos métodos y mejores tecnologías.

A pesar de todo ello, la mayoría de la información fue recogida a través de documentos oficiales aportados y fuentes de información canónicas, debido a la poca accesibilidad que mostraban algunos de los expertos.

\section{Documentación empleada}

Al margen de los folletos informativos que nos facilitaron en las clínicas citadas, hemos extraído algunas informaciones y artículos importantes de la Asociación Española de Cirujanos, junto a los datos obtenidos gracias al acceso online al texto completo de Cirugía Española. Se trata de una revista que se presenta como órgano oficial de expresión de la Asociación Española de Cirujanos. Además, nos hemos informado acerca las guías de la AEC que abordan temas muy diferenciados: guía de 
cirugía colorrectal, guía de infecciones quirúrgicas, guía de cirugía endoscópica, guía de cirugía endocrina, guía de gestión clínica en cirugía...

El acceso a una de las organizaciones estéticas más avanzadas de Europa, Corporación Dermoestética, nos ha permitido documentarnos sobre el desarrollo de cada una de las intervenciones y las técnicas empleadas en cada una de ellas.

Nos hemos informado sobre las teorías y explicaciones incluidas en algunos de los libros y manuales de cirugía más destacados. Entre ellos podemos citar: Cirugía estética de Angelika Taschen; Cirugía estética reconstructiva en implantes de ABD El Salam El Askary; Cirugía estética sin trampa ni cartón de Jorge Planas y Tu decides: todo sobre la cirugía estética de Antonio Tapia.

\section{Historia de una 'necesidad social'}

La bibliografía remonta la historia de la cirugía plástica hasta India por lo menos al año 1500 a.C., cuando Sushruta publica el Sushruta Shamita. Él fue el precursor del colgajo frontal para reconstruir la nariz, que hoy conocemos como colgajo Indio y continúa en uso. Este uso era debido a que la nariz era considerada como un órgano de reputación y respeto, por lo cual era frecuente amputar la nariz o las orejas para castigar a los criminales y a los habitantes de pueblos vencidos en una guerra, incluso se llego a pagar recompensa por cada nariz u oreja del enemigo traída en la guerra.

Estos conocimientos quirúrgicos pasaron, más tarde, a Egipto, donde se encontraron algunas referencias tangenciales de injertos de piel tomados de la región glútea, después de producir una anestesia de la zona por medio de golpes.

Pasó un largo periodo sin que se escribiera nada sobre cirugía plástica., hasta que Aulos Cornelius Celsus (25 a. C. -50 d. C.) reuniera en sus 8 libros De Re Medica 
(sobre la naturaleza de la medicina), todos los conocimientos médicos y quirúrgicos de los hindúes, los árabes, los egipcios, los griegos, los hebreos y los romanos, hasta sus días. En este tratado se describen operaciones de reconstrucción de nariz, labios y orejas, tomando colgajos de vecindad. Es considerado como el verdadero precursor de la cirugía plástica.

En los siglos VI, VII y VIII, la cirugía, y por ende la plástica, se frenó. El Corán prohibió la salida de sangre en los humanos producida por médicos. La iglesia romana prohibió las disecciones realizadas en humanos y la corrección de las malformaciones congénitas o adquiridas, porque se oponían a los designios divinos. Luego, durante el comienzo del Renacimiento, apareció en Italia una familia de médicos cirujanos, los Branca, que revivieron las técnicas hindúes de reconstrucción de nariz, pero con modificaciones. Para no dejar cicatrices deformes en la frente, tomaron del brazo del mismo paciente un colgajo de piel para reconstruir la nariz. Más tarde, un cirujano de Bolonia, Gasparo Tagliacozzi (1546-1599), autor de la obra De Cortorum chirurgia per incitionem (Sobre los cortes quirúrgicos mediante incisión), publicado en Venecia en 1597, mejoró la técnica de los Branca, la describió y la ilustró. También escribió el Nosotros restauramos, reparamos y volvemos a hacer esas partes del cuerpo que la naturaleza dio pero que el infortunio ha quitado, no tanto como para deleitar la vista. Pero, si lo suficiente como para elevar el espíritu y ayudar a la mente del afligido lo que constituye todo un desiderándum profesional. Por ello se le considera el padre de la cirugía reconstructiva nasal. Su atrevimiento no fue del agrado de la Santa Inquisición, por lo que fue perseguido y finalmente lo condenado a muerte. Sus libros fueron lanzados a la hoguera en la plaza pública. Afortunadamente algunos ejemplares se salvaron.

En el siglo XIX destacan en Alemania el cirujano Graefe, quien fue el primero en usar el término plástica en su libro Rhinoplastik publicado en Berlín en 1818 y el cirujano Zeis, quien publicó el libro Handbuch der plastischen Chirurgie en 1838 lo que popularizó finalmente el término Cirugía. 
La moda en la Inglaterra victoriana fue tal que el médico especialista Soth, llegó a escribir en 1847 que "los colgajos eran de uso tan común en Inglaterra que ya no se hacían comunicaciones sobre tal operación".

No obstante los problemas con las uniones injertadas eran muchos ya que las técnicas y el instrumental empleados eran aún rudimentarios. Así, Jaques Louis Reverdin (francés) y Fedor Krause (alemán) presentaron a la Academia de Cirugía de Francia los primeros injertos de piel que tuvieron éxito.

De Europa la cirugía plástica pasó en el siglo XIX a Norteamérica y de allí se extendió por el resto del mundo Americano.

La cirugía plástica, por tanto, cobra independencia de la cirugía general a raíz de la primera guerra mundial (1914-1919). Quedaron tantos miles de civiles y militares destrozados por las armas de fuego, las quemaduras, los accidentes, etc., que se vio la necesidad de que un grupo de cirujanos se dedicara exclusivamente a estos casos.

Éste fue, sin duda, el acelerante necesario para la mejora en las técnicas quirúrgicas de todo orden y en la Cirugía Reconstructiva en especial. Ejemplos palpables son Morestin, Sir H. Gillies y V.H. Kazanjian, creadores del instrumental y técnicas de Reconstrucción que aún hoy día usamos y llevan sus nombres, durante la Primera Guerra Mundial. A ellos, finalmente podemos unir el nombre de Padget, inventor del Dermatomo, aparato que toma injertos de piel de un espesor constante.

Por tanto, queda constatado como desde comienzos del siglo XX se estaba haciendo cirugía estética. Hoy, un $17 \%$ de las cirugías que se realizan en cualquier institución hospitalaria, corresponde a alguna de las ramas de la cirugía plástica: piel, manos, cara, tronco, senos, órganos genitales externos, quemaduras, anomalías congénitas, estética, microcirugía, etc. 
En el transcurso de los años la Cirugía Plástica se ha dividido, desde un punto de vista práctico, en dos campos de acción:

- Cirugía Reconstructiva o Reparadora, que incluye a la microcirugía, está enfocada en disimular y reconstruir los efectos destructivos de un accidente $o$ trauma. La Cirugía Reconstructiva hace uso de técnicas de osteosíntesis, traslado de tejidos mediante colgajos y transplantes autólogos de partes del cuerpo sanas a las afectadas.

- Cirugía Estética (o cosmética) es realizada con la finalidad de cambiar aquellas partes del cuerpo que no son satisfactorias para el/la paciente. En algunos casos, sin embargo, hay razones médicas (por ejemplo, Mamoplastía de reducción mamaria cuando hay problemas ortopédicos en la Columna lumbar, o la Blefaroplastía en casos graves de Blefarochalasis que incluso impiden la vista)

Esta división ha sido marcada por la sociedad, y los servicios de salud Pública y Privados (Compañías de Seguros), puesto que los servicios de salud sólo cubrirían los gastos de Cirugía Plástica que estén relacionados con Enfermedades Congénitas, Adquiridas y los Accidentes; pero no cubrirían los gastos de Cirugía Plástica asociados a la mejoría estética de la persona.

Aquí se muestra una lista de las operaciones que se incluyen dentro del catálogo de la Seguridad Social (lista orientativa)

- Cirugía abdominal: cuando se realiza para aliviar problemas médicos, como dolor de espalda, úlceras, irritaciones cutáneas o hernias, o para permitir andar de manera normal.

- Cirugía de la mama: para corregir asimetrías congénitas, mamas muy voluminosas que produzcan problemas médicos, para reconstruir una mama tras un cáncer, para eliminar una ginecomastia. 
- Cirugía de las orejas: cuando se realiza para corregir anomalías congénitas o para reconstruir orejas lesionadas por un traumatismo o enfermedad.

- Cirugía de los párpados: cuando se realiza para corregir una caída excesiva de los párpados superiores que cause problemas de visión o para corregir malas posiciones de los párpados inferiores.

- Cirugía facial: para corregir asimetrías de la cara producidas por una parálisis facial, para tratar lesiones que afecten a los labios, las mejillas o los músculos de la cara; para tratar deformidades traumáticas y deformidades de la cabeza o el cuello.

- Cirugía de la mano: toda la cirugía de la mano.

- Cirugía de la nariz: para corregir deformidades de nacimiento o traumáticas y para tratar problemas respiratorios.

\subsection{Procedimientos y técnicas de la cirugía estética:}

- Abdominoplastia: remodelación y reafirmación del abdomen. Este procedimiento es una forma de cirugía que logra remodelar de manera total el abdomen, la cintura y la forma del tronco del cuerpo. Los principales candidatos para someterse a esta operación de cirugía son:

o Personas con obesidad mórbida, es decir, que tenían un gran sobrepeso y lograron resolverlo, lo cual provocó que la piel que rodea el tronco (abdomen y tórax) cuelgue de su cuerpo dando una imagen de sí mismos muy desagradable.

o Mujeres que han tenido uno o más embarazos. En los embarazos se forma piel extra y después del parto se ve floja, y hace ver el abdomen abultado.

- Este procedimiento suele ser más demandado por las mujeres de mediana edad, ya que son quienes más se preocupan por recuperar la figura perdida por la flacidez, la edad... 
Como aspecto negativo de la intervención debe tenerse en cuenta la aceptación de una cicatriz horizontal situada sobre el pubis y que va más o menos de cadera a cadera, suyas características en cuanto a grosor y color dependen de la idiosincrasia cicatrizal de cada paciente.

- Blefaroplastia: Cirugía de rejuvenecimiento de párpados, resección de piel y bolsas de grasa. Es muy frecuente cuando llegamos a los 40 años los párpados estén caídos por el exceso de piel en ellos, esto ocurre tanto en los de arriba como los de abajo y eso hace que se empiecen a caer. A esto debe agregarse la presencia de esas molestas bolsas en los párpados (sobre todo en los inferiores) y hasta "olanes" en muchas ocasiones. De hecho el problema de las bolsitas (que es grasa acumulada en los párpados) puede encontrarse desde edades muy tempranas. En algunas ocasiones, los párpados han caído tanto que incluso obstruyen la visión.

Los mejores candidatos para la cirugía del párpado son hombres y mujeres quienes están físicamente saludables, son psicológicamente estables y son realistas en sus expectativas. La mayoría de los candidatos presentan edades de 35 años o más, sin embargo, si los párpados caídos son típicos de los rasgos de su familia, podrá decidir someterse a la cirugía del párpado a una edad más temprana.

Hay ciertas condiciones médicas que pueden hacer que la blefaroplastia sea más arriesgada, éstas incluyen problemas de la tiroides tales como el hípertiroidismo y la enfermedad de Graves, problemas de falta de humedad en el ojo o falta de suficiente lagrimeo, alta presión sanguínea u otros trastornos de la circulación, enfermedades cardiovasculares y diabetes. Una retina desprendida o glaucoma también es una razón por la cual hay que tener precaución; verifique con su oftalmólogo antes de hacerse la cirugía.

- Mamoplastia de aumento: El Aumento del Tamaño del Busto se debe efectuar mediante el uso de prótesis, pero nunca por la inyección directa de sustancias en el pecho. Los motivos habituales por lo que se necesita este tipo de cirugía son el pobre ó nulo desarrollo de la glándula mamaria o la atrofia 
que se produce algunas veces después de varios embarazos. La búsqueda de la delgadez, la incorporación al trabajo, el no amamantar a los hijos..., pueden estar conduciendo a la progresiva reducción del busto en la mujer.

Las prótesis pueden introducirse en la mama por varias vías: periareolar, submamaria, periumbilical y axilar. El criterio estético, pero sobre todo la habilidad del cirujano, le hacen elegir una u otra técnica. La vía axilar y la posición del implante retropectoral suele ser preferible.

También hay varios tipos de prótesis en el mercado: gel de silicona, hidrogel, suero salino, y gel cohesivo de silicona. Normalmente suele ser una operación solicitada por las más jóvenes o las mujeres de median edad tras un embarazo u otros.

- Peeling (literalmente despellejamiento): Consiste en la eliminación de distintas capas de la epidermis para favorecer la regeneración de la piel. El número de capas a eliminar dependerá del tipo de peeling que se realice: superficial, medio o profundo. Además, puede ser físico o químico. El peeling está indicado en casos de envejecimiento fisiológico o actínico y para el tratamiento de manchas y acné. No obstante, puede emplearse como un medio para "mantener una piel sana, tersa, libre de impurezas y luminosa".

Entre las sustancias empleadas en el peeling se encuentran el fenol y los ácidos glicólico, tricloracético, salicílico y kójico. La elección de estas sustancias dependerá del objetivo del tratamiento (despigmentante, antiacnéico o antiarrugas). En todo caso se consigue mejorar la calidad de la piel y la producción de colágeno y elastina.

Podemos diferenciar tres tipos de peeling.

o Peeling superficial: Cierra los poros, atenúa las cicatrices originadas por el acné y las arrugas finas. Además, aporta uniformidad al tono de la piel y un aspecto más juvenil y saludable. Este tipo de peeling ayuda a "controlar el acné, las foliculitis y las secreciones sebáceas, y pone a la piel en mejores condiciones para recibir cualquier tipo de tratamiento dermatológico". 
o Peeling medio: Está indicado en el caso de envejecimiento solar o tóxico, ya que actúa sobre las arrugas finas y de profundidad media, y para controlar las manchas actínicas. También se emplea como "paso previo o complemento de muchos tratamientos médicos, como la microdenervación, lifting o rellenos".

o Peeling profundo: Con resultados espectaculares, el peeling profundo consigue actuar sobre "las arrugas superficiales, medias y profundas, eliminar manchas actínicas y solares y queratosis. Asimismo, produce la retracción de la piel, lo que mejora notablemente los problemas de flacidez". La profundidad del peeling determinará la recuperación de la piel, que puede ir de unas horas a cinco días.

Esta intervención, normalmente, suele estar más solicitada por las personas de mayor edad, quienes luchan lógicamente contra los signos de envejecimiento a través de liftings, descolgamiento de párpados y cuello.

- Mastopexia: Su finalidad es reafirmar los senos. La mejor candidata es la mujer que tiene expectativas realistas tratando de mejorar sus dolencias y aspecto y no aquella que busca la perfección. La intervención consiste en elevar el pecho caído, remodelar la mama y situar el complejo areola-pezón en una posición más alta, para ello es necesario extirpar el exceso cutáneo y adaptarlo al volumen mamario que va a quedar. Existen múltiples técnicas para realizar la mastopexia. La elección depende de las características de la mama y de la preferencia del cirujano; en esencia se pueden resumir dependiendo de las cicatrices que originan: Cicatriz periareolar pura, cicatriz en "T invertida", cicatriz en "J" o en "L", cicatriz vertical. Las tres últimas también dejan cicatriz alrededor de la nueva areola. La "T invertida" deja una cicatriz vertical que se extiende desde el polo inferior de la areola hasta la mitad del surco submamario. La cicatriz en "J" o en " $L$ " es como la anterior pero la cicatriz horizontal se extiende desde el centro del surco submamario hacia las axilas. Las de cicatriz vertical solo dejan cicatriz desde el polo inferior de la areola hasta el centro del surco submamario. 


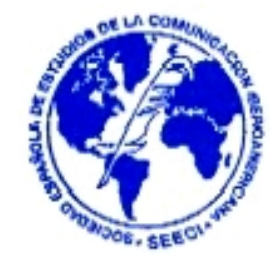

- Rinoplastia: Tiene la finalidad resolver principalmente los problemas estéticos de la nariz tales como la giba ósea, que es ese hueso que sobresale del dorso de la nariz a semejanza de una joroba, las desviaciones hacia la derecha o izquierda de la totalidad de la nariz y las malformaciones congénitas que se ven sobre todo en pacientes con secuelas de labio y paladar hendido. Cuando se busca una solución de la función de la nariz por desviación de los huesos internos generalmente nos estamos refiriendo a la Septumplastía que si bien es un procedimiento diferente si puede realizarse ambos el mismo día. Esta cirugía se ha popularizado en la juventud; ya que ha tenido una mayor aceptación social, a diferencia de otros procedimientos de la Cirugía Plástica y se realiza en una proporción muy semejante tanto en hombres como en mujeres.

Esta cirugía se puede realizar bajo anestesia local más sedación, o bien bajo anestesia general, dependiendo de las condiciones y deseos del paciente.

Se inicia la cirugía realizando unas pequeñas incisiones en el interior de la nariz, a través de las que se despega la piel del armazón nasal, lo que permite acceder al cartílago y al hueso para ser remodelados y manipulados. Con los huesos nasales se forma un puente más estrecho, y extirpando cartílago se reduce el volumen de la punta nasal.

Al terminar, se colocan tapones en las fosas nasales, que se mantendrán 24 horas, y una pequeña escayola externa, que se mantendrá siete días.

Al realizarse la intervención a través de incisiones internas, no queda ninguna cicatriz.

- Otoplastia: Corrección de las deformidades de la oreja; estas pueden ser muy variadas desde la ausencia total de la oreja (microtia) a simplemente una proyección muy notable de la misma por la ausencia del antehelix o el helix.

La Cirugía_plástica ofrece muchas alternativas, una de ellas es:

o Técnica de Brent: que consiste en cuatro tiempos quirúrgicos y reconstruye la oreja en un periodo de 2 años tras un gran trabajo quirúrgico y artesanal. 
En los casos de hiperproyección de la oreja por la ausencia del hélix (Repliegue semicircular que forma el borde externo del pabellón auricular) o el antehélix se logra su corrección con cirugías en las cuales se busca reconstruir este. Es ideal realizar estos procedimientos durante la infancia porque las posibilidades de que la oreja regrese a su estado previo son menores. En el caso de la microtia es mejor esperar a que hayan cumplido de 8 a 11 años según diferentes autores hasta que la oreja sana haya alcanzado el tamaño adulto y el cartílago costal sea suficiente para poder realizar el injerto de cartílago que se realiza en el primer tiempo de Brent.

En la mayoría de los casos la cirugía de rinoplastia en general se realiza en chicos entre 4 y 14 años. Las orejas están casi completamente desarrolladas a la edad de 4 años, y cuanto mas precoz sea la cirugía, el niño sufrirá menos a causa de sus orejas en el colegio o con sus compañeros. La cirugía de la orejas en adultos también es posible, y tampoco hay riesgos adicionales relacionados con la cirugía en pacientes mayores.

La otoplastia es la cirugía que moldea las orejas, y también comprende las intervenciones encaminadas a corregir el tamaño excesivo de las orejas, del lóbulo e incluso la falta parcial o total del pabellón auricular.

- Ritidectomía: Su meta es rejuvenecer la cara en su totalidad. El envejecimiento de la cara puede ser atenuado por tratamientos de la piel tales como: las cremas, peelings químicos, dermoabrasiones, etc. En la gente de avanzada edad, por los efectos de la gravedad, la exposición al sol, las preocupaciones de la vida pueden aparece arrugas en la cara. Aparecerán arrugas profundas entre la nariz y la boca; la línea de la quijada se afloja y queda flácida; los pliegues y depósitos de grasa de la piel aparecen alrededor del cuello.

El estiramiento de la piel facial generalmente toma varias horas o a veces más cuando se realizar más de un procedimiento. Para procedimientos extensos, ciertos cirujanos prefieren programar dos sesiones por separado. 
Cada cirujano tiene un método propio para el procedimiento. Algunos completan un lado de la cara primero y otros trabajan en ambos lados a la vez. La ubicación exacta de las incisiones y la secuencia de los eventos depende de su estructura facial y de la técnica que utilice su cirujano. Generalmente las incisiones comienzan por la línea del cuero cabelludo sobre las sienes, se extienden con una línea natural hacia el frente de la oreja ( 0 justo por dentro del cartílago hacia el frente de su oreja), y continúa por detrás de la oreja hacia el área inferior del cuello cabelludo. Si es necesario trabajar sobre el cuello podrá hacerse también una pequeña incisión por debajo del mentón.

En general el cirujano separa la piel del tejido grasoso y del músculo interior. La grasa podrá ser cortada o succionada por el área del cuello o del mentón para mejorar el contorno. Después el cirujano procede a estirar el músculo interno y la membrana, jala la piel hacia atrás y retira el exceso de la misma. Se aseguran las capas de tejido y se cierran las incisiones con suturas; podrán usarse sujetadores o clips metálicos sobre el cuero cabelludo.

Después de la cirugía, se podrá colocar temporalmente un pequeño y delgado tubo por debajo de la piel por atrás del oído para drenar sangre que se pueda acumular en ese lugar. Probablemente el cirujano también cubra su cabeza con vendajes no muy justos para minimizar el amoratamiento y la inflamación.

- Liposucción: Cirugía con la que se pretende "esculpir" el cuerpo del paciente y eliminar acumulaciones de grasa indeseadas.

La técnica, que siempre se realiza en un quirófano, consiste esencialmente en la aspiración de la grasa mediante la introducción de una cánula que está conectada a una máquina de vacío o a una jeringa especial, según el caso, y realizando numerosos túneles en el área previamente marcada. Esta operación durará entre una o dos horas y no es necesario que la persona sea ingresada, todo depende del área y de la cantidad.

Tras la cirugía se pueden colocar tubos de drenaje bajo la piel durante dos o tres días para disminuir la posibilidad de que se acumulen fluidos. Se colocará 
una faja, medias o vendaje elástico sobre la zona tratada para controlar el hinchazón y el sangrado y para ayudar a la piel a adaptarse al nuevo contorno. Suele ser necesario llevarlo durante dos o tres semanas, y luego sólo durante el día unas semanas más, dependiendo de las instrucciones del cirujano plástico. También pueden administrarse antibióticos para prevenir la infección. Es normal que las áreas liposuccionadas estén hinchadas, con hematomas e, incluso, puede existir una sensación de quemazón. El dolor puede aliviarse con la medicación prescrita por su cirujano plástico. No se deben evaluar los resultados de una liposucción antes de que hayan transcurrido un mínimo de tres meses.

Los candidatos ideales para someterse a una liposucción son aquellas personas que poseen un peso relativamente normal pero que tienen cúmulos de grasa en áreas localizadas.

- Mentoplastia: Cirugía para aumentar o disminuir el mentón. Esta operación se divide en dos grandes campo según el fin de la misma, ya sea el de aumentar la proyección y/o tamaño del mentón o por el contrario la propuesta sea la de disminuirlo.

o En el caso de aumento, van a existir dos tipos de operaciones:

- Mediante prótesis: A través de una pequeña incisión situada bien en la mucosa oral, bien debajo de la barbilla, se coloca un implante. Existen diversas formas, tamaños y diversos materiales como son silicona, medpor, biocoral. Su fin es conseguir una proyección o cambios en la forma y/o tamaño del mentón que sea armónico, proporcionado y equilibrado con el resto del conjunto facial, ya sea visto de frente o de perfil. Dicha prótesis puede ser rígida o inyectable. Normalmente no requiere de ingreso hospitalario, ya que se trata de una intervención ambulatoria.

- Cirugía de Avance mandibular: Esta cirugía es practicada en mayor frecuencia por el Cirujano maxilofacial en colaboración 
con un Ortodoncista en pacientes que tienen Retrognatia (mandíbula inferior de pequeño tamaño y localizada hacia atrás). Consiste en hacer cortes en la mandíbula por debajo de las raíces de los dientes que permitirán avanzar la parte libre de la misma y con material de osteosíntesis (alambres o placas con tornillos) se fija en la posición planeada por el Cirujano.

o Cuando lo que se quiere es disminuir el mentón, generalmente se usa una anestesia local pero en ocasiones puede requerir anestesia general. Debido a especiales características del mentón, ésta operación consistente en la reducción de la proyección ósea. El tipo de incisiones son las mismas que las usadas en el aumento.

- Inyecciones de Colágeno: procedimiento utilizado para rellenar arrugas.

Usando agujas finas, el cirujano plástico puede inyectar el relleno de colágeno por debajo de la piel de cada arruga. El relleno empuja la arruga hacia arriba haciendo que sea menos visible. Se origina un incomodidad transitoria durante la inyección, que desaparece al finalizar la misma. Puede aplicarse inmediatamente su maquillaje y retornar al trabajo.

Tipos de Colágeno:

o Colágeno Bovino: es extraído de la piel del ganado, purificada, esterilizada y procesada bajo forma líquida. Una vez inyectado su duración es de 6 a 12 semanas. Aunque es una variedad poco utilizada al producir alergia y potenciales desordenes del tejido conectivo

o Inyección Autologa: es colágeno de su propia piel, extraída durante una intervención quirúrgica y procesada luego bajo una forma líquida.

o Inyección Isologa: es colágeno de su propia piel, clonada en un laboratorio y procesada luego en forma líquida. Se recomiendan 3 inyecciones con intervalos de 2 semanas. La primera inyección mejorará las arrugas en un $15 \%$, la segunda en un 35\% y la tercera en un $70 \%$. 
o Dermalogen: es colágeno de piel de un cadáver que ha sido esterilizada, purificada y luego procesada a una forma líquida. Transmisión de infección de parte del donante es un riesgo teórico pero debido a que el Dermalogen es esterilizado y procesado no han ocurrido infecciones. De 2 a 3 inyecciones son recomendadas con intervalos de 2 a 3 meses a fin de obtener el máximo beneficio.

Pasado un tiempo se necesitarán nuevas inyecciones indiferentemente del tipo de colágeno utilizado.

- El bótox (toxina botulínica): En la piel existen fibras musculares muy superficiales que provocan una contracción involuntaria de la piel. Esto es especialmente cierto para las arrugas en las patas de gallo, en la frente, el entrecejo y otras regiones de la cara. Cuando parte del bótox alcanzaba la piel, se reducían y se borraban parcialmente las arrugas.

Pronto se comenzó a emplear el bótox para las arrugas periorales, perioculares, frontales, y su uso superó con creces a otros procedimientos como los rellenos de arrugas con colágeno u otras sustancias.

El bótox se inyecta muy superficialmente en la piel, con una aguja tan fina que apenas produce dolor. A partir del día de la inyección, tarda aproximadamente 5 días en verse su efecto. Una vez establecido perdura durante 20 semanas. Quienes se inyectan bótox en la piel de la cara deben realizar el procedimiento dos veces al año. Se aprecia con el bótox una reducción de las arrugas, no una desaparición, puesto que esta sustancia no impide la contracción muscular sino que debilita la misma.

Apenas existen reacciones adversas, y si se producen, duran unos pocos días sin dar problemas. Existen pocos procedimientos en dermatología tan seguros como el bótox.

- Ginecomastia: Aunque nos es frecuente oír hablar de este problema, actualmente es bastante común. Se estima que la ginecomastia afecta a un 40-60 \% de los hombres. $Y$ puede afectar a una sola mama o a las dos. Aunque ciertas drogas o medicamentos y algunos problemas médicos pueden 
estar unidos al sobredesarrollo de la mama masculina, En la gran mayoría de los casos no hay causa conocida. El procedimiento quita grasa y tejido glandular de las mamas, y en casos extremos también extirpa piel sobrante, dando lugar a un tórax plano, firme, y bien contorneado.

Si el exceso glandular es la causa primaria del aumento mamario, este debe ser retirado con bisturí. Este procedimiento puede ser realizado solo o con liposucción. Si la ginecomastia consiste fundamentalmente en un exceso de tejido graso, utilizamos la liposucción para retirarlo. En casos extremos, cuando se quitan grandes cantidades de grasa, la piel puede no ajustar bien con el nuevo contorno corporal. En estos casos, el exceso de piel puede tener que ser extirpado para permitir a la piel restante reajustarse correctamente al nuevo contorno mamario.

Cuando se realiza la cirugía de reducción mamaria por un cirujano plástico cualificado, las complicaciones son infrecuentes y generalmente menores. De cualquier manera como en cualquier cirugía, siempre hay ciertos riesgos.

- Cirugía de alopecia: transplante de cabello. Se pueden diferenciar tres modalidades en el uso de la cirugía en la alopecia:

o Los implantes de cabello: la justificación para el implante de cabello es que el cabello obtenido de una zona no susceptible a la alopecia trasplantado a una zona con alopecia permanecerá en esta última tanto tiempo como en su lugar original. Las zonas utilizadas para obtener cabello son habitualmente el cuero cabelludo temporal, parietal y occipital. Los inconvenientes de este método son: la necesidad de varias intervenciones para lograr el efecto deseado; el cabello del implante se cae y vuelve a crecer en 3-6 meses. Este procedimiento puede causar dolor y molestias, aunque se utilice anestesia. Además, la anestesia también conlleva riesgos.

o La reducción del cuero cabelludo consiste en escindir una parte del cuero cabelludo calvo y unir los bordes del cuero cabelludo restante con el fin de extender las zonas con cabello a la zona originalmente 
calva. Las limitaciones de esta técnica están relacionadas con el tamaño de la zona de calvicie y la elasticidad del cuero cabelludo.

o El trasplante del cuero cabelludo consiste en extirpar un área de piel con cabello de la zona lateral del cuero cabelludo y volverla sobre su eje para que descanse sobre la parte superior de la cabeza. Se denominan también "colgajos". La ventaja principal de este tipo de cirugía es que el cabello del colgajo continúa creciendo después de la cirugía, debido a que se mantiene el suministro de sangre. Entre los inconvenientes están las llamadas "orejas de perro" que pueden producirse tras la inversión del colgajo y que han de escindirse quirúrgicamente.

- Braquioplastia: Una de las zonas en las que se nota el paso de la edad es la cara interna de los brazos. La pérdida elasticidad de la piel en esta zona hace que "cuelgue". También tras adelgazamientos importantes se produce un exceso de piel relativo, dado que la piel no se retrae tanto.

El tratamiento clásico de esta zona es la dermolipectomía (denominada braquioplastia). La técnica consiste en extirpar todo el tejido sobrante de esta zona, dejando una cicatriz que va desde el codo hasta la axila. La operación suele dar buenos resultados pero deja esta cicatriz larga, con lo que potencialmente puede haber problemas de cicatrización y a veces hay problemas de sensibilidad por afectación de pequeños nervios sensitivos que van a la piel.

Otra opción es la liposucción, más sencilla y con menos complicaciones, de ahí que cada vez se vayan haciendo menos Braquioplastias.

- Cirugía maxilofacial: Una especialidad de la Odontología que implica la mandíbula y el maxilar así como los dientes, resuelve principalmente problemas de malformaciones congénitas de el maxilar y la mandíbula, Se entrelaza en forma muy significativa en estas áreas con la Cirugía plástica; aunque no en lo relacionado a los dientes: Cirugía de tercer molar, implantes de titanio para prótesis dentales y muchos otros procedimientos más. 
- Cantopexia: Este tipo de intervención quirúrgica va encaminada a elevar el ángulo externo del párpado cuya caída da a la cara una expresión de tristeza. La intervención se efectúa con anestesia local, realizando una pequeña incisión que inmediata al borde palpebral, luego se desinserta el ligamento que sujeta el ángulo parpebral reinsertándolo en una posición más alta. El resultado es un ojo alegre y vivaz.

\subsection{Paso a paso de una intervención}

Hablamos aquí de una intervención tipo ya que pueden producirse alteraciones en este protocolo debido a diversas causas.

Durante la primera consulta se elabora la historia clínica (antecedentes, etc.), se valora el motivo de la consulta y se procede a la exploración y evaluación del problema.

A continuación se informara a los pacientes de las opciones de tratamiento, tipo de anestesia, etc., especificando los pros y los contras. Se le facilita una copia del consentimiento informado y unas peticiones de estudio preoperatorio.

En la segunda consulta se verifican los resultados del estudio preoperatorio, el paciente firma el consentimiento informado que ha podido consultar durante unos días, se programa el día y la hora de la intervención y se facilitan las normas de ingreso.

En el día de la intervención, el/la paciente deberá ingresar una hora antes del inicio programado de la operación. Es una norma habitual de las Clínicas, el solicitar una determinada cantidad en concepto de depósito, y obligan a que un acompañante esté junto al paciente durante el post-operatorio inmediato. Una vez dibujado en la piel el marcaje preoperatorio, para tener referencias cuando el paciente esté 
tumbado en la mesa de operaciones, el camillero le acompañará a quirófano, el anestesista procederá a preparar la anestesia. La duración de las intervenciones varía según la técnica y el tipo de alteración tratable.

Una vez operada, el/la paciente será acompañado/a a la habitación, donde descansará unas horas. Los vendajes, drenajes y sueros que tenga colocados no deben ser manipulados.

En el post-operatorio se desglosan las siguientes fases:

Día después: El paciente notará una sensación de tirantez, ya que la zona operada estará hinchada. Se cambiarán los vendajes por uno más pequeño y retirará los drenajes (si los hubiere). Una vez se haya completado el informe de alta y prescrita la medicación (antibióticos, analgésicos...) para tomar en el domicilio, se procederá al alta hospitalaria.

$3^{\circ}$ Día: El paciente notará que la hinchazón va disminuyendo, y podrá ducharse. $5^{\circ}$ Día: Se retiran las suturas que lo precisen.

Los controles posteriores se efectuarán en la consulta al mes, los 2 meses, y los 6 meses, en los que se efectuarán fotografías de control y seguimiento.

\section{Cuestión de imagen}

En el estudio de campo llevado a cabo, se ha basado en los anuncios más repetidos en los distintos Medios de Comunicación para Masas.

La especial incidencia de algunas clínicas se debe a una publicidad más agresiva en cuanto a número de impactos buscados. 
Las campañas en televisión y radio también fueron muy extendidas, destacando algunas malas noticias para el sector como la muerte de alguna celebridad.

Pasamos a referir, a guisa de ejemplo, los seguimientos de algunas radios punteras como Onda Cero y La Cadena SER.

\section{Oda Cero:}

Destacó la noticia del 25 de octubre sobre el deceso de la esposa del Presidente de Nigeria tras someterse a una operación de cirugía estética en Marbella.

Esta noticia apareció en el programa Herrera en la onda (de 06.00 a 12.30 de la mañana). En él Herrera comentó esta muerte recalcando que la cirugía no es un juego y debe ser tomada en serio por quien decida ser intervenido.

Horas más tarde, en el programa Noticias Mediodía (de 14.00 a 15.00 horas) se vuelve a emitir la noticia acaecida el 24 de noviembre en Marbella. Se hace hincapié en que la Primera Dama iba a cumplir los 60 años y que ya ingresó en estado de muerte clínica en el Hospital de Marbella donde se hallaba aún el cadáver el día 25.

El día 29, en el programa En buenas manos (sábados de 16.00 a 19.00 horas) se comentó de nuevo lo sucedido advirtiendo el presentador del riesgo que conlleva este tipo de operaciones.

\section{Cadena SER:}

El análisis se centró especialmente en los programas punteros como 'La Ventana', 'Hora $25^{\prime}$ y 'Hoy por hoy'. La página web de la cadena (www.cadenaser.com) suele contener las grabaciones de todos los programas emitidos. 


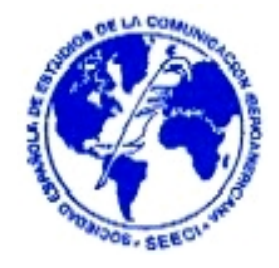

- El 24 de octubre: Varios programas se hicieron eco de la muerte de la Primera Dama de Nigeria en Mallorca ese mismo día. Comentaron que era bueno romper el silencio oficial decretado por las autoridades nigerianas ya que su forma de morir no era políticamente correcta en un país pobre como Nigeria.

- El 25 de octubre: Durante la tertulia en La Ventana, se realiza una conexión con el corresponsal en la Costa del Sol (Málaga), Joaquín Guirbal, en la que se explican durante más de 5 minutos las últimas versiones sobre la muerte de la Primera Dama nigeriana. Se comenta que parece ser que en el post-operatorio hubo complicaciones y que no son convincentes las explicaciones del Gobierno nigeriano.

- El 15 de noviembre: En el matutino 'Hoy por hoy' se produce una tertulia de unos 20 minutos en la que se reflexiona sobre la cirugía estética. A los contertulios habituales se les agrega un experto cirujano. Se habla del notable aumento en el número de operaciones de finalidad estética entre los jóvenes y los fraudes de ciertas empresas de belleza que ofrecen deficientes tratamientos a muy bajo coste.

- 20 de marzo: Los informativos de la SER dieron cuenta de la operación de trasplante de rostro llevada a cabo por cirujanos franceses. Esta noticia fue muy nombrada durante todo el día en los informativos.

El caso de las televisiones el tratamiento es más espectacular ya que las imágenes suelen ser de impacto.

Antena 3 ha sido la cadena que más seguimiento ha dado a la Cirugía Estética. Pasamos a reseñar los principales hitos durante el tiempo de la investigación: Telenoticias, programas de debate, de investigación, talk shows y espacios publicitarios han sido analizados detenidamente con el siguiente resultado:

- Espejo público (30 de octubre de 2005): 'El precio de la belleza'. A raíz de la muerte de la Primera Dama nigeriana como consecuencia de una operación de 
cirugía, el programa analiza la situación de otras victimas de intervenciones de estética.

- ¿Dónde estas corazón? (12 de noviembre de 2005): Se realizo una entrevista de Mirta Rubira, una diputada italiana operada por el Dr. Zelicovich.

- Sexo en Nueva York (15 de noviembre de 2005): Una de las protagonistas quería hacerse una operación con Botox pero le aconsejaron realizarse un pilling químico que finalmente le abraso la cara.

- Telenoticias Antena 3 (29 de noviembre de 2005): Se incluyen las operaciones de estética en el IPC.

- Telenoticias Antena 3 (1 de diciembre): Se realiza el primer transplante de rostro.

- "A tortas con la vida"(Capítulo de esta serie del 8 de noviembre de 2005): Los protagonistas, quienes poseen una clínica de cirugía estética son demandadazos como consecuencia de una intervención donde la paciente no quedo satisfecha.

- "A tortas con la vida" (Capítulo de esta serie del 13 de diciembre de 2005): Por problemas económicos, los dueños de la clínica operan a un famoso narcotraficante.

Canal + es la cadena que tiene actualmente la única serie de ficción sobre este mundo de la Cirugía Estética:

Canal + ha emitido durante su programación, de forma ocasional, contenidos relacionados con el tema, tratando siempre de mantener una postura neutral tratando estos temas desde el respeto y el buen humor (siempre se incluyen estos contenidos en programas humorísticos o de ambiente distendido).

Es interesante incluir referencias a contenidos emitidos anteriormente en Canal+ o los canales de Digital Plus, ya que Cuatro procede del mismo grupo de comunicación, Sogecable, y tiene una línea editorial parecida. 
En el canal de Digital Plus People\&Arts se emite el programa Extreme Makeover: Cambio radical, en el cual los concursantes son seleccionados entre miles de solicitudes para realizarse todas las operaciones de cirugía estética que siempre desearon con el fin de lograr presentar la imagen de sus sueños.

También cuenta entre el repertorio de series de Canal Plus Nip/Tuck: $A$ golpe de bisturí, serie dramática centrada en la vida profesional y personal de dos cirujanos plásticos. Hay que tener muy en cuenta el tratamiento que Nip/Tuck hace del tema: la serie es terriblemente crítica con la labor de los cirujanos plásticos y sus supuestos modos de vida, de hecho, la crudeza de algunas de las imágenes que aparecen en la serie podrían quitarle las ganas de someterse a semejantes operaciones a buena parte de los espectadores.

La Cuatro es una televisión muy dada al glamour de sus presentadores de programas de variedades y a la frivolidad de algunos comentarios al respecto. En su seguimiento hallamos varios programas en los que se aborda el tema, en general en tono jocoso:

- Channel no 4 (9 de noviembre): Se habla de que la cantante brasileña e ídolo infantil Xuxa, se arrepiente de haberse operado. Boris Izaguirre afirma que Xuxa está fabulosa.

- Channel no 4(14 de noviembre): Se comentan los 'arreglillos' que se ha hecho la presentadora colombiana Laura.

- Soy el que más sabe de televisión del mundo (8 de enero): Nombran la cirugía estética para responder a una pregunta acerca de un personaje de la serie $A$ tortas con la vida de Antena 3, que es cirujano y luego aparece la opción 'Cirugía Plástica' como opción de respuesta a una pregunta sobre un anuncio.

- Channel no 4(21 de febrero): Los tertulianos recuerdan un programa de Aquí hay tomate en el que se trató el tema de la cirugía. Más adelante sale una imagen del canal People \& Arts en el que una pareja estadounidense se ha sometido a una serie de operaciones de cirugía amplias y se ha casado. Durante el programa preguntan a la invitada Cristina Tárrega que si se ha 
operado y comenta que sí, para reducirse el pecho por motivos de salud. Boris (tertuliano de plantilla) afirma que él también se ha operado pero por estética. Cristina Tárrega concluye recomendando a quien desee ser intervenido vaya a una clínica con cirujanos competentes. Se cierra el programa criticando a Yola Berrocal por haberse operado exageradamente de mamas.

- Channel no 4 (13 de marzo): Invitan a una señora operada, con unas mamas de 2,5 kilos cada una. Las muestra orgullosa al público. Comenta que dentro de unos años se las quitará.

Tele Madrid es la televisión que más anuncios ha emitido al respecto del tema que nos ocupa, quizás debido a que el público diana al que estas clínicas dirigen sus mensajes es urbanita. En su seguimiento encontramos:

Las campañas que se han emitido han sido de las siguientes empresas: Corporación Dermoestética, Clínica Menorca, Esbeltic Model. La que ha invertido más dinero ha sido Corporación Dermoestética, ya que la mayoría de los anuncios emitidos han sido de esta empresa. Los anuncios han sido emitidos todos los días del seguimiento y en diferentes franjas horarias. Nos podemos encontrar con unos tres anuncios al día de estas empresas.

En cuanto a las noticias, la ausencia de éstas ha sido lo más significativo, ya que en el periodo de seguimiento sólo ha habido una, y es la de la mujer que vive en Francia, a la cual le hicieron un transplante de cara ya que había tenido un accidente. Esta noticia apareció los días tres cuatro y cinco del mes de diciembre. Hubo también un debate en el programa Alto y claro para ver si la cirugía estética tiene que ser también parte de loa servicios que da la seguridad social.

La otra noticia que podemos citar es la del fallecimiento de la Primera Dama de Nigeria al someterse a una operación de cirugía estética. Realmente esta noticia no 
pertenece al periodo de seguimiento, pero hubo algún comentario de ella durante el seguimiento. Por lo tanto la podemos incluir como parte del informe.

No ha habido ningún especial, ni programas de debates en los cuales se haya tratado el tema.

Para finalizar el repaso a los medios y las principales campañas, queremos resaltar los Anuncios de Corporación Dermoestética:

Se han centrado en 7 tipos de tratamientos:

- Acné.

- Arrugas.

- Fotodepilación.

- Láser Vasculight.

- Liposucción.

- Soluciones integrales (en especial mamoplastias).

- Tratamientos faciales (en especial dentición).

Estos puntos dan idea de la cantidad de intereses que se mueven en torno a un mundo, el de la Cirugía Estética (no reconstructiva) que cada vez más se halla presente en nuestro mundo informativo.

Para poder comprobar este hecho, hemos elegido, como muestra, los anuncios publicados en varios medios (muy repetidos) entre los que destacamos: 


\section{REVISTA DE LA SEECI}

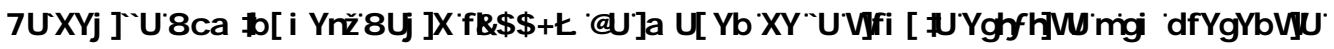

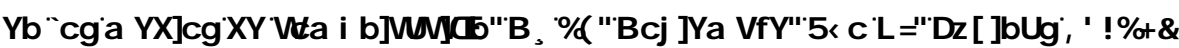

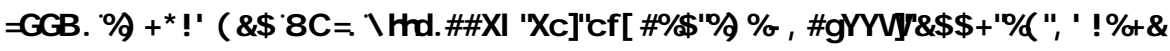

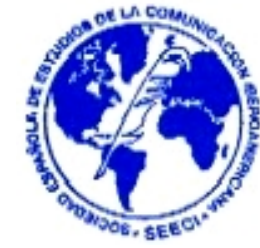

Imagen 1: Octubre 2005

12 uIfRCOLS 26 \% CCTUER LE $\mathrm{MB}$

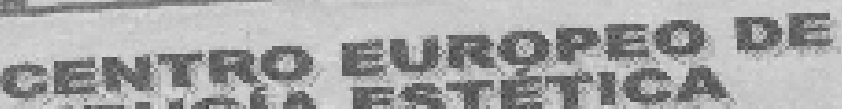

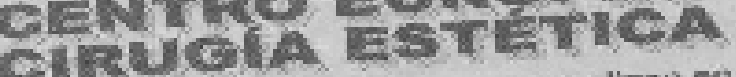

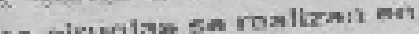
CHatiens haspitatimisu FINANCIACION A SU MEDIDA 1 ; Consulta gratuita Medicina y Cirugia Estetica

902200092

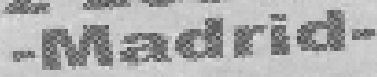
C) Maldonado 44, bajo

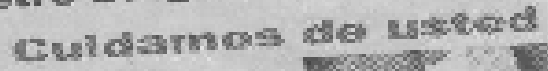
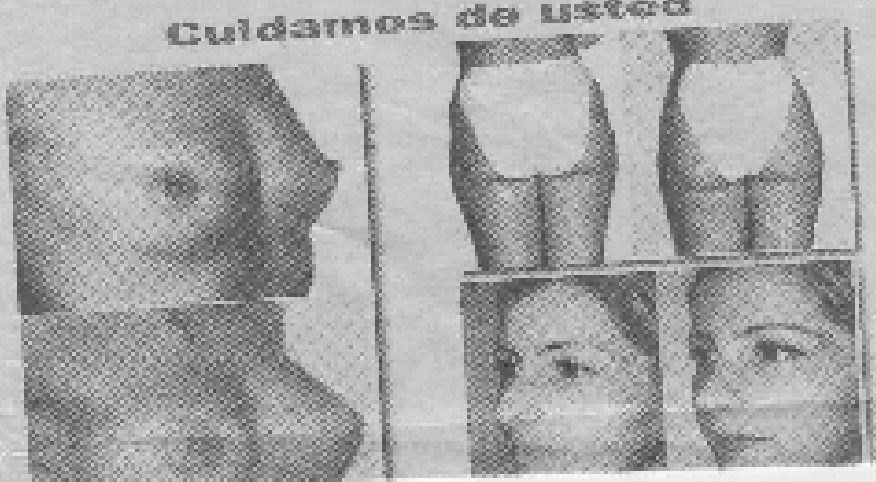

Diliajlit

miscuin

19icinte

ticitas

ituner

cos:ser

os thati

мuा pक्ष

antios

1 sinicos

Dipers

timsorm.

Itmesn.

domsop

Grith

spinas?

in tsin

raecom:

isiners

:1- je

instr:

How

! jarses:

neL.91

turo in

uétn

ligen

forn:

Lawe

(w) +

$\mathrm{x}$ 


\section{REVISTA DE LA SEECI}

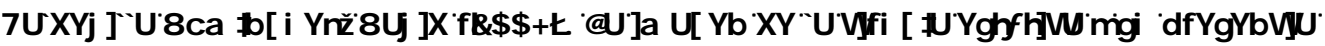

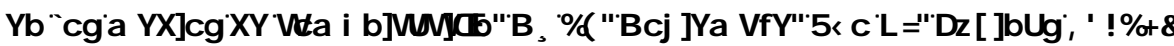
, 661 ए।

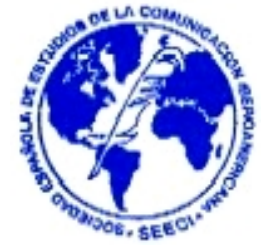

Imagen 2: noviembre 2005

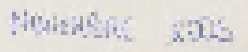

CLINICA NUEVA ESTETICA MEOICINA ESTETICA PERSONALIZADA

Un nuevo concepto de estética inspirado en ti 


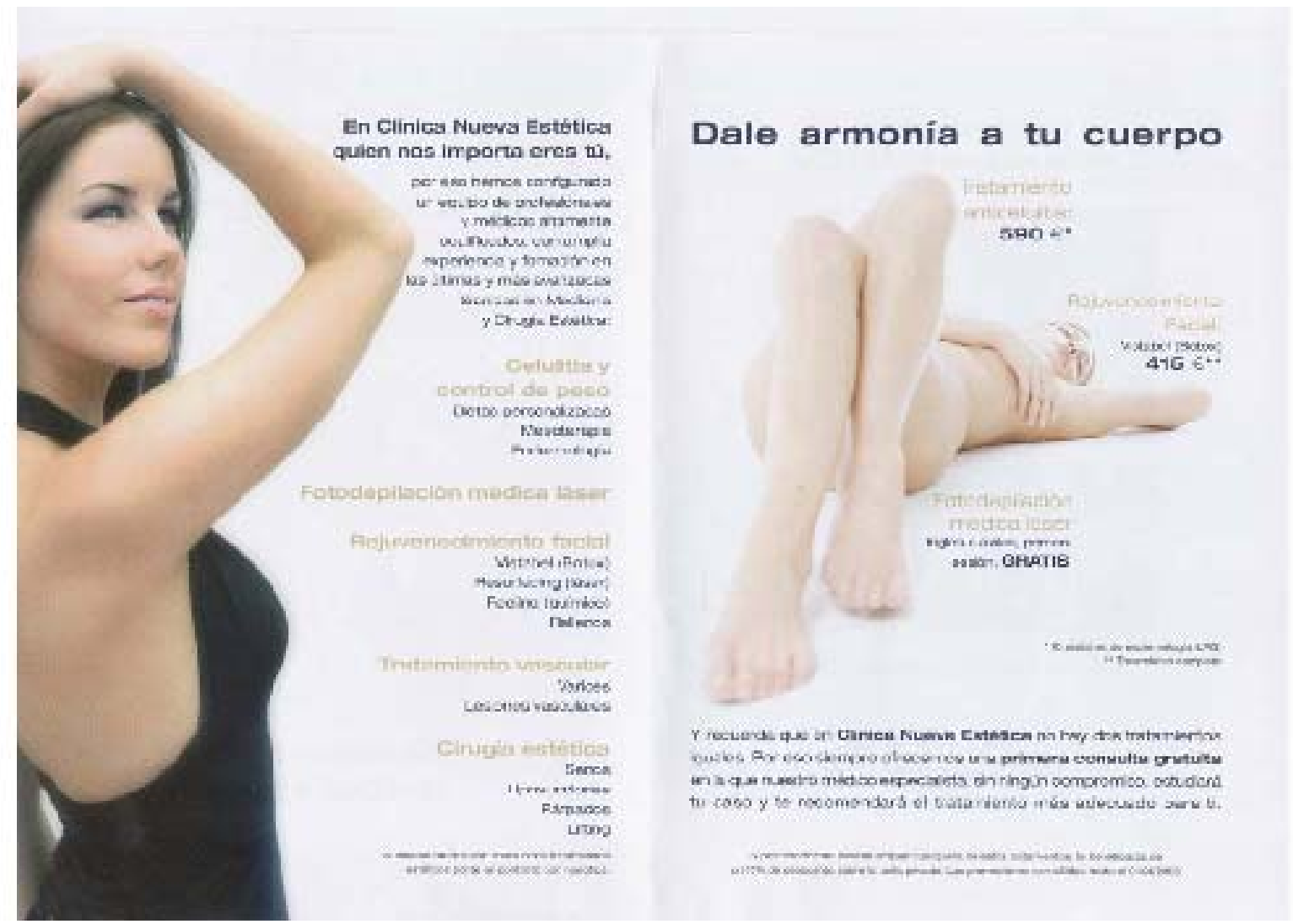


Ven ป conacamog:

OLINICA NUEVA ESTETICA

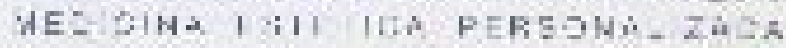
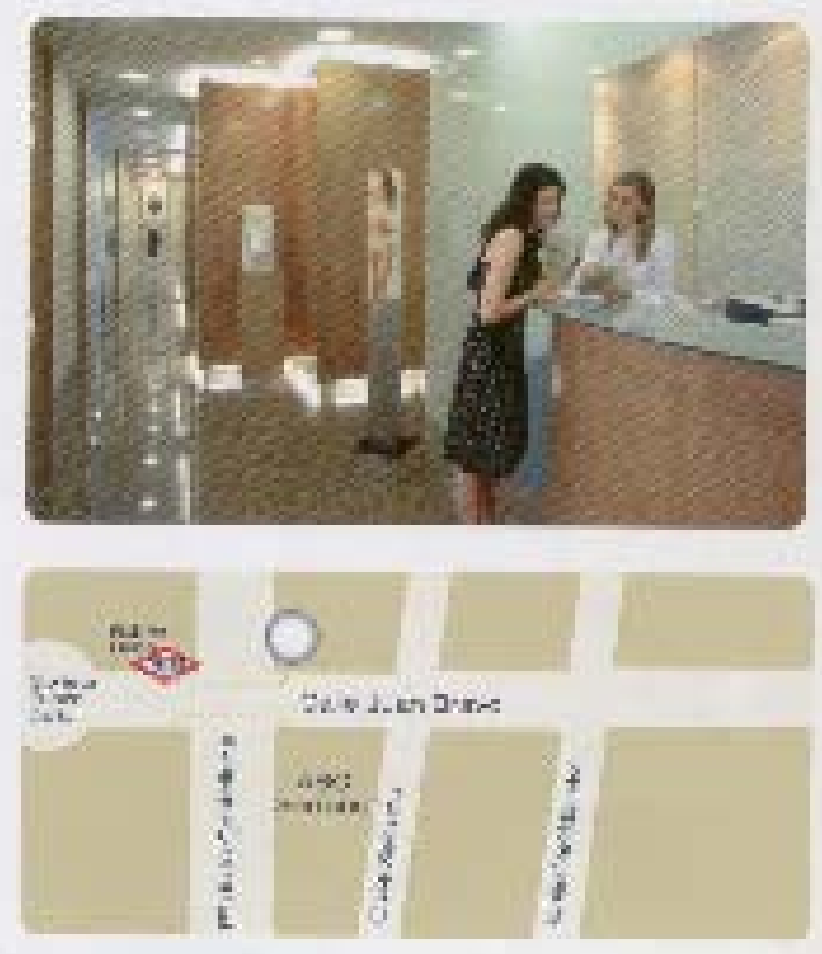

Paseo de la Castellana. 42

\section{4}

whwrlinicanueveestetica corr 


\section{REVISTA DE LA SEECI}

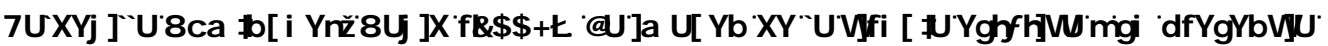

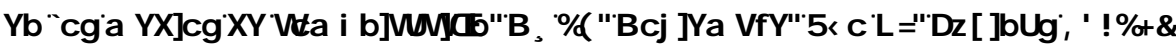

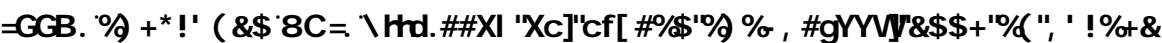

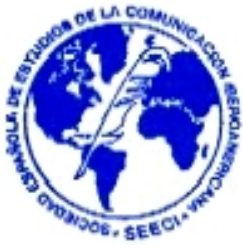

Imagen 3: Noviembre 2005

Pachithese

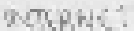

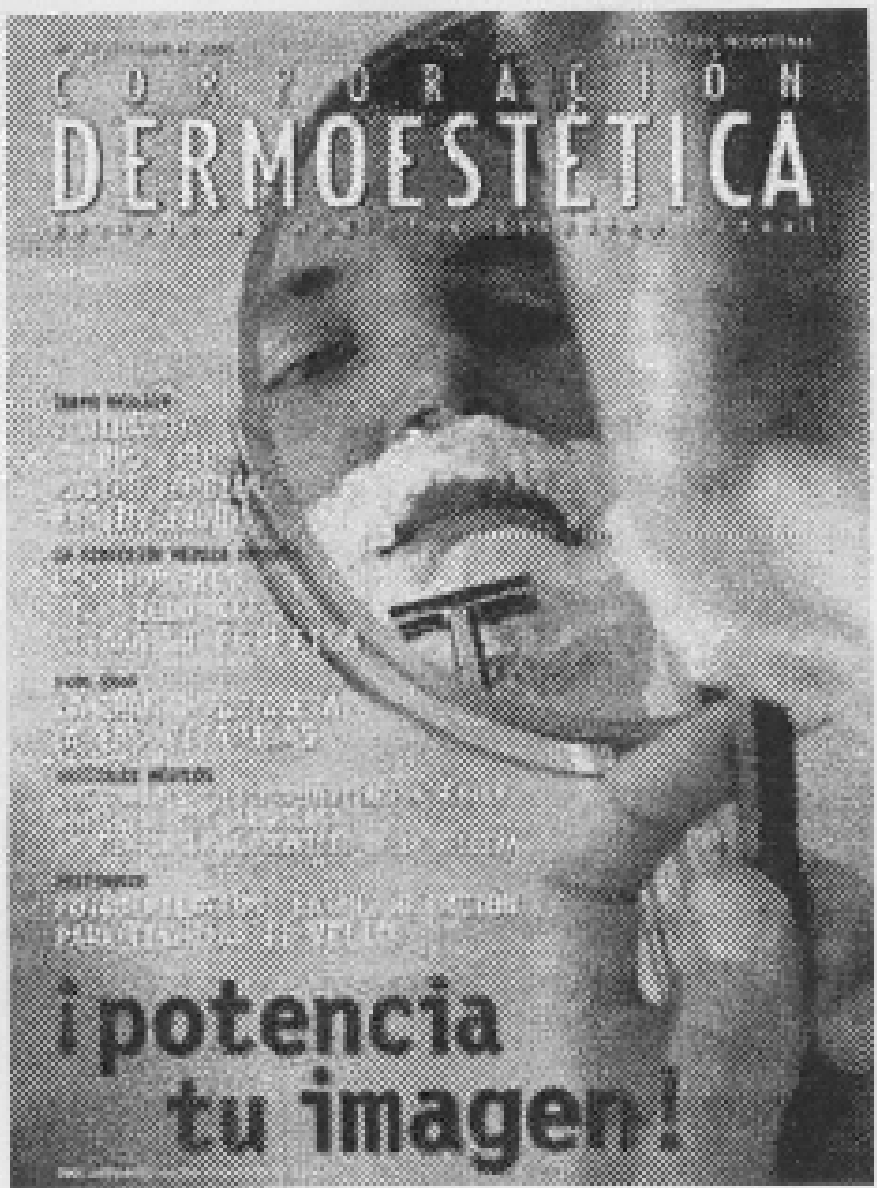




\section{REVISTA DE LA SEECI}

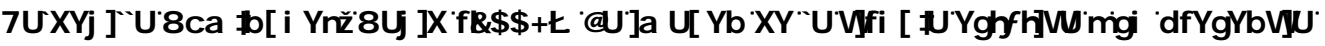

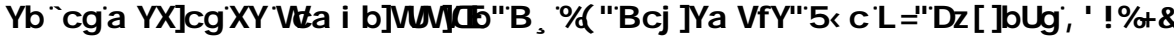

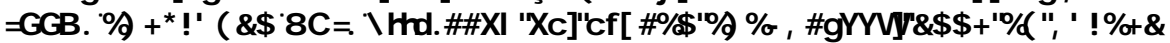

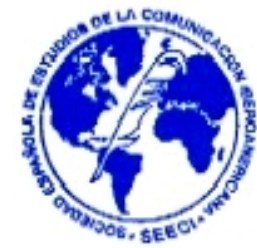

Imagen 4: Noviembre 2005

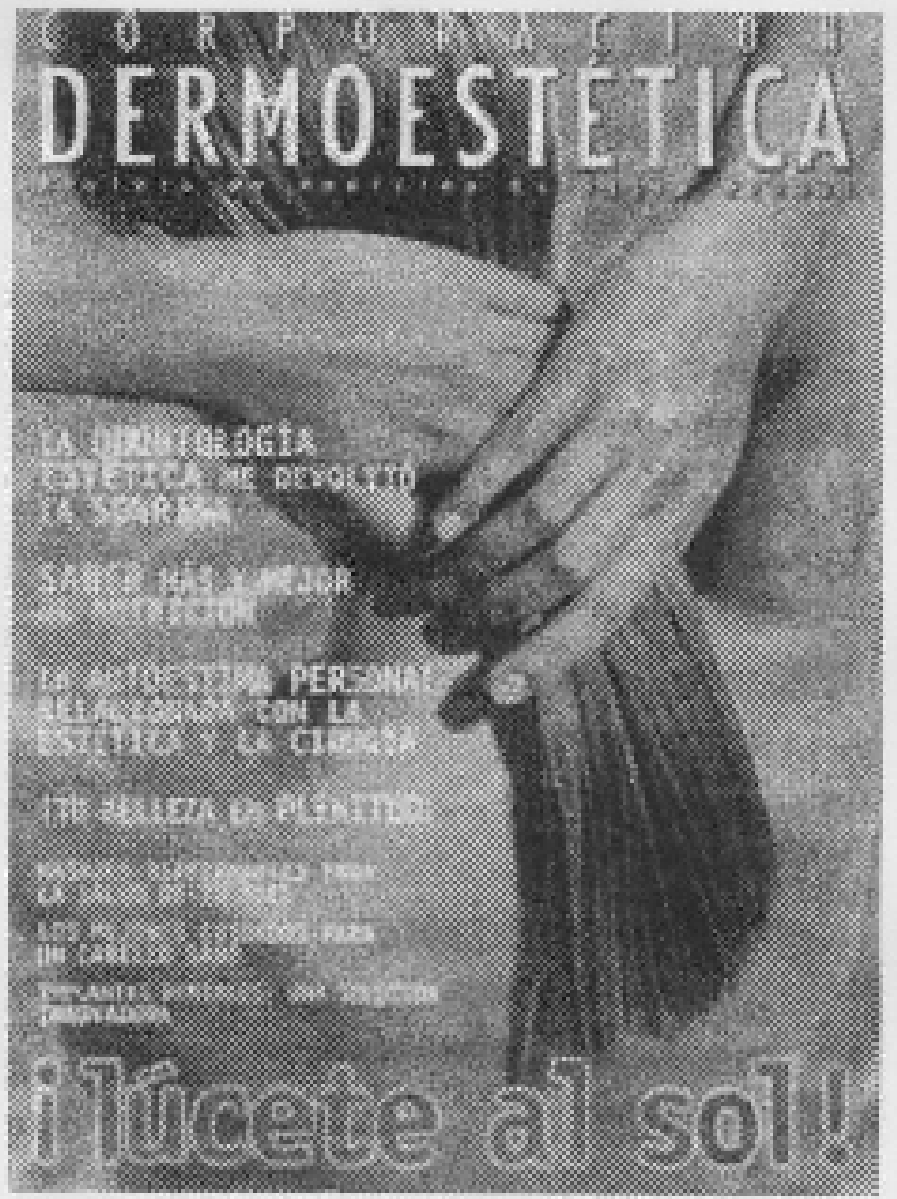




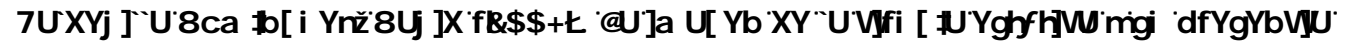

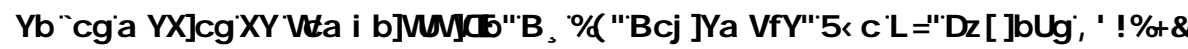

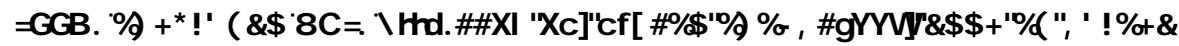

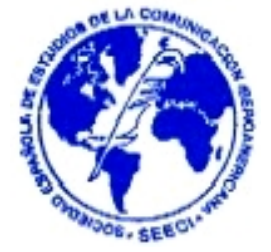

Imagen 5: Noviembre 2005

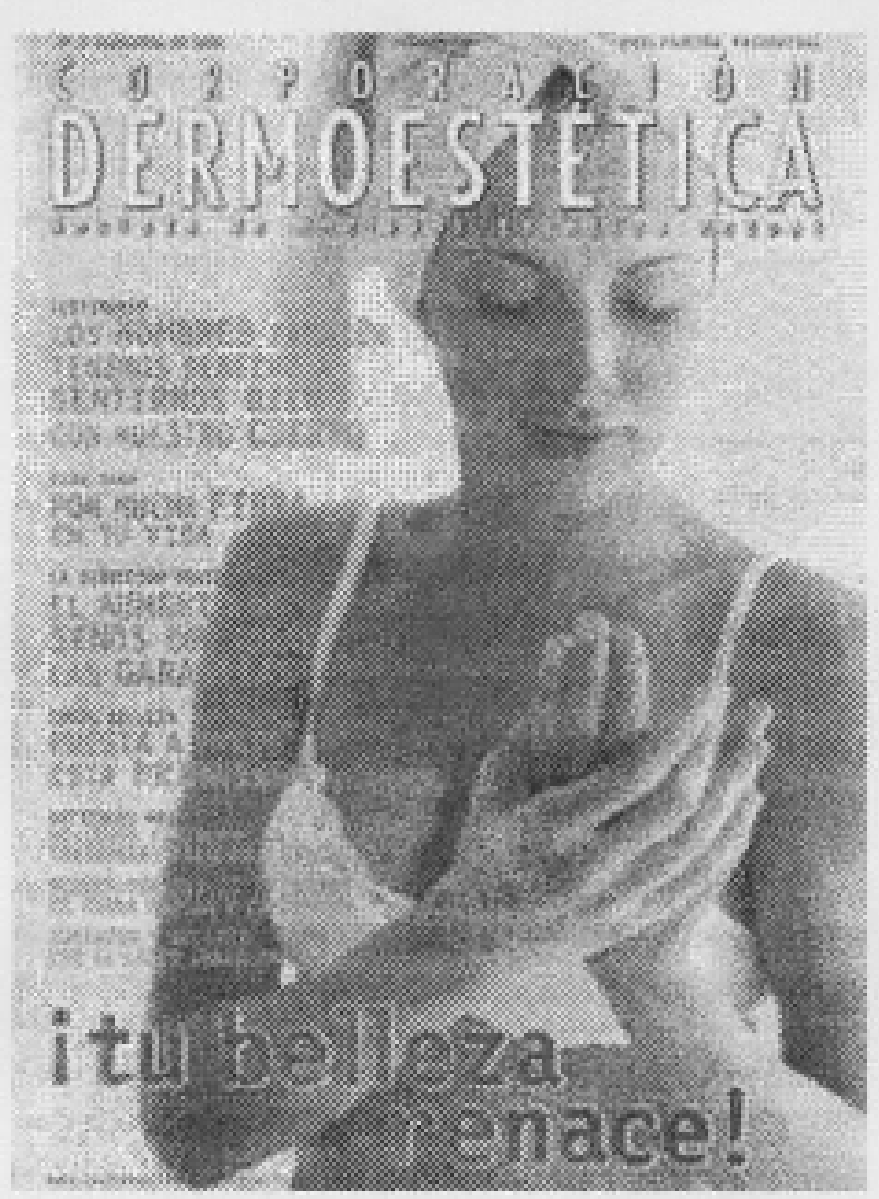




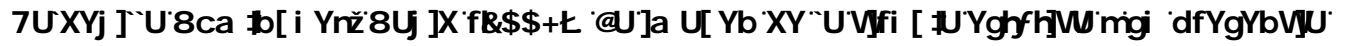
HQQVPP HGRVGHFRP XQIFDFLQ 11 1

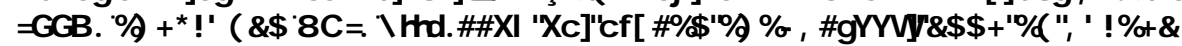

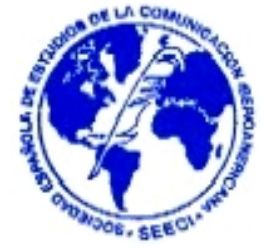

Imagen 6: Noviembre 2005

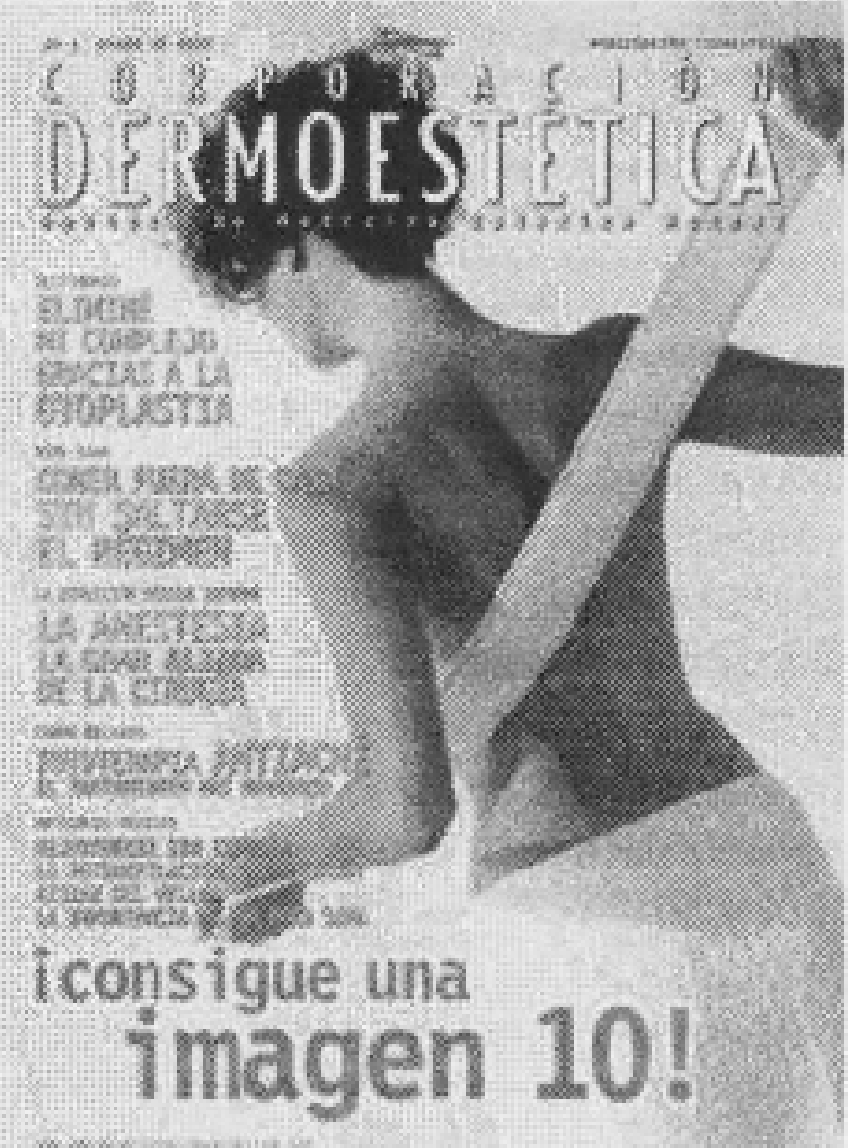




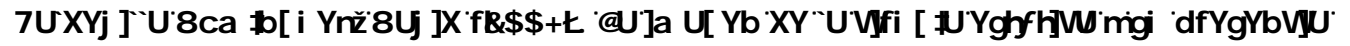

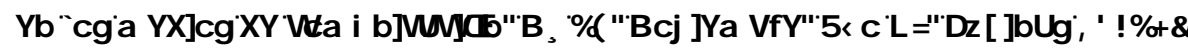

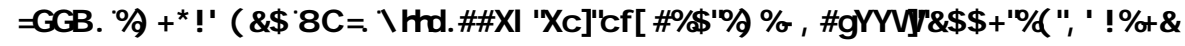

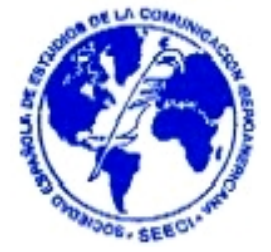

Imagen 7: Noviembre 2005

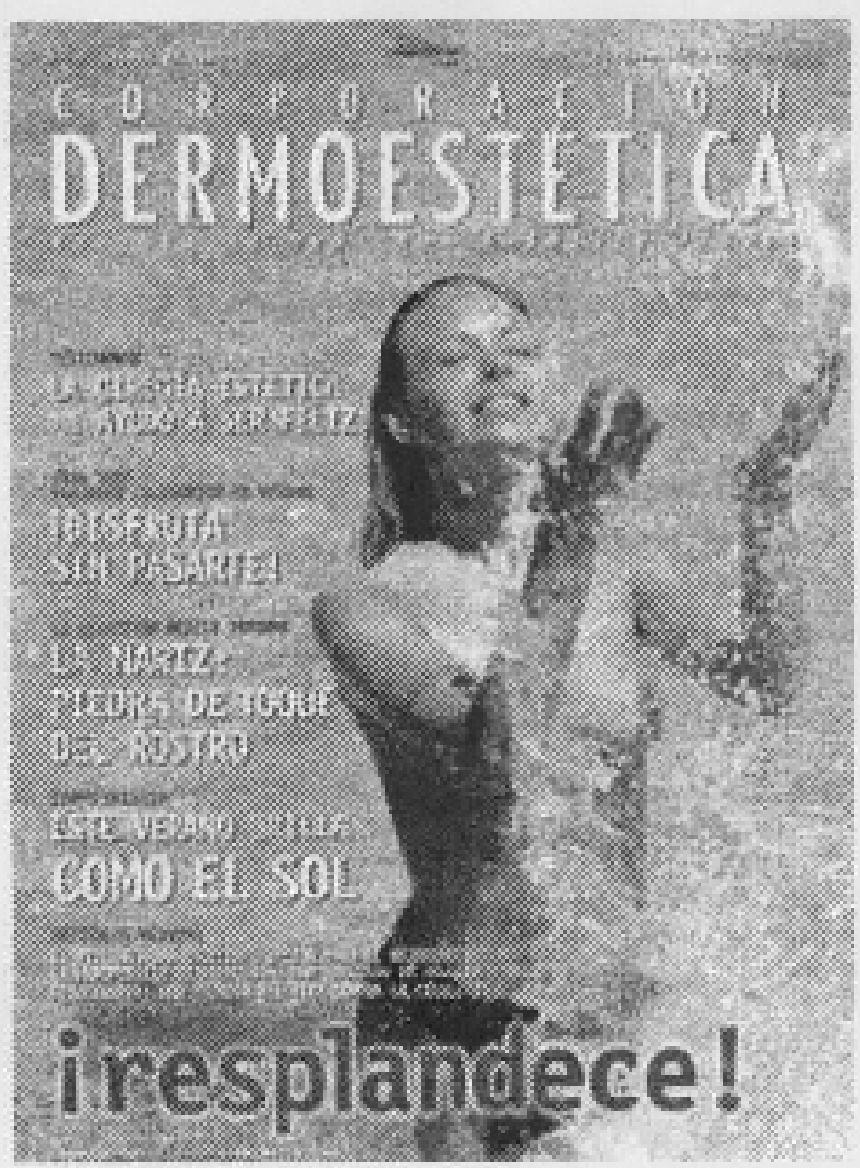




\section{REVISTA DE LA SEECI}

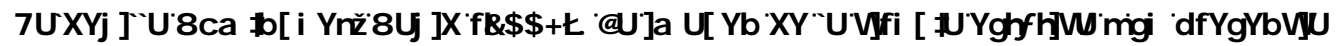

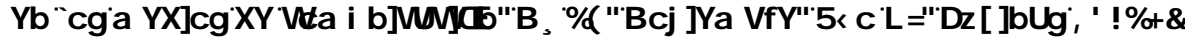

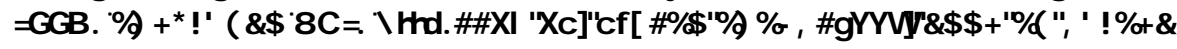
(

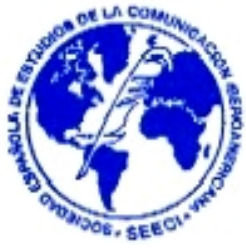

-Imagen 8: Noviembre 2005

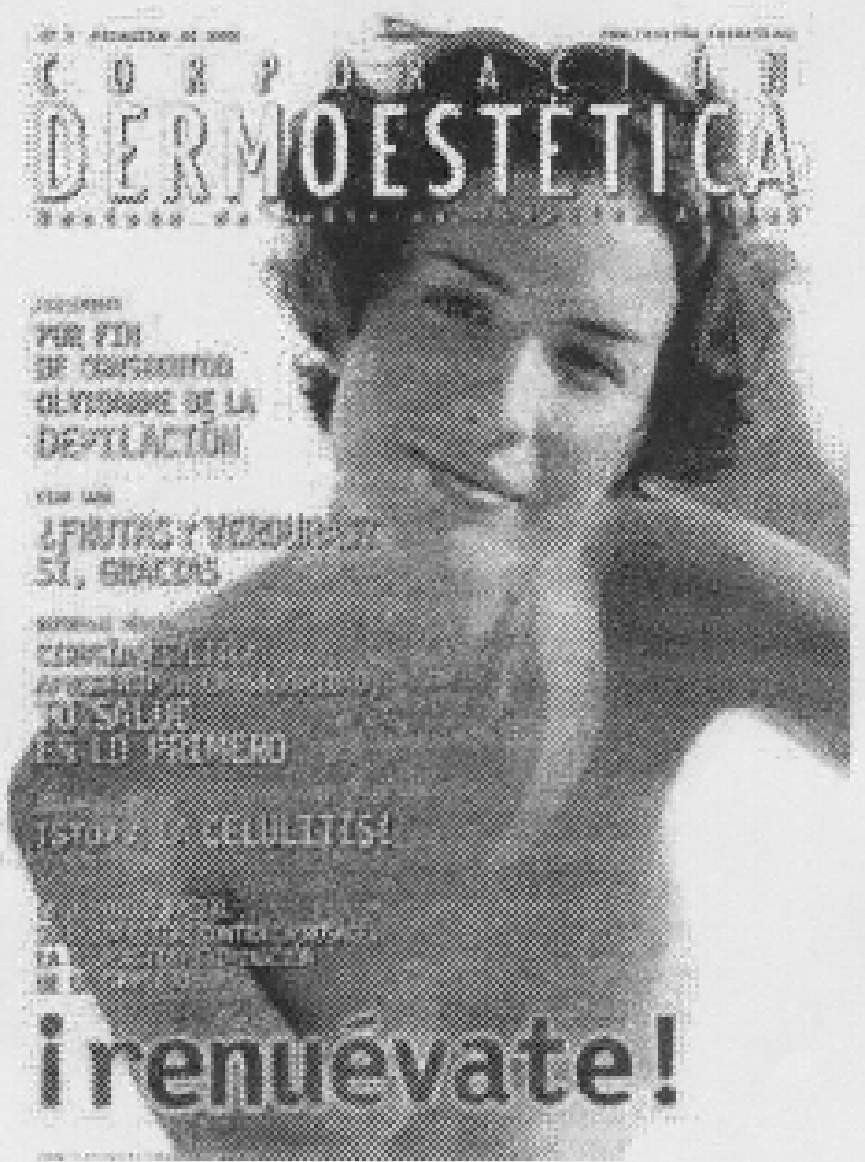


Caldevilla Domínguez, David (2007): La imagen de la cirugía estética y su presencia

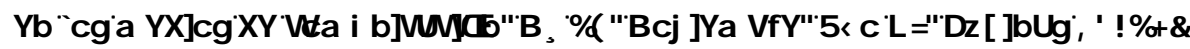

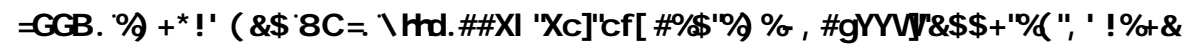

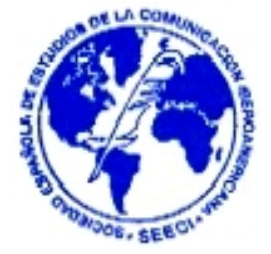

Imagen 9: Noviembre 2005

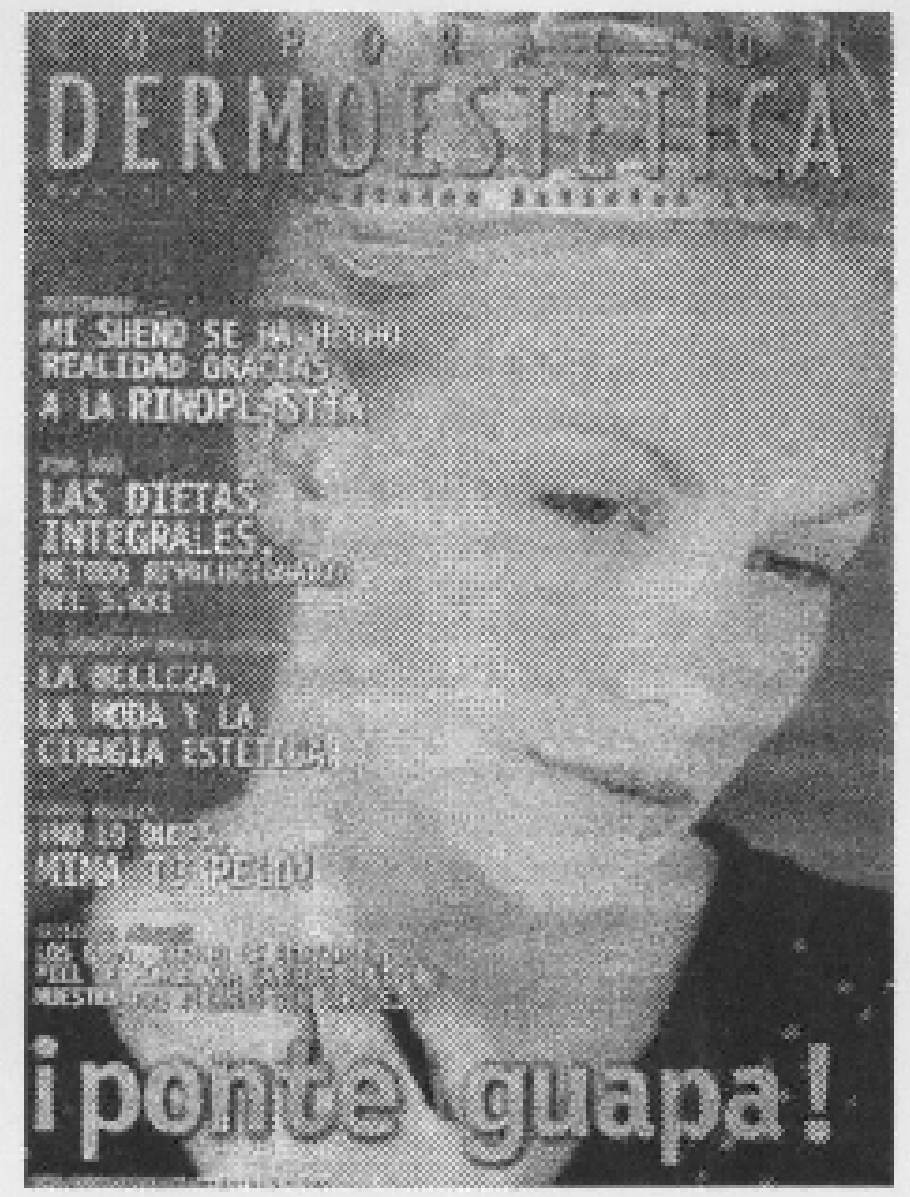


Caldevilla Domínguez, David (2007): La imagen de la cirugía estética y su presencia

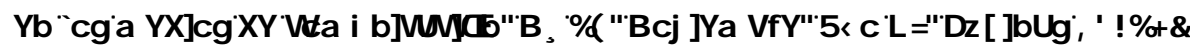

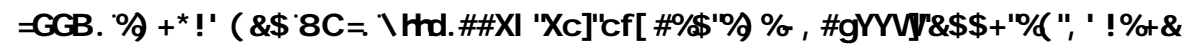

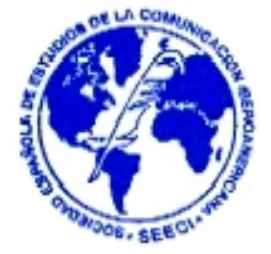

Imagen 10: Noviembre 2005

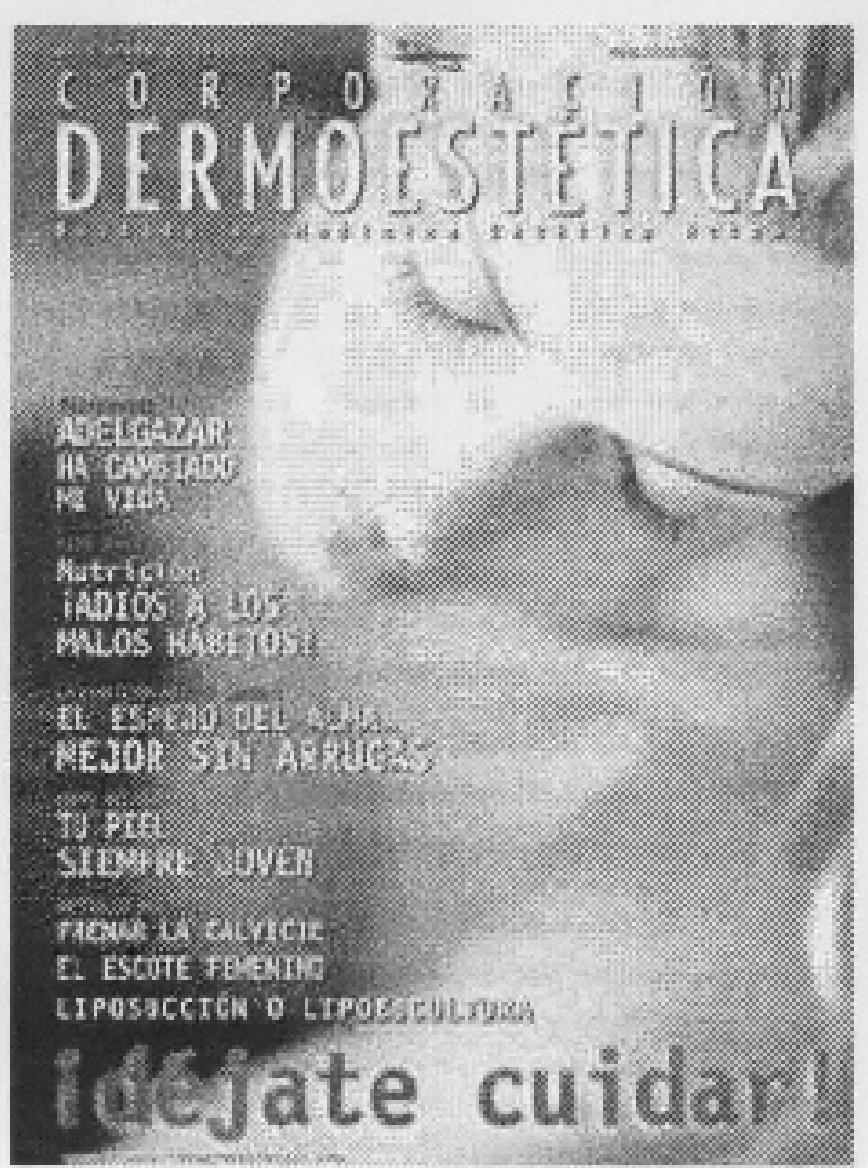




\section{REVISTA DE LA SEECI}

Caldevilla Domínguez, David (2007): La imagen de la cirugía estética y su presencia

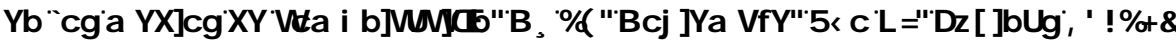
, 661 血

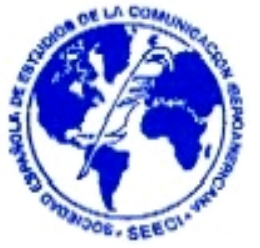

Imagen 11: Noviembre 2005

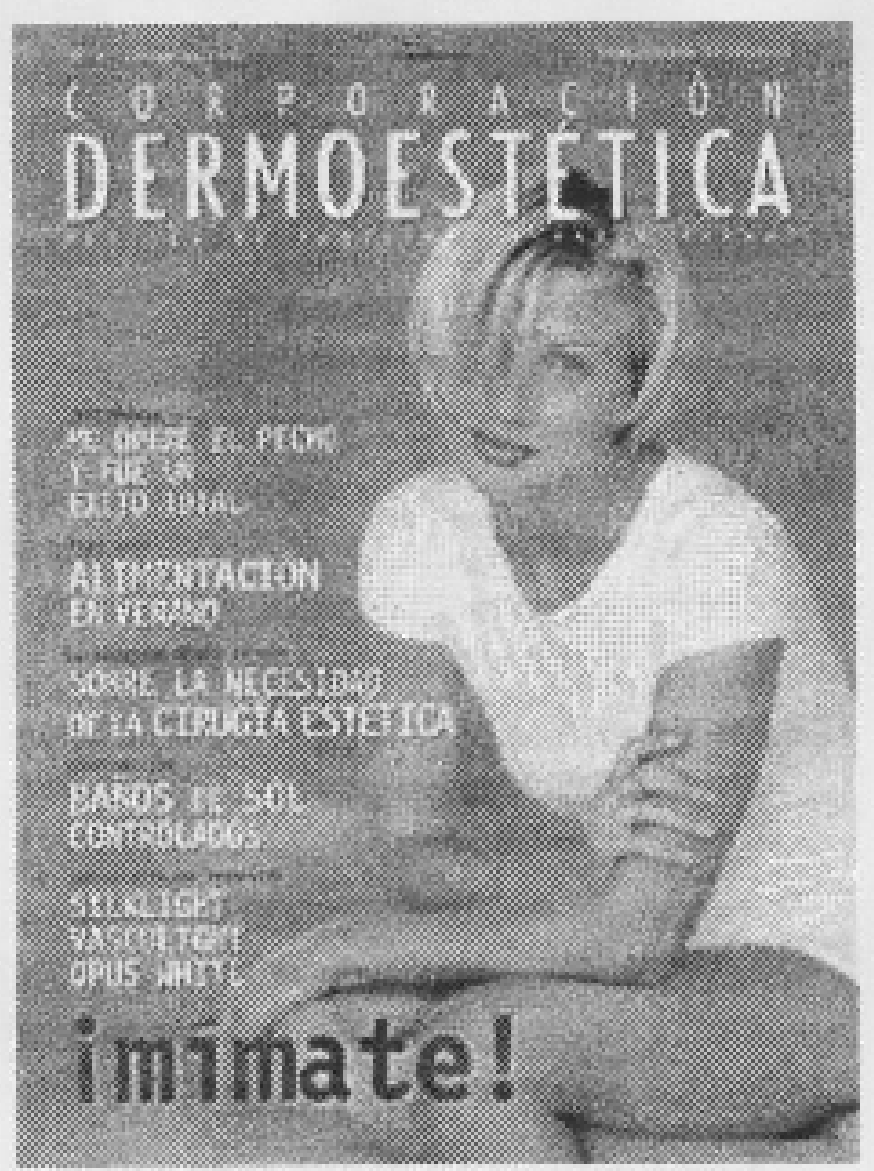


Caldevilla Domínguez, David (2007): La imagen de la cirugía estética y su presencia

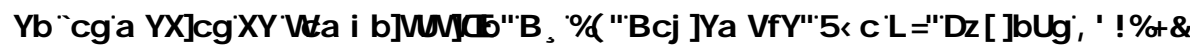

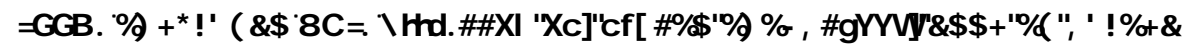

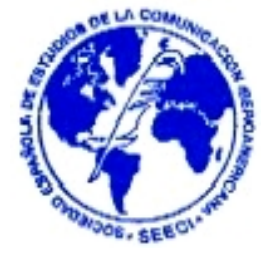

Imagen 12: Noviembre 2005

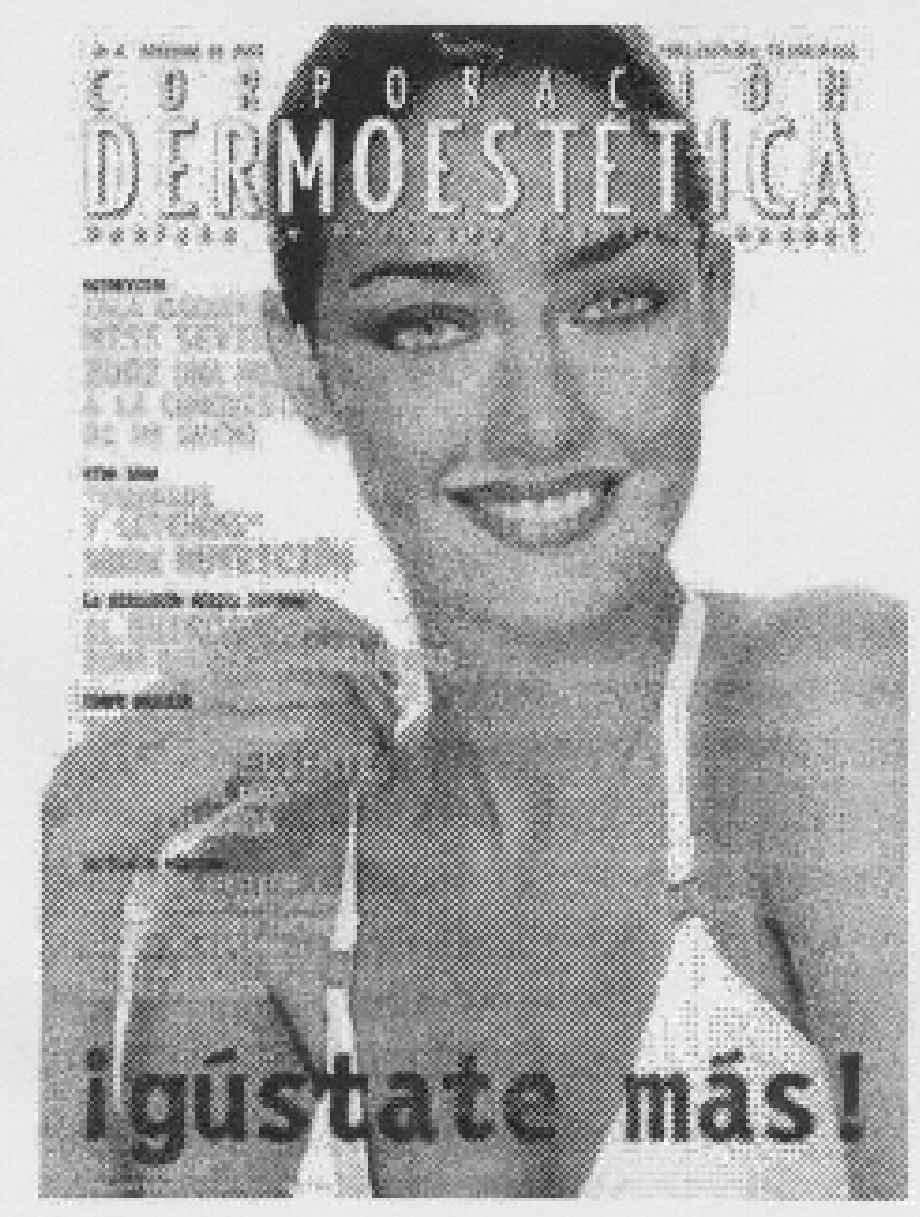




\section{REVISTA DE LA SEECI}

Caldevilla Domínguez, David (2007): La imagen de la cirugía estética y su presencia

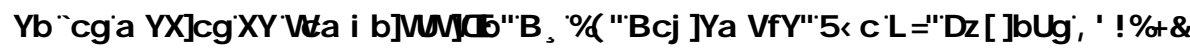

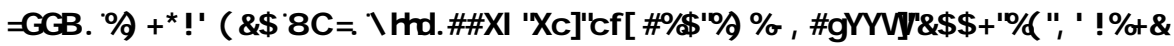

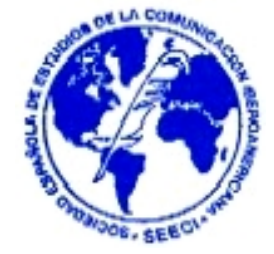

Imagen 13: Diciembre 2005

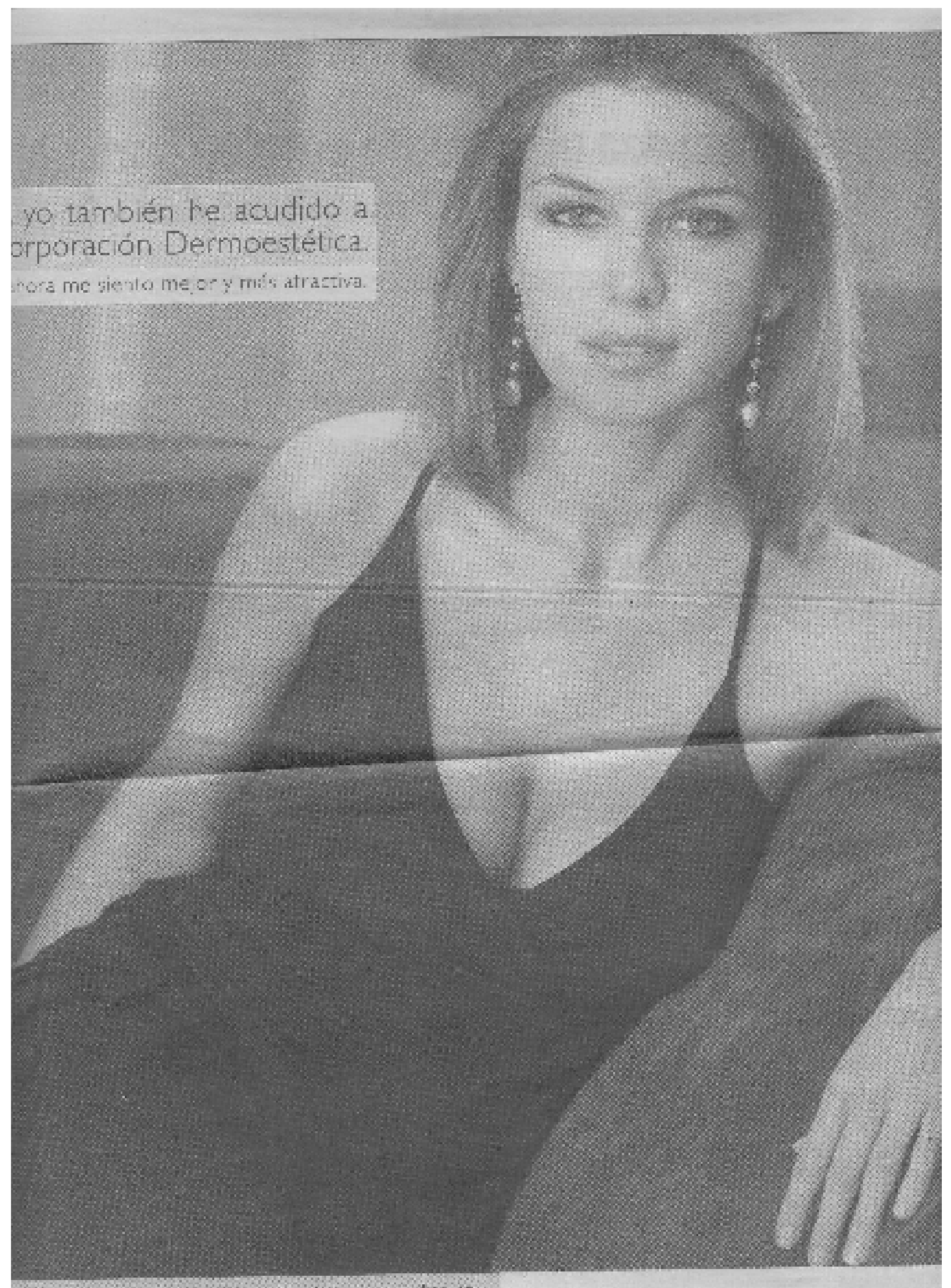




\section{REVISTA DE LA SEECI}

Caldevilla Domínguez, David (2007): La imagen de la cirugía estética y su presencia

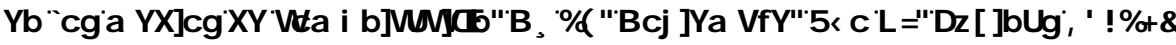
, 661 血

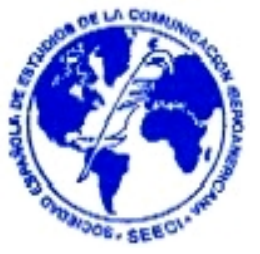

Imagen 14: Diciembre 2005

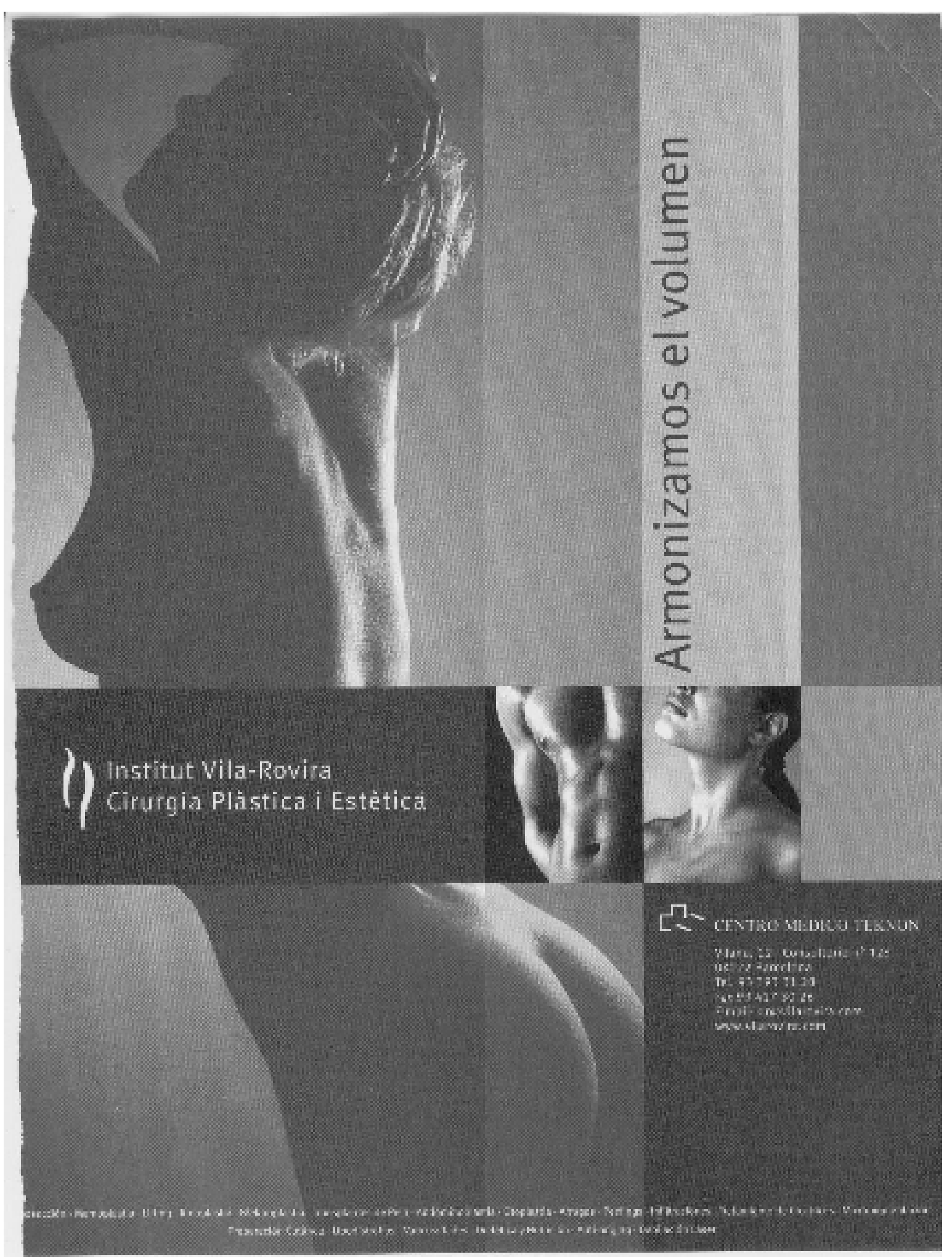



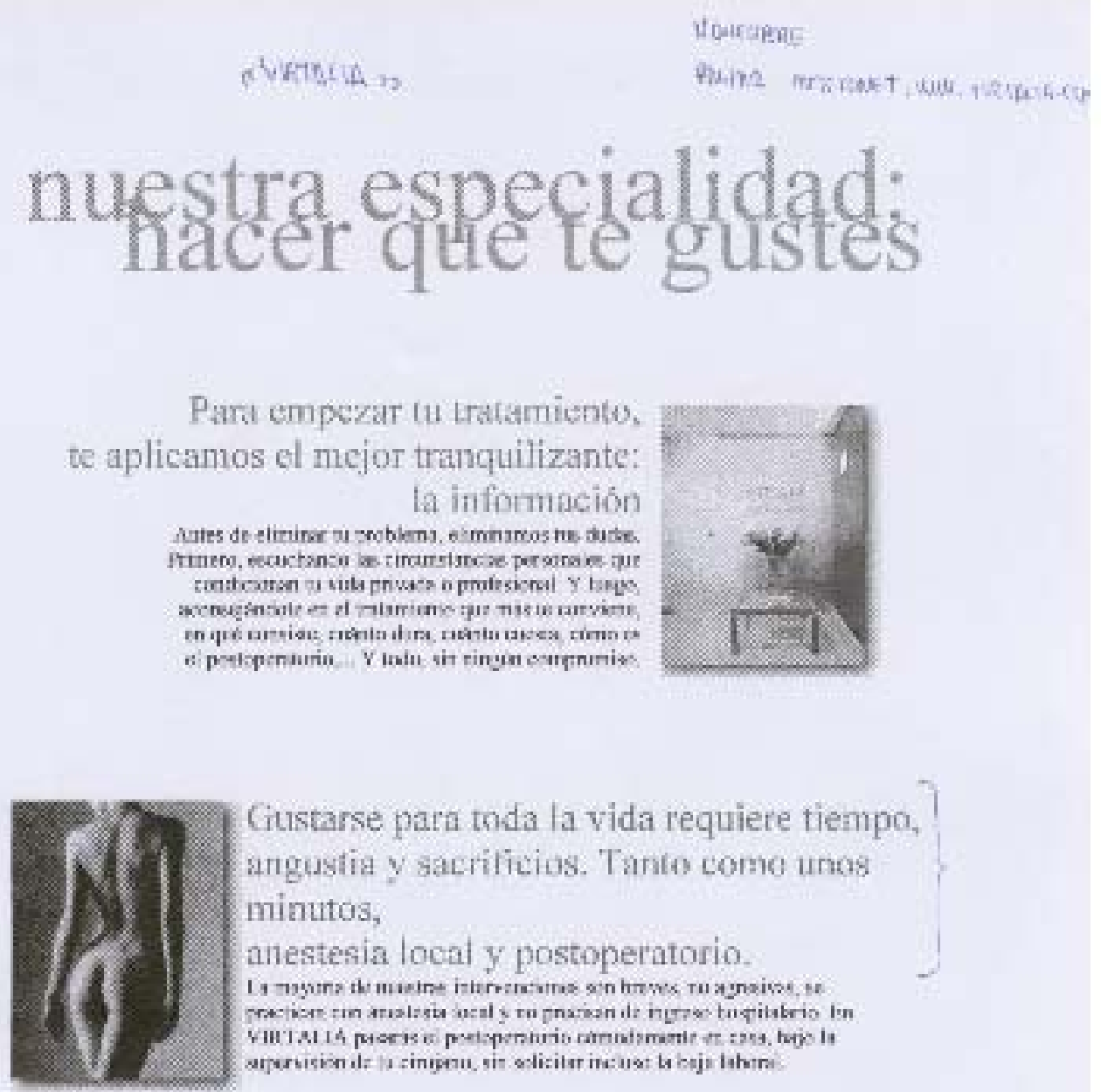

Gustarse para toda la vida requiete tiempo, angustia y sacriticios. Tanto come unos minutos,

anestesia local y postoperatorio.

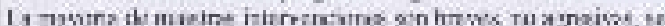

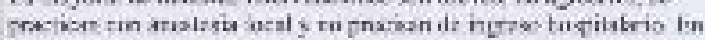

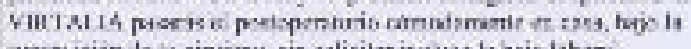

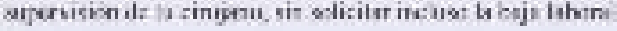

\section{Nuestros tratamientos tienen} precio cerrato, O sea, todo incluido hasta que sonrías.

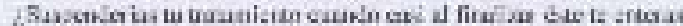

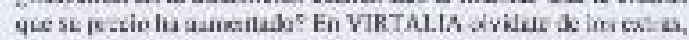

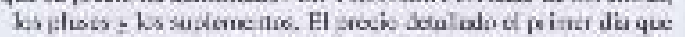

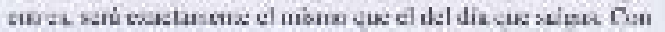


Imagen 16: (mes de enero)

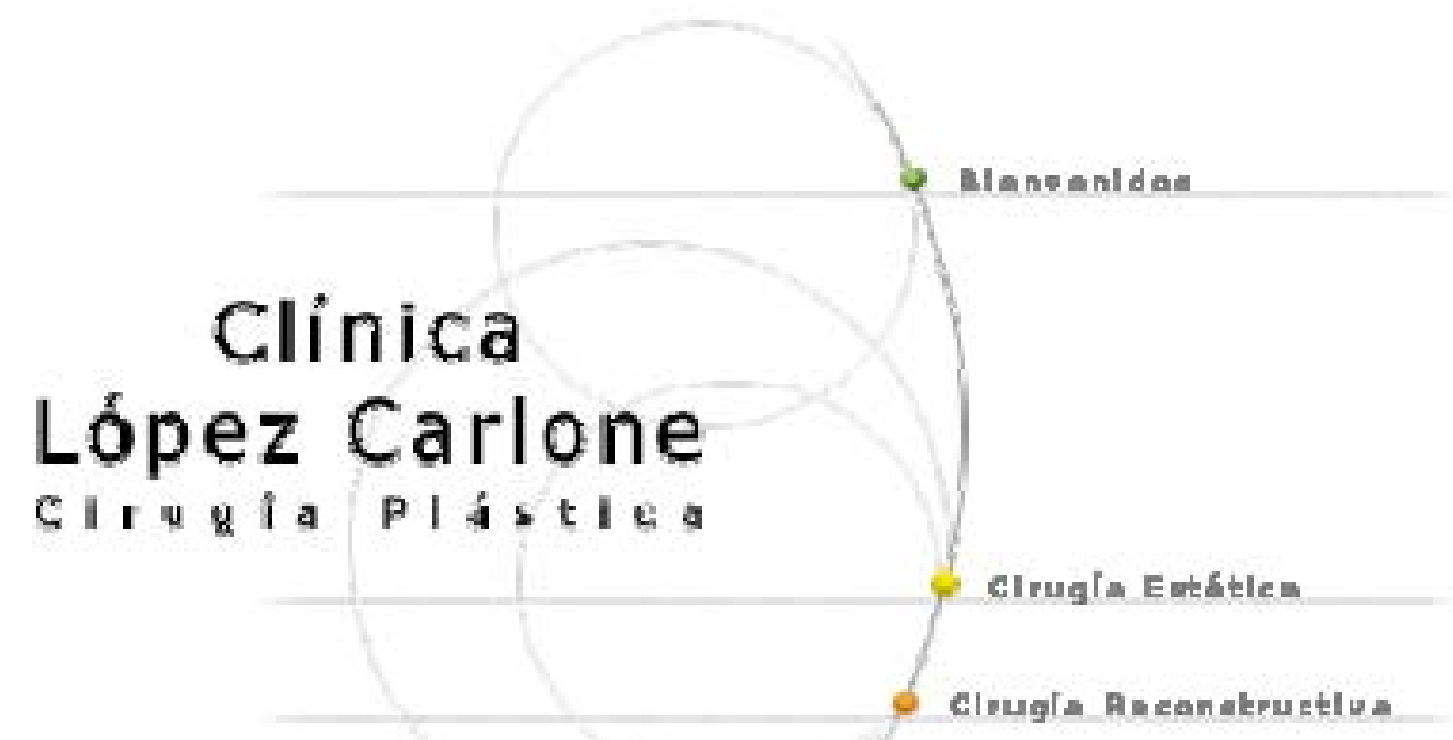

Imagen 17:(mes de enero)

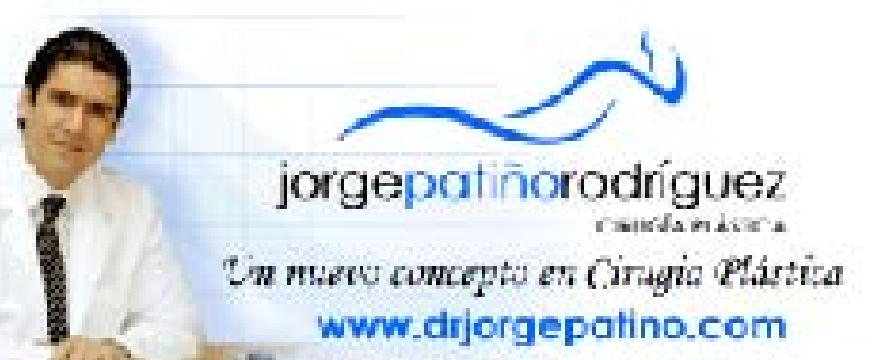

- Contomo corncral

- Cingiace momos

- Rejuveracimiento tacicl

- Pinoplastia

- Quemacos

Clínca Aicivar, Canar Be9 y Corored 1er. Piso Tedelono: 234-5091 Kennedy horte Av. Luis Orrantis Edificio Udimei il : to piso Te efono 268-401 Cel-la: 09:32360/ Skyte: $251515^{\circ}$ BuEyaquil - Ecuasior 


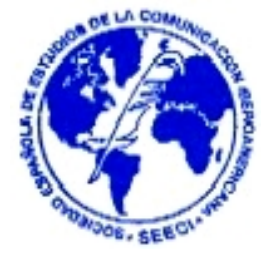

Imagen 18: (mes de febrero)

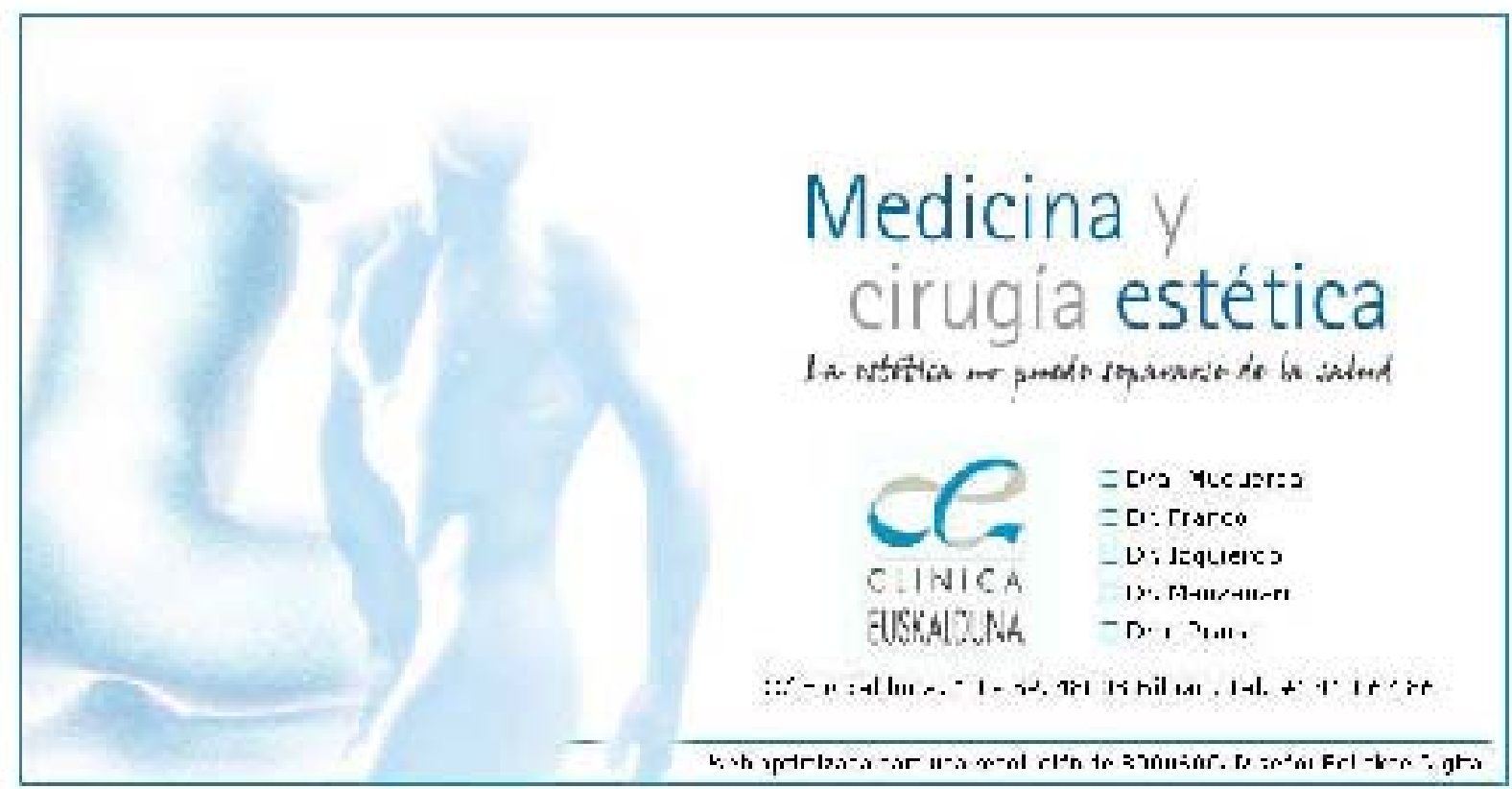

Imagen 19: (mes de febrero)

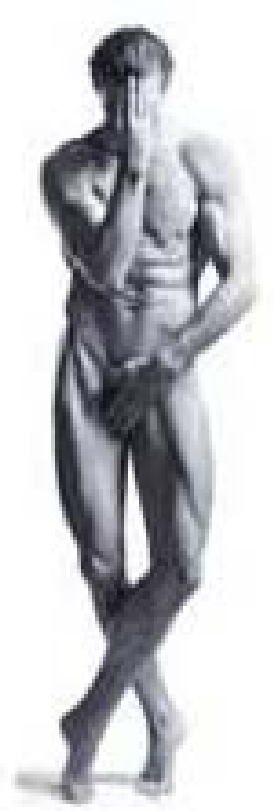

La belleza también es cosa de hombres 


\section{REVISTA DE LA SEECI}

Caldevilla Domínguez, David (2007): La imagen de la cirugía estética y su presencia

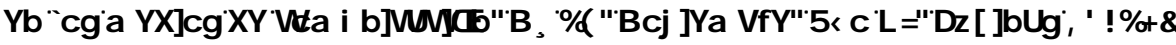
, 661 血

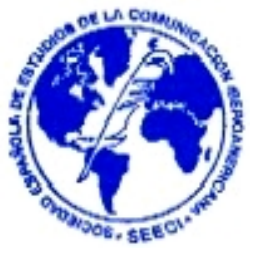

También la prensa especializada en estilismo y moda suele tocar el tema desde la publicidad y desde reportajes, periódicos y especiales que abarcan este tema. Elegimos Vogue y Yo Dona como representantes de este tipo de publicaciones.

Imagen 20: Vogue

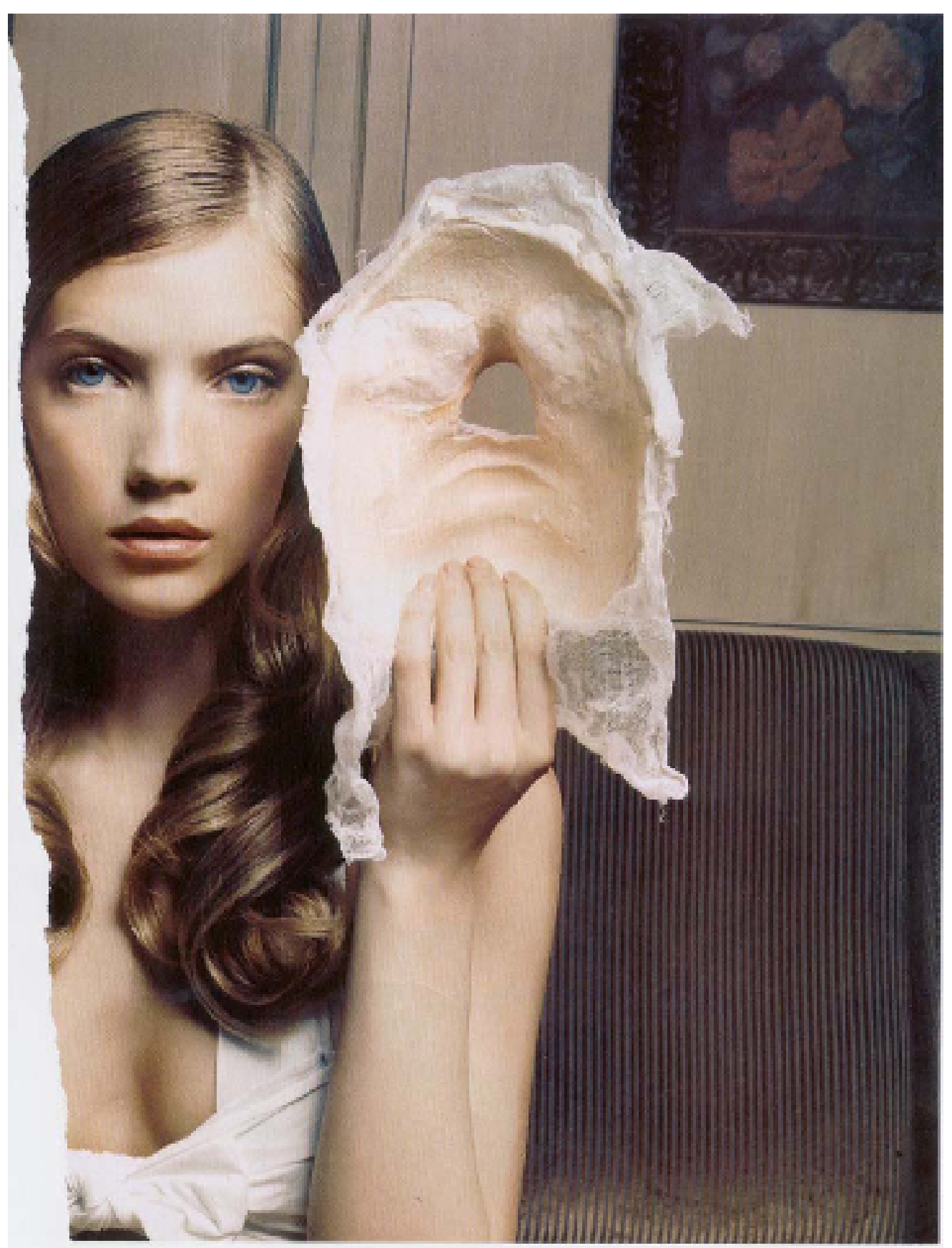




\section{REVISTA DE LA SEECI}

Caldevilla Domínguez, David (2007): La imagen de la cirugía estética y su presencia

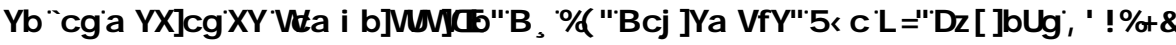
, 661 血

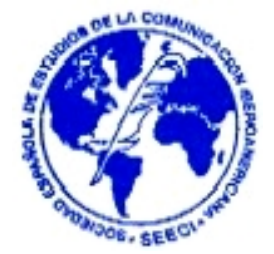

\section{Imagen 21: Vogue}

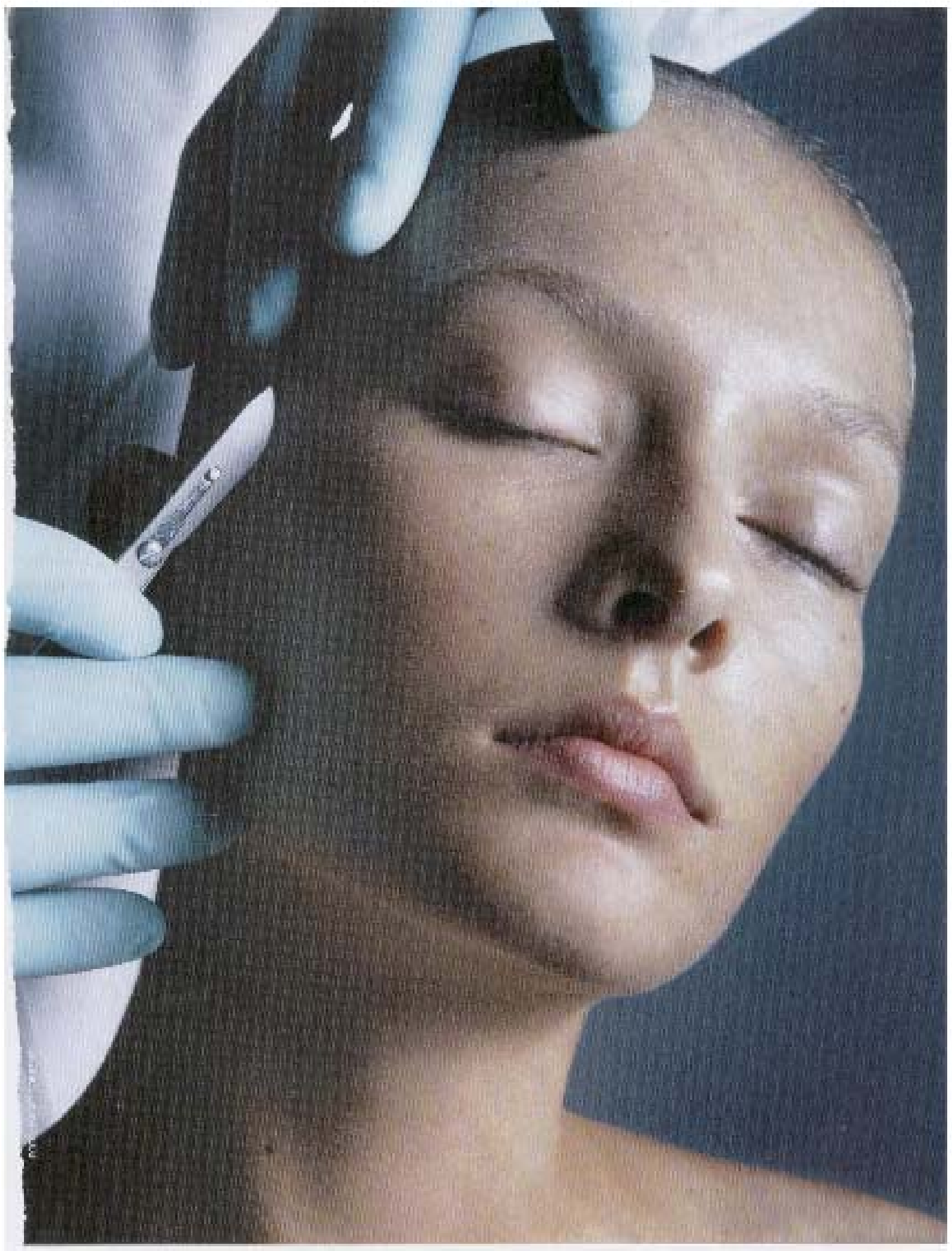




\section{REVISTA DE LA SEECI}

Caldevilla Domínguez, David (2007): La imagen de la cirugía estética y su presencia

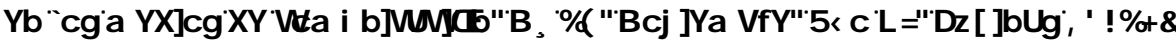
, 661 血

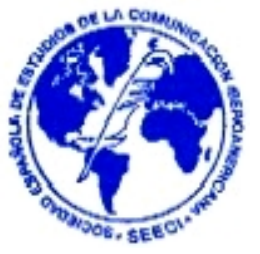

\section{Imagen 22: Vogue}

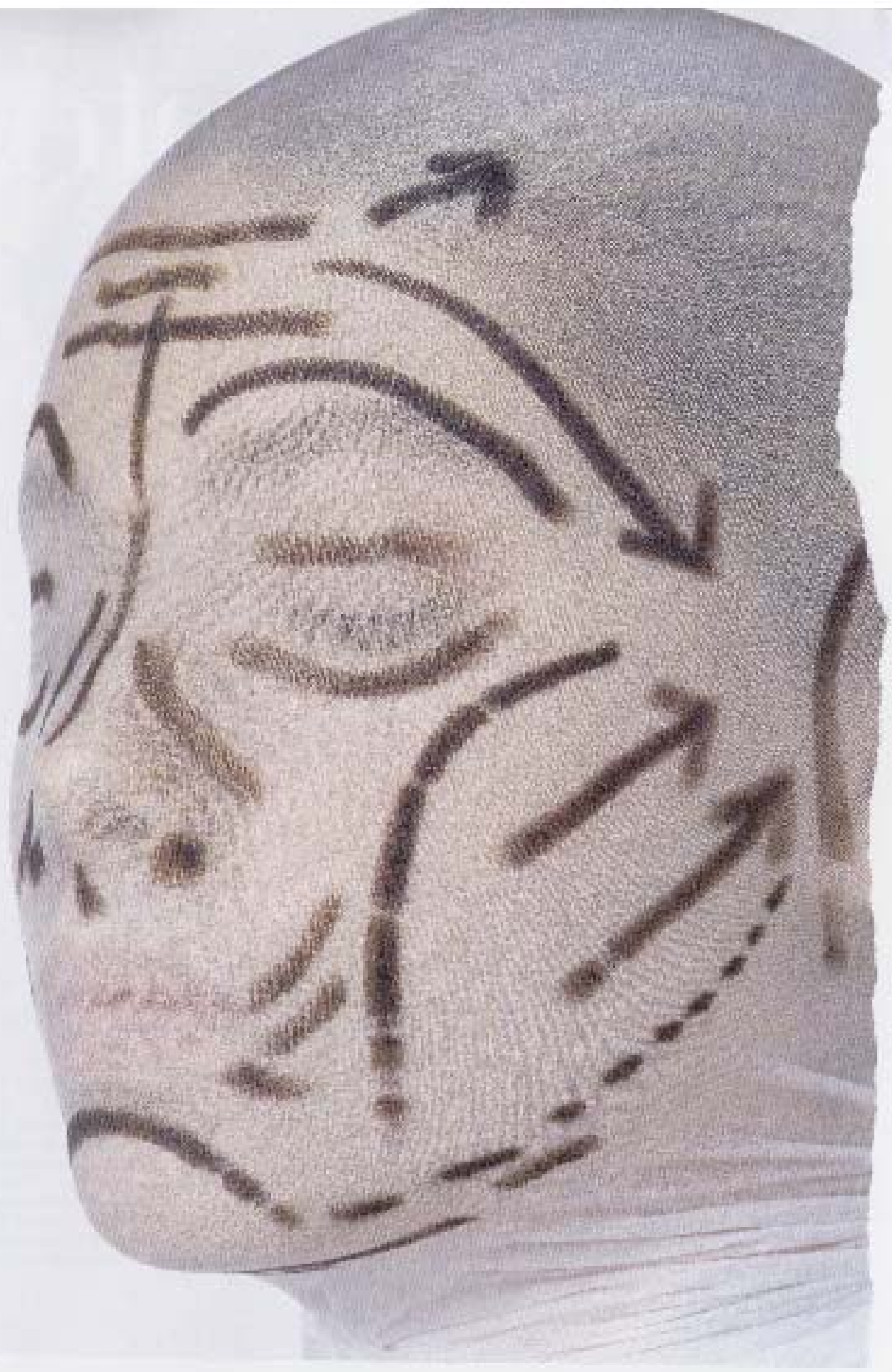




\section{REVISTA DE LA SEECI}

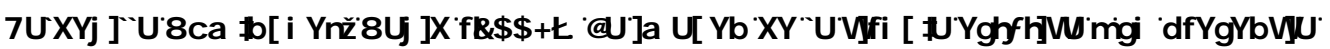

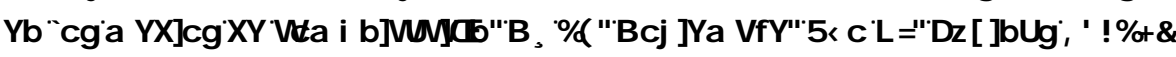

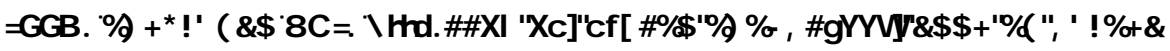

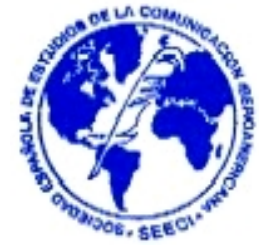

Imagen 23: Vogue

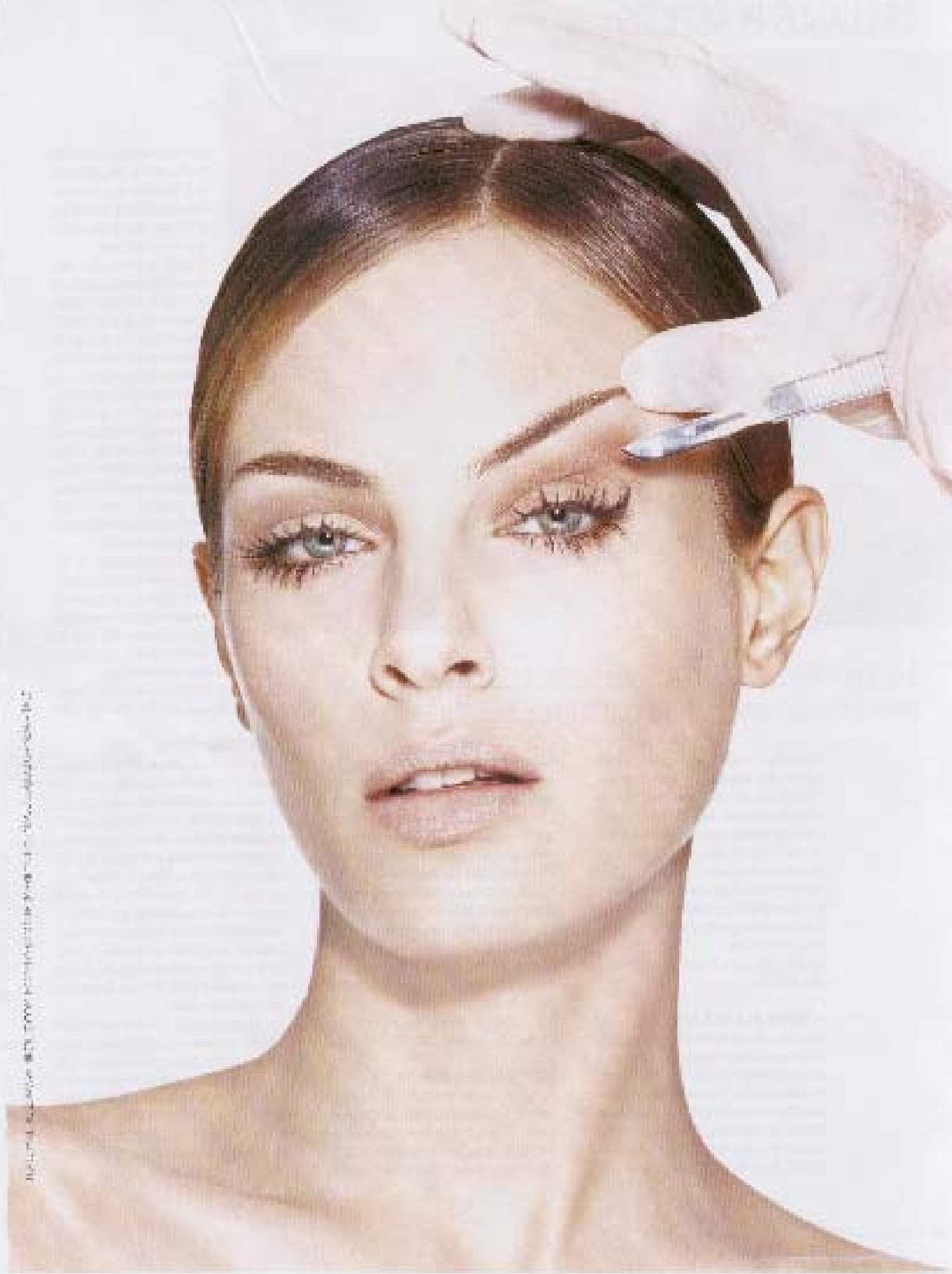




\section{REVISTA DE LA SEECI}

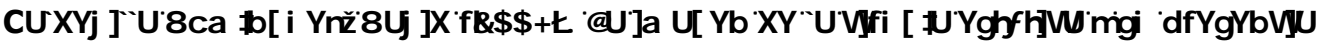

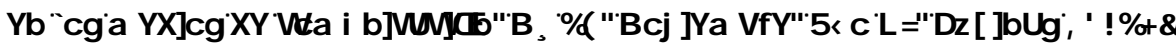

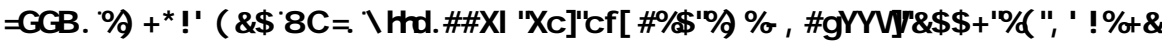

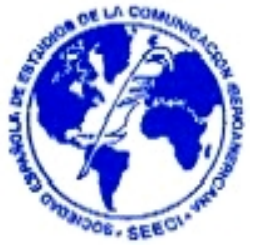

\section{Imagen 24: Vogue}

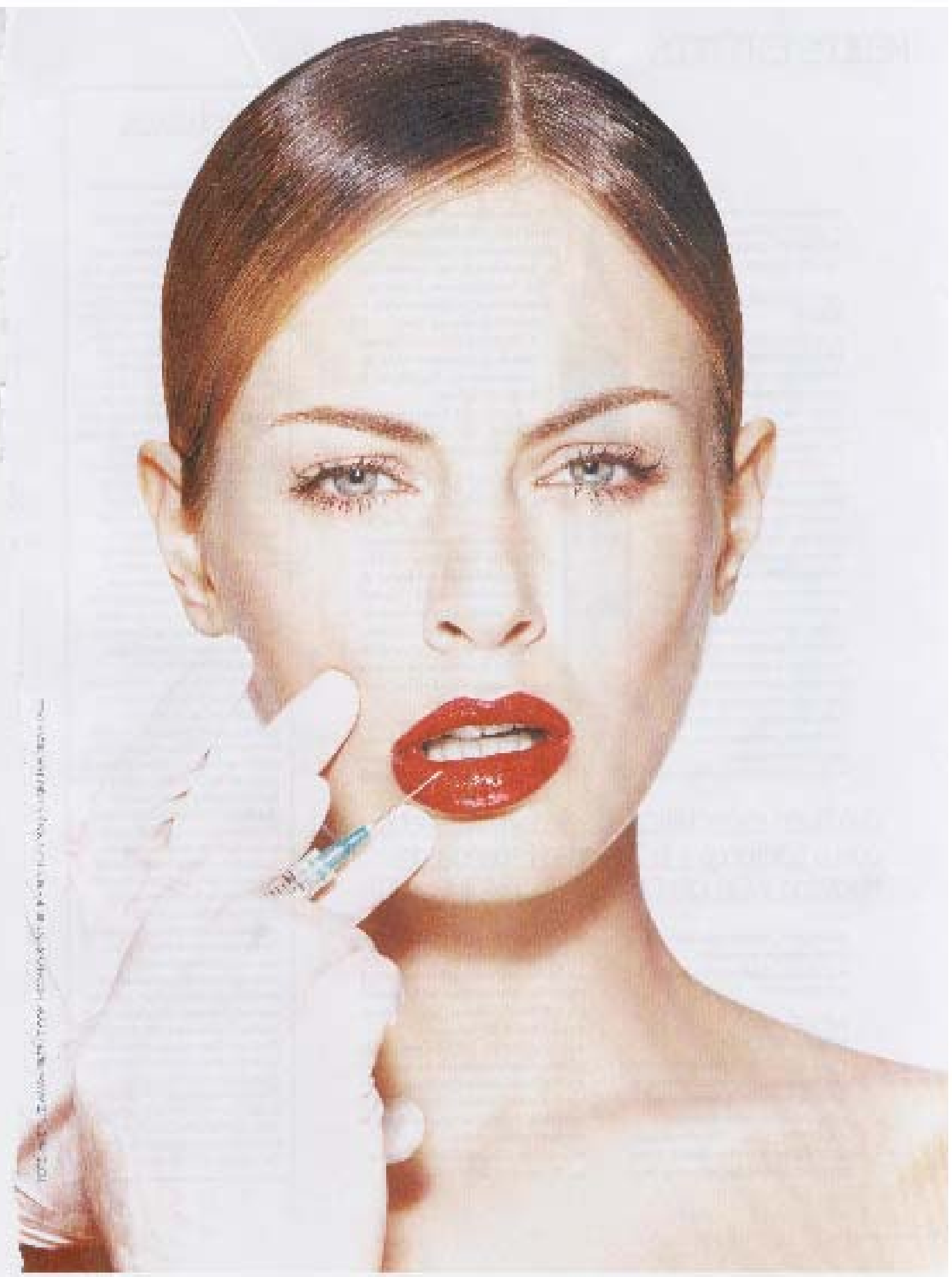




\section{REVISTA DE LA SEECI}

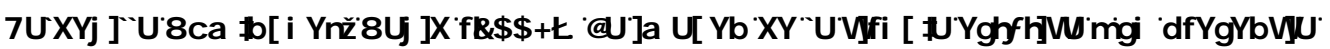

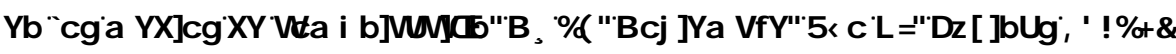

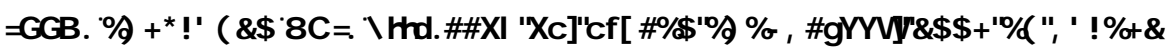

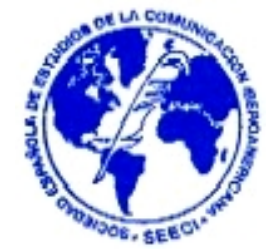

\section{Imagen 25: Vogue}

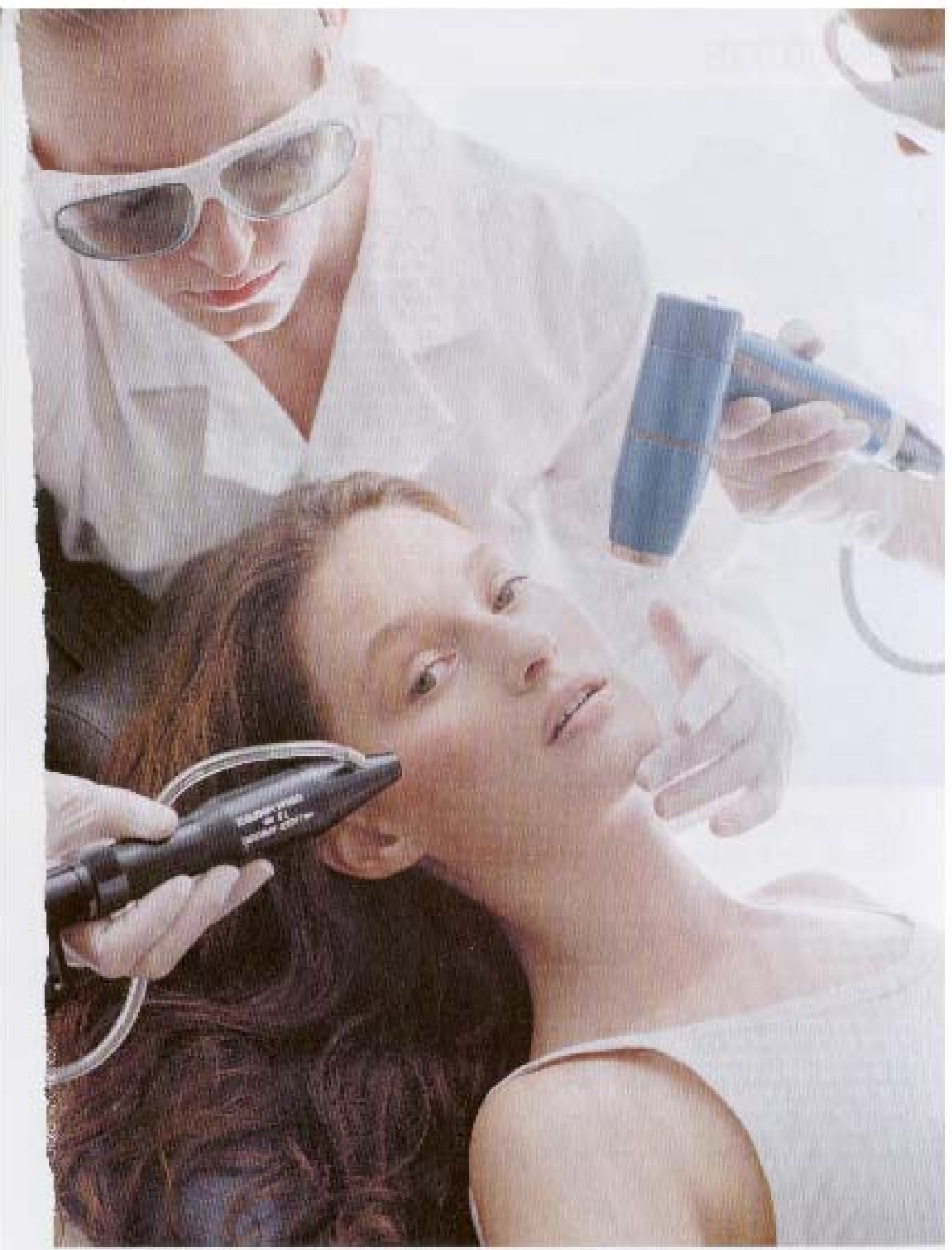




\section{REVISTA DE LA SEECI}

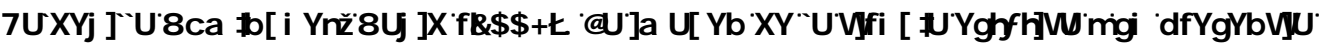

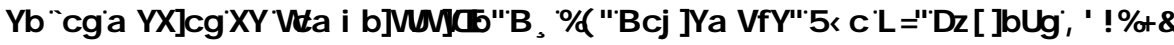

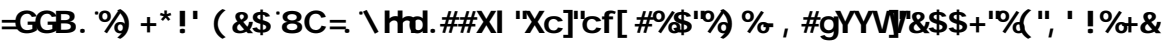

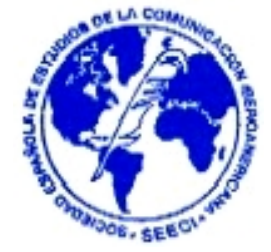

Imagen 26: Vogue

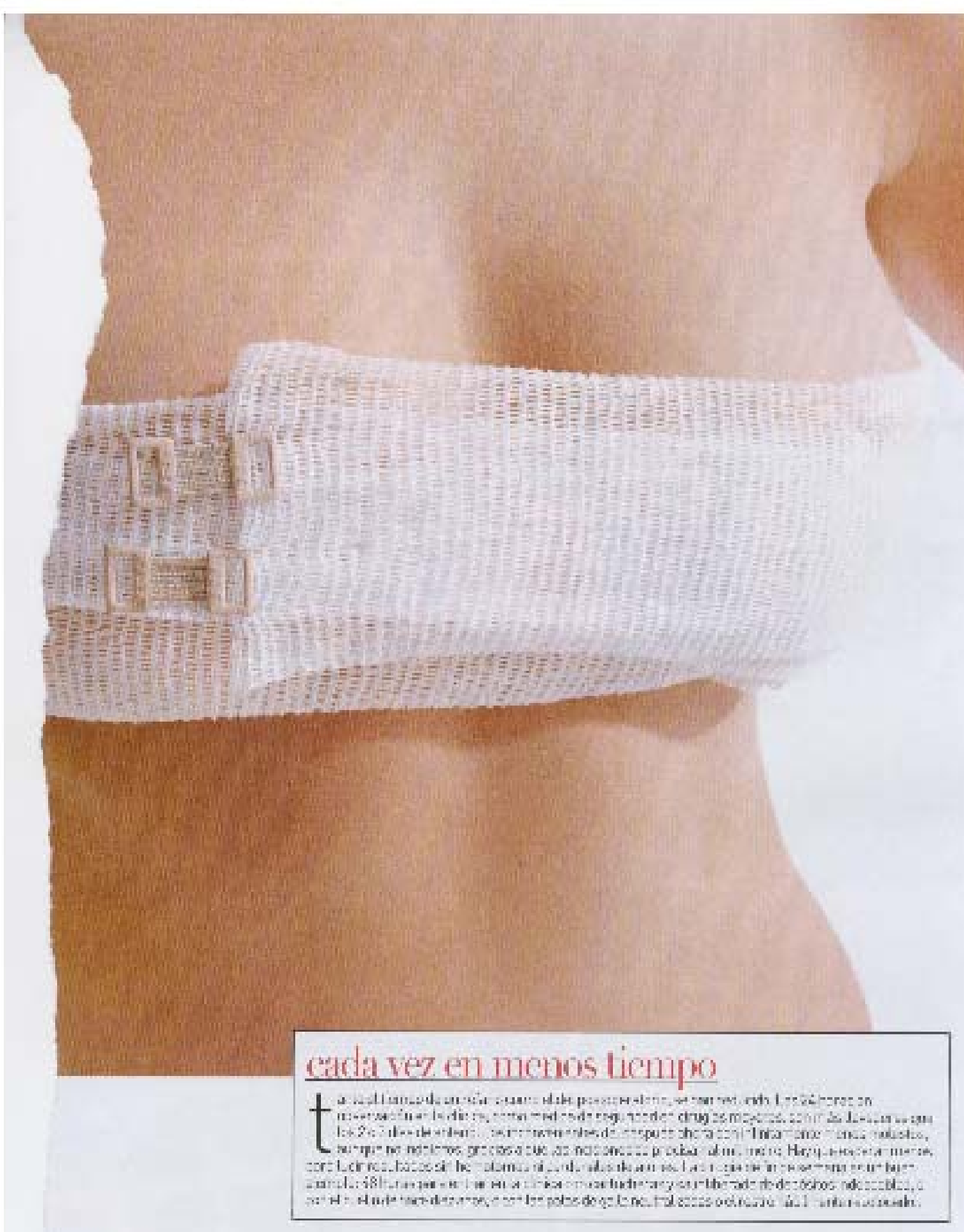




\section{REVISTA DE LA SEECI}

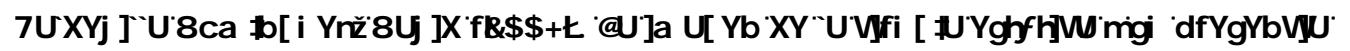
HQRVPP HGRVGHFRP XQIFDFYQ 11 1 , 661 [ण

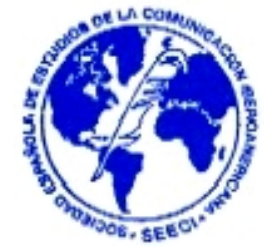

\section{Imagen 27: Yo Dona (mes de Noviembre)}

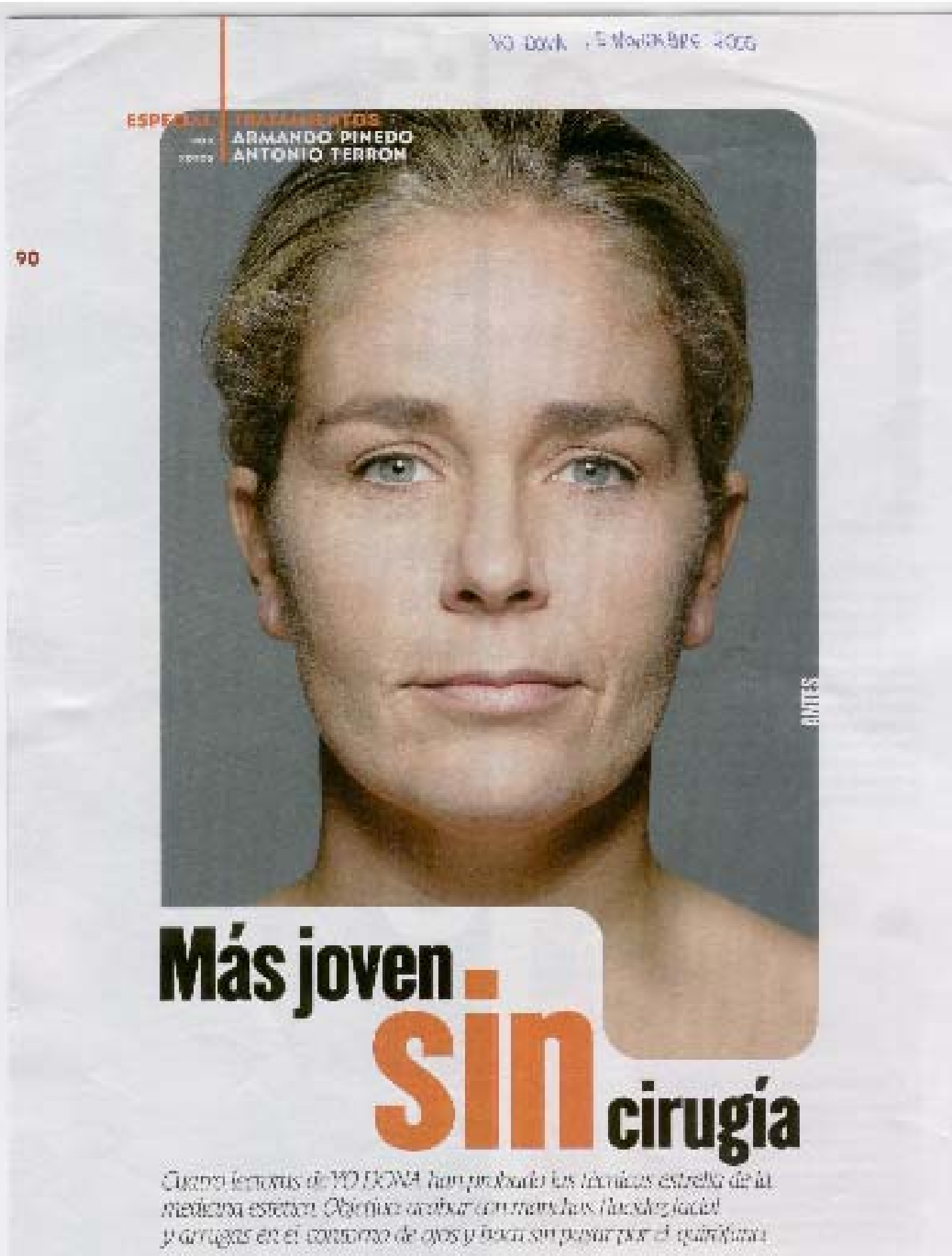




\section{REVISTA DE LA SEECI}

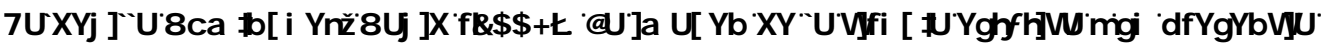

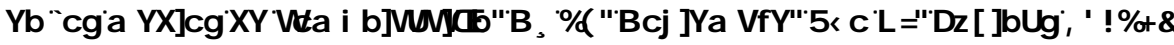

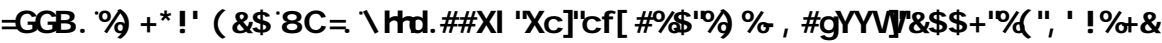

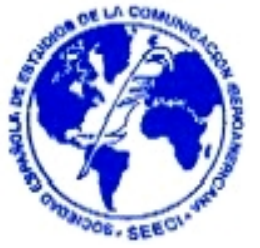

Imagen 28: Yo Dona (mes de Noviembre)

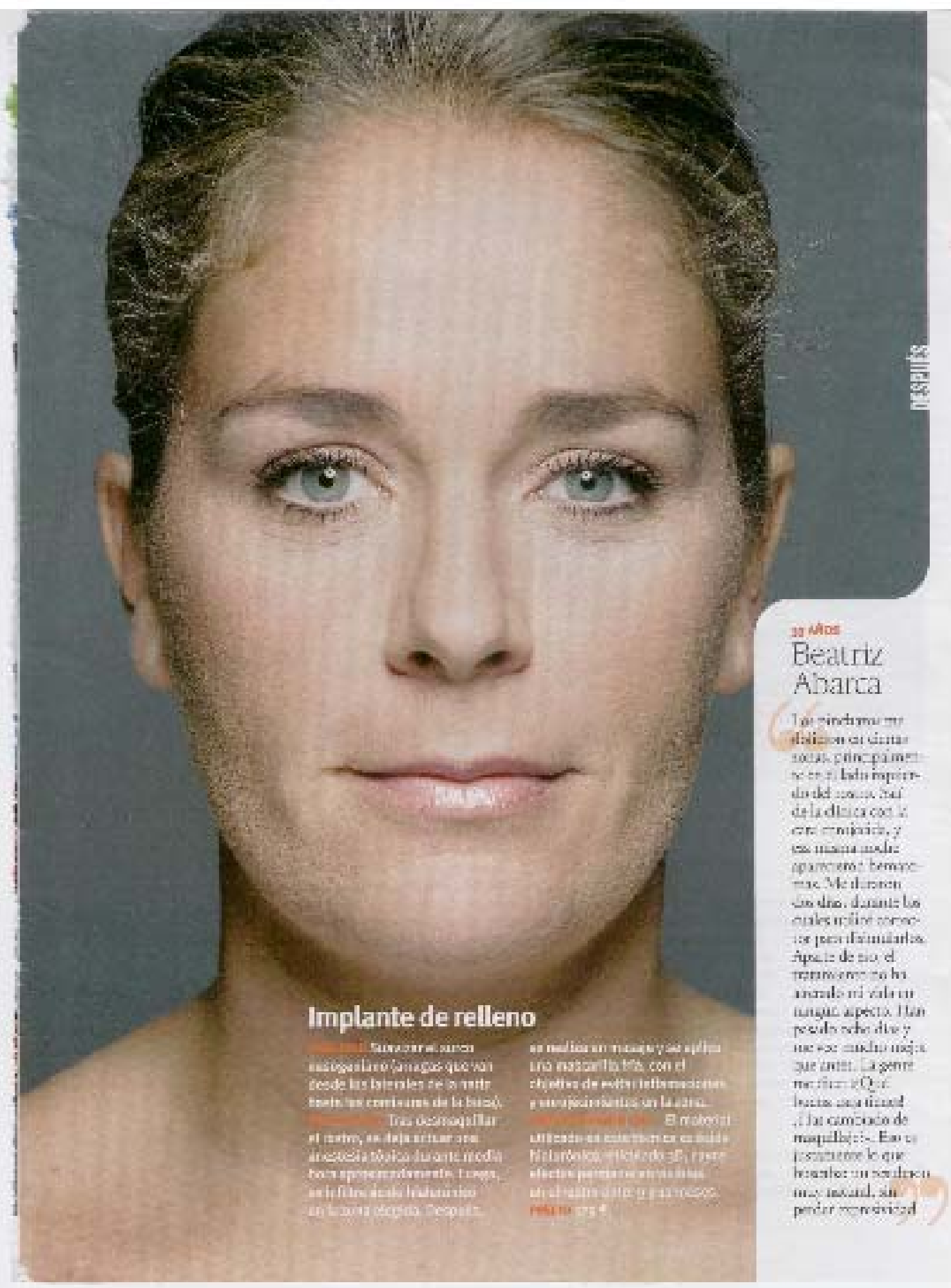




\section{REVISTA DE LA SEECI}

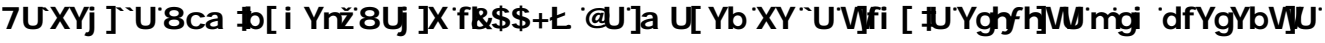

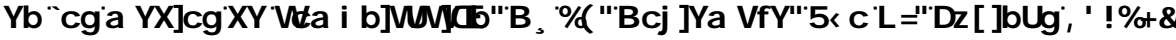

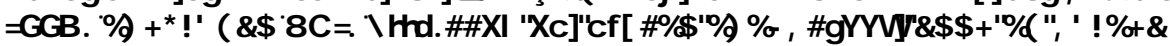

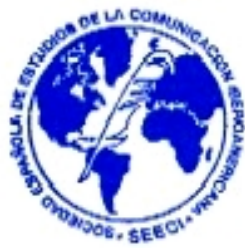

Imagen 29: Yo Dona (mes de Noviembre)

92

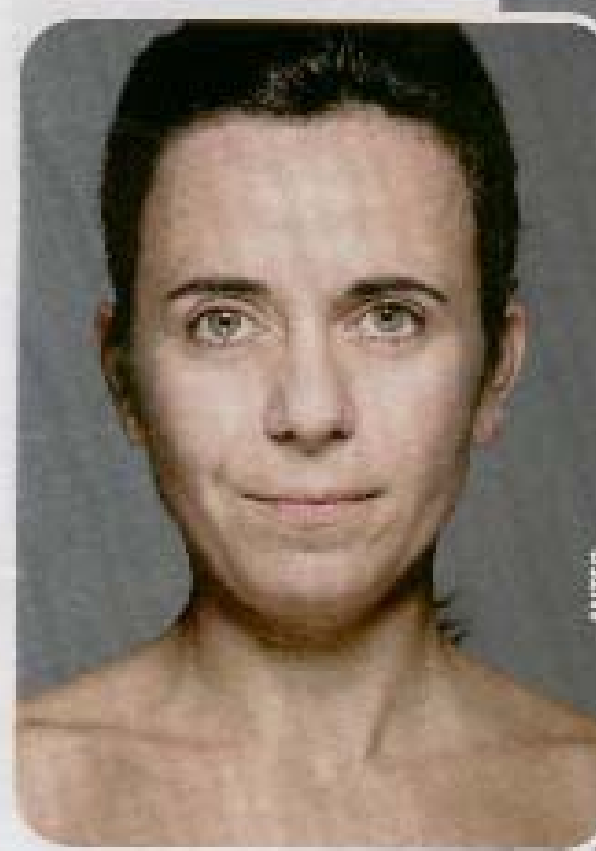

Jeations

latima Rodrigues

Antimanchas

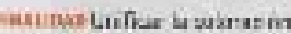

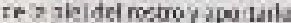

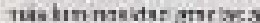
If swisy dasiamentante.

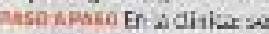
spitatm riens ceres bs naciespartule lewe vas disis acharerte oustroydioco auc. Encese tovquaigsore

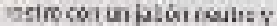
utfires tma rens desalenser

Gitk seyer fisea caratte in

peibio desirpayas dppecirest re sodzczea comathestion. A noes is

weweris rempithel tys cikatucoi una sesiátideleser. mono bga C.

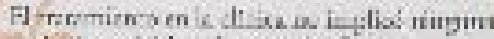

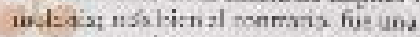

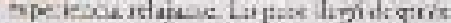

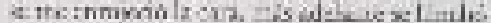

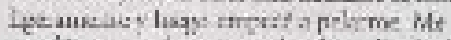
cuede encus d artary d cuims alta rigrien

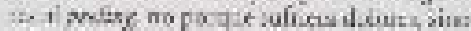

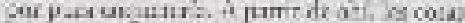

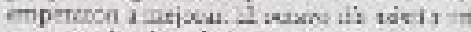

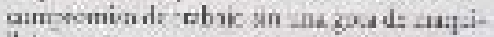

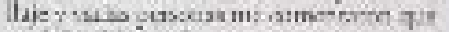

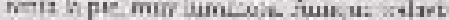

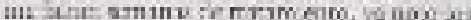

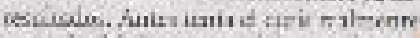

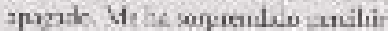

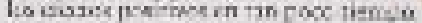


Imagen 30: Yo Dona (mes de Noviembre)

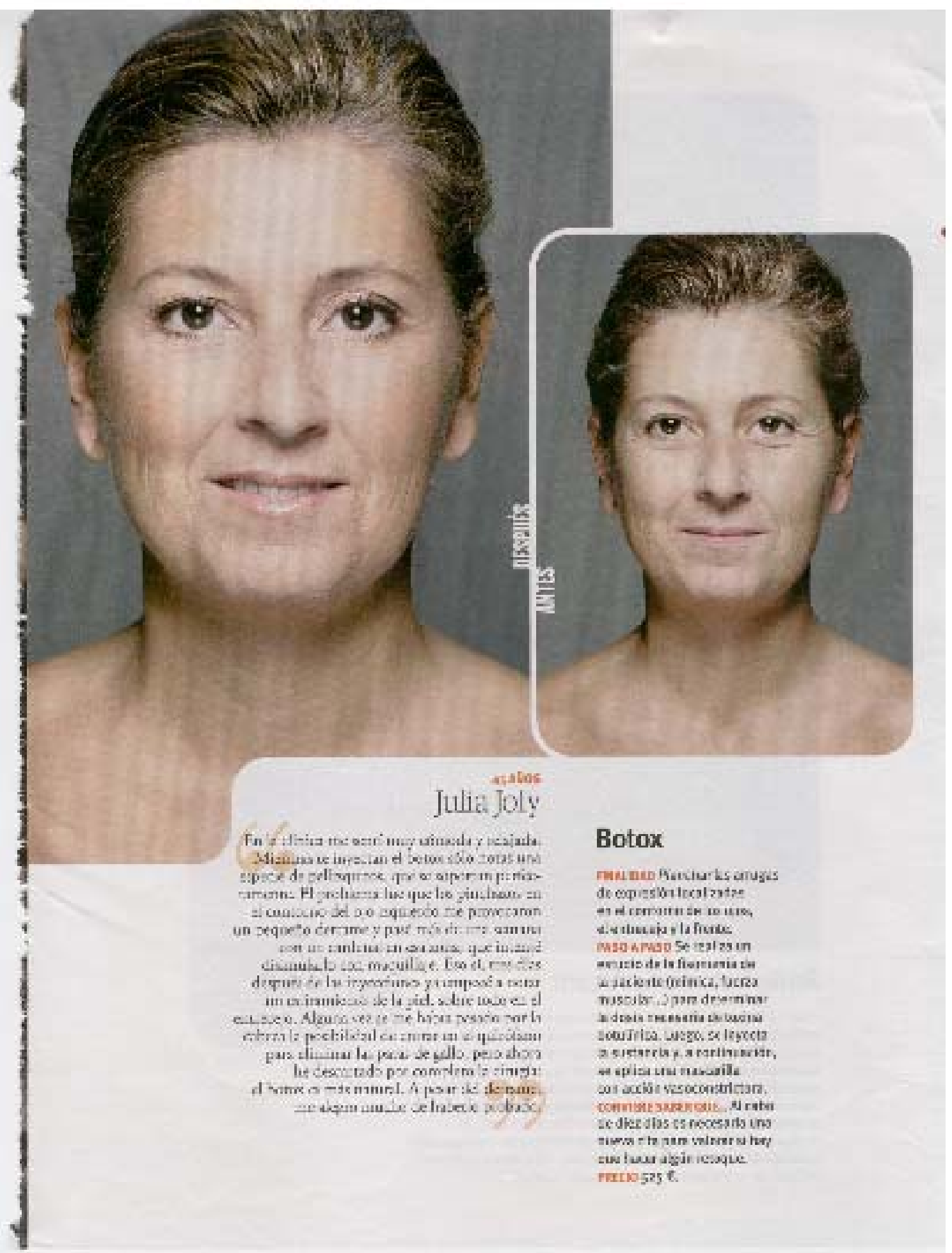




\section{REVISTA DE LA SEECI}

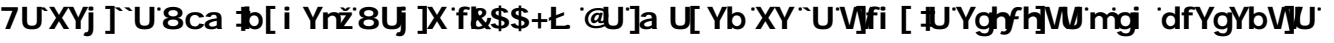

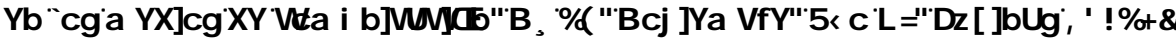

, 661 [U

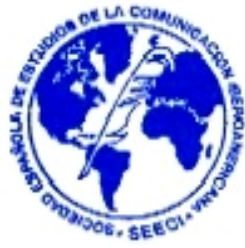

Imagen 31: Yo Dona (mes de Noviembre)

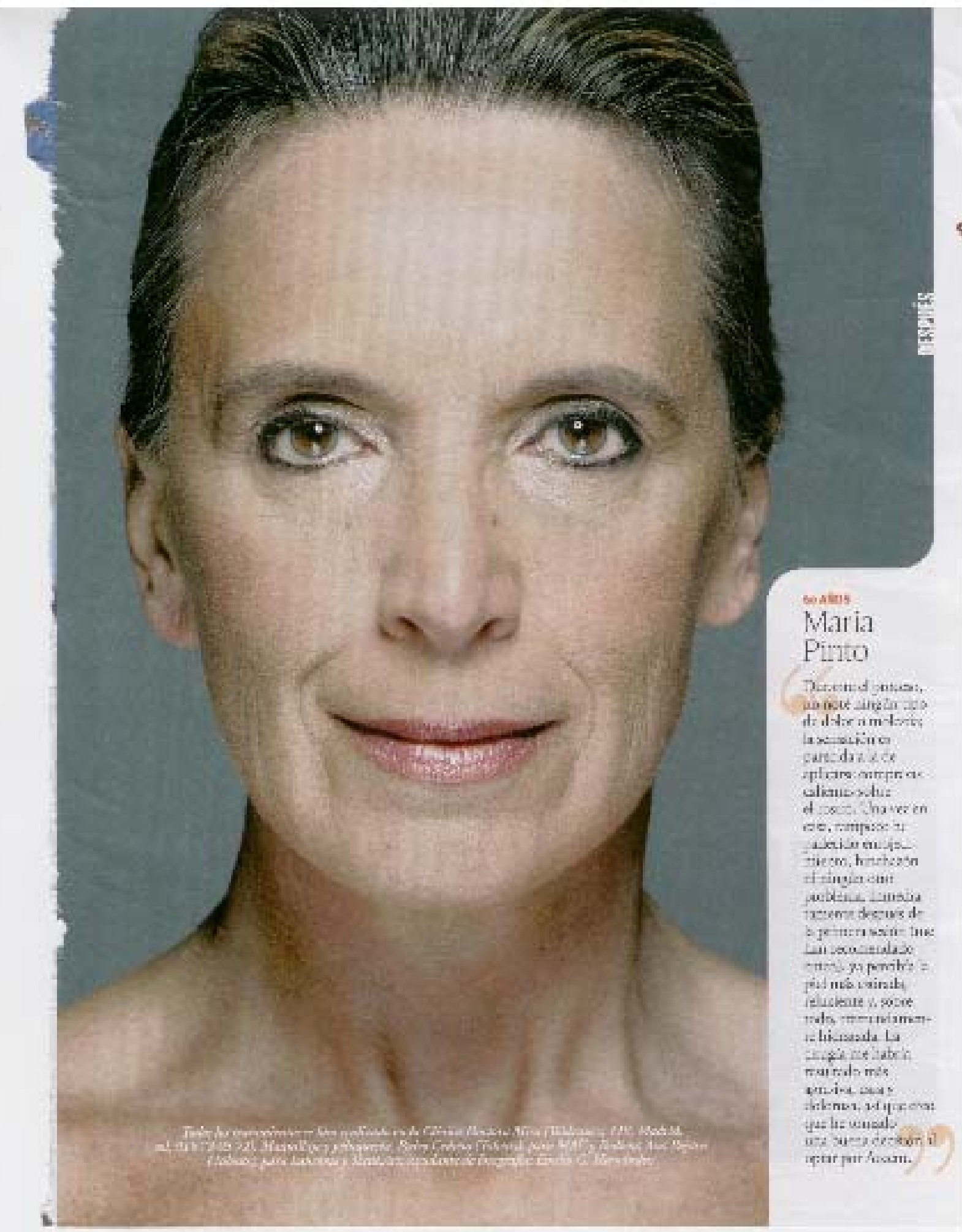


Imagen 32: Yo Dona (mes de Diciembre)

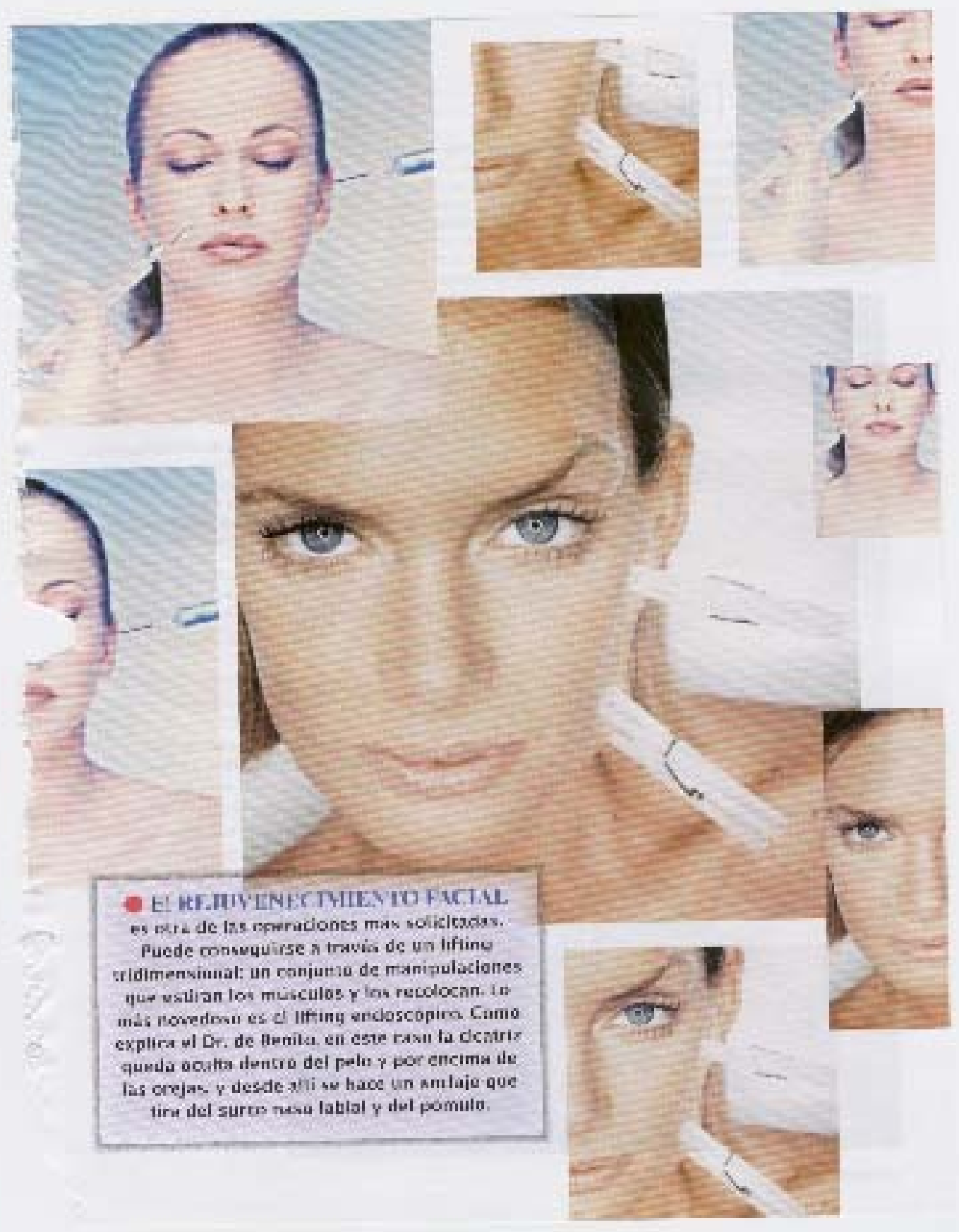




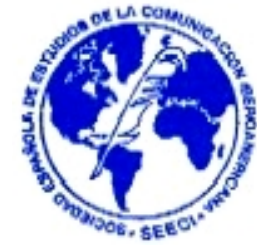

Reportaje de Vogue del mes de noviembre sobre cirugía estética, médicos especialistas y operaciones.

Imagen 33:

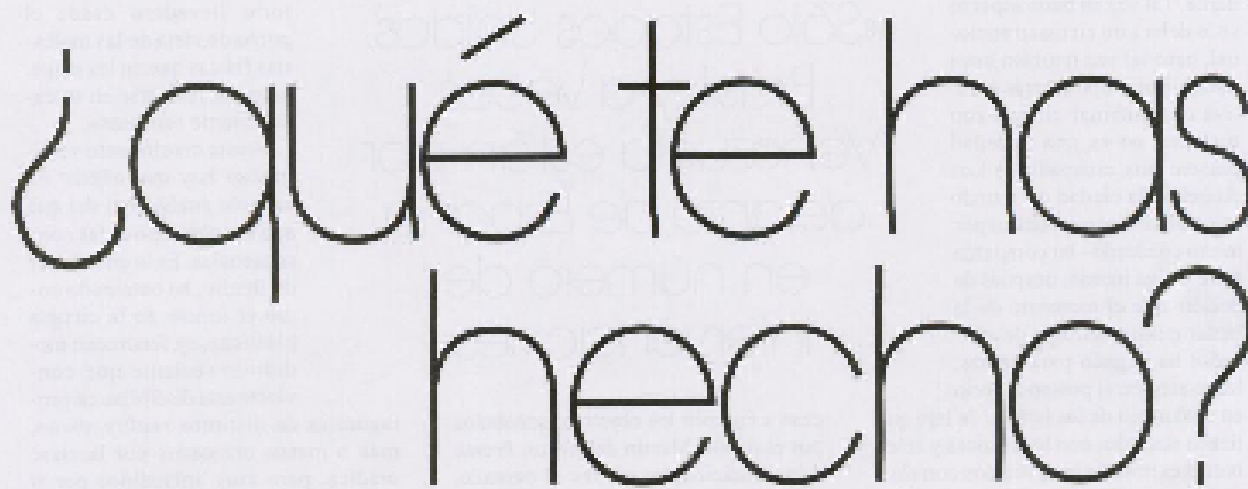

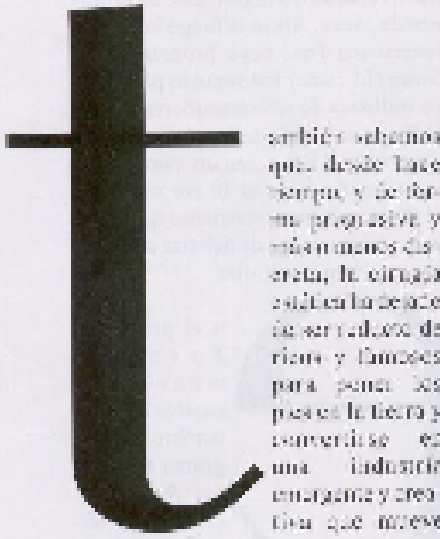

till-1, allizyzre

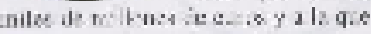

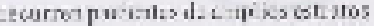

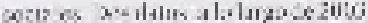

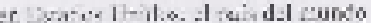

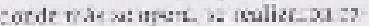

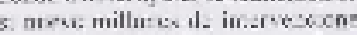

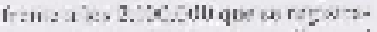

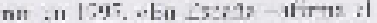

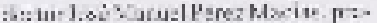

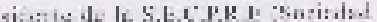

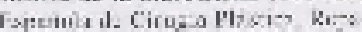

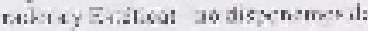

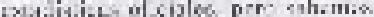

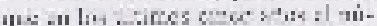
mavil. te racosoes hrximanial:. III 73; quec.cosancere, I ty tis i-

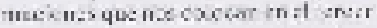

1. H. IUNO levines ath (พ) werts

10.tins?

iximis

iving

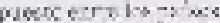

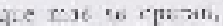
descues dis listalus Lnises $y$ Irasil: uirar, ou ol curin, d: spa: de ertos dus reinas y

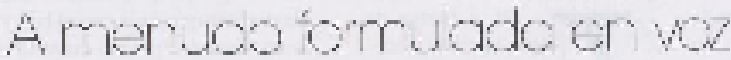

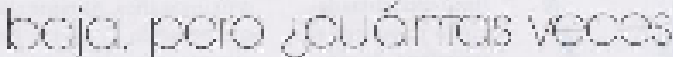

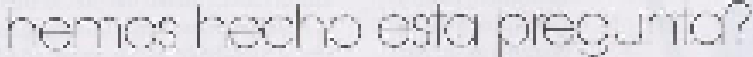
El boom de la cirugía plástica vrotome moractos. vomorryod ondiza

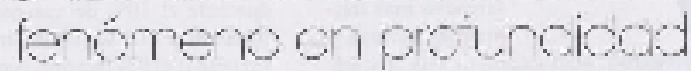

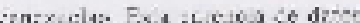

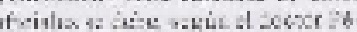

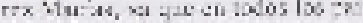

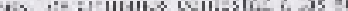

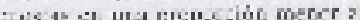

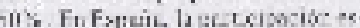

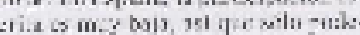
:

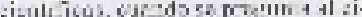

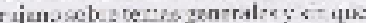

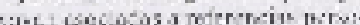

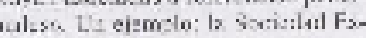
Hii.

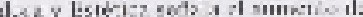

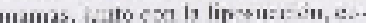

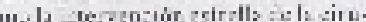
pis pustico pxel n are: ik pritexs

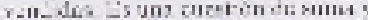

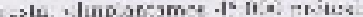

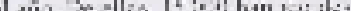

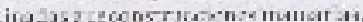

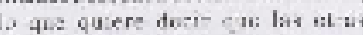

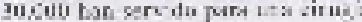

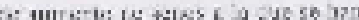

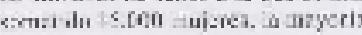
juin:n:s:e

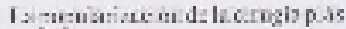

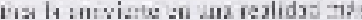

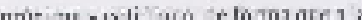
Lic id resitrble -e cetriler bo $4:$ it.e di estc. c arjells wiriz pars d:s.

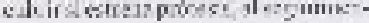

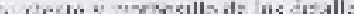

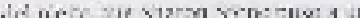
sit -icas px dzat que w. haksu surt;

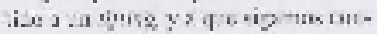

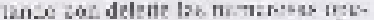

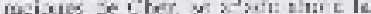

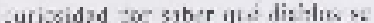

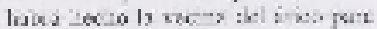

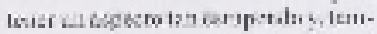
bisin, $p a$ sjpuesto, quian he siln :

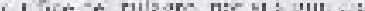

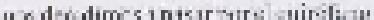

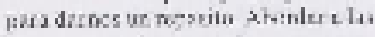

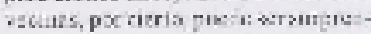


REVISTA DE LA SEECI

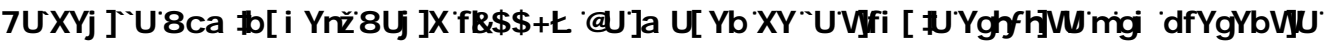

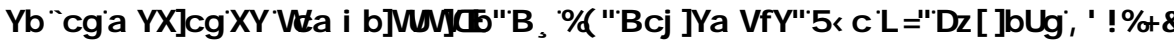

, 661 血

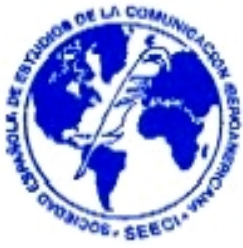

Imagen 34:

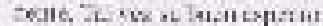

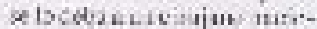

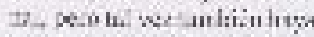

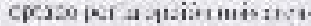
toz de soub is e an is ist

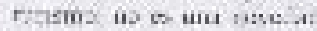

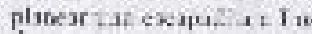

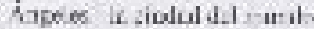

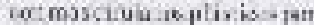

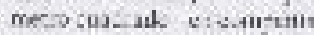
de Iu naliga in. L desprisit: - endir vuze inmivis. is I N:bisplasis ictou is blel pir-

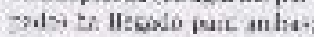

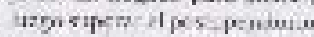

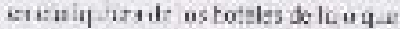

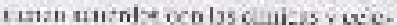

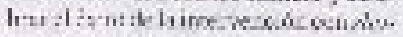
Hong t:m: lite masds.
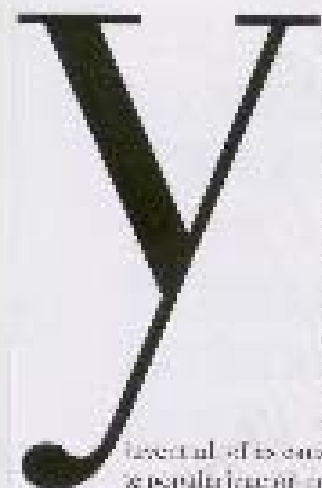

451. 2 tiesz da at vecieas. Lui. pravenosisal. coras cise to el gnimbtrax lacenalj plastice ac. J. hy:itricosein in:-

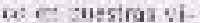
dise 1 - uns foclo ris ita 5.60105212

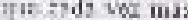
grm peese pard taver m-did las hrivelos:cas in $70<$ ite tellers

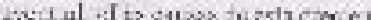

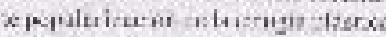
se tras as alisal a ir jens plastico do sé Lua R.fu lim dal Vers ms te la

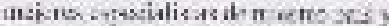

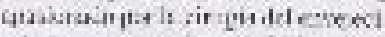

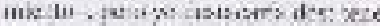

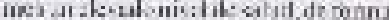

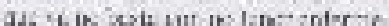
doics, Jions sikef.4t indes arwes:

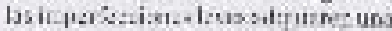

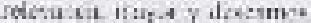
correcitls. Fo nint :alin be

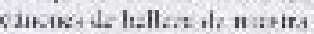

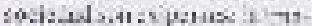
2ac se stluk s Ilat fits isch

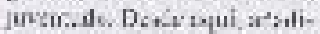

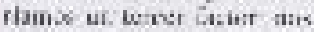

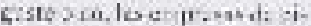
rakis platiza suryi:as an lie if

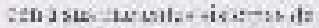
farn-is-iak au- di-sladie t

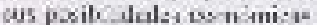
ano couri-uhit a que calt :at?

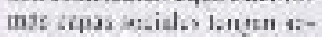

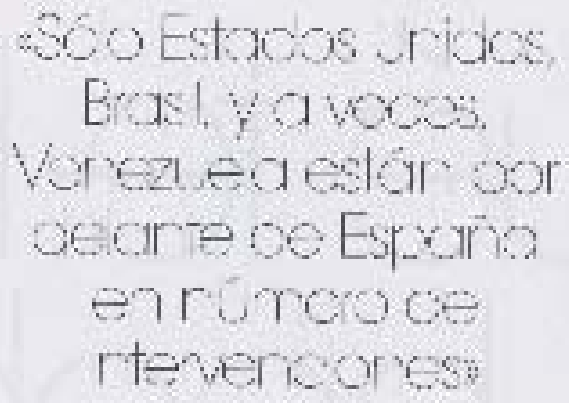

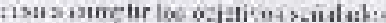
per us aber Whet de Yen \& F.ne

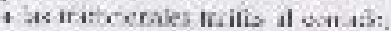

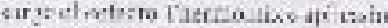

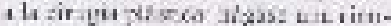

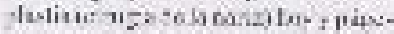

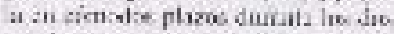

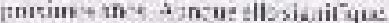

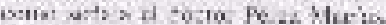

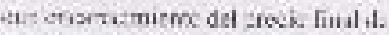

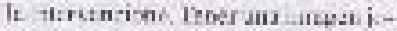

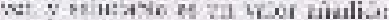

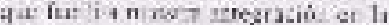

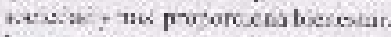

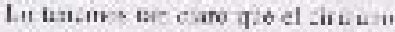

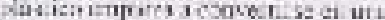

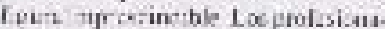

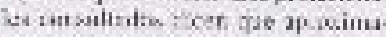
4. uant: at aro de sas socianas st

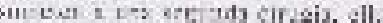

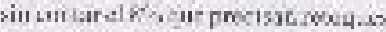

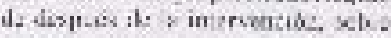
bis: alukit as rota de rieopustiss

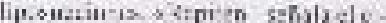

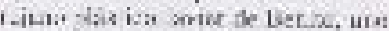

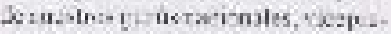

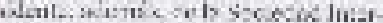

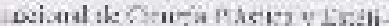
a ciataliven ipu'be vuencs resul-

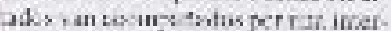

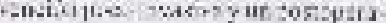

\section{Q Mod we no:} $\mathrm{T}$ weres vojor ar undara in ma Los Argotes cor:de orrtos x poctom uno bofarovestio. tein I wevierc desdy el gurt: ivescad de I/s in. Ats-

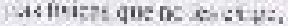

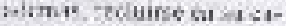
it : thratre ceonasose.

Aisut tresimiserce :ar.irin:s; hy qus absitir uh.

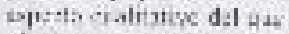
uit arecatrectectax las cen.

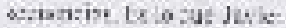
ceEsini, habre zadk a val al swese co b cir asia Hiviz:s.t7 inorteas at filis ratom are cou viscedus sif nazn-n

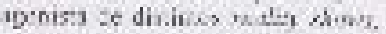

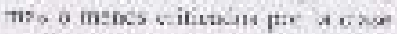
mtatizz, peio and uslevilitus pre

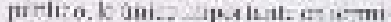

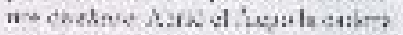

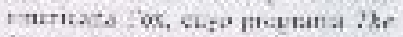

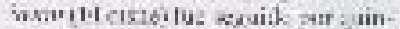

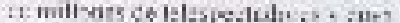

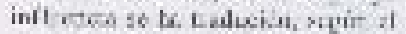

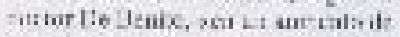

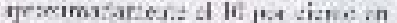

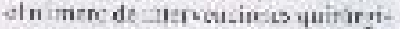

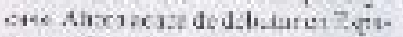
th irra fremult s inic.

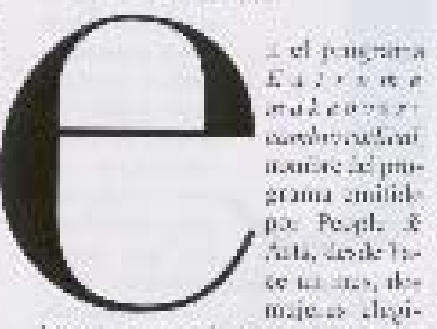

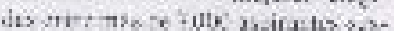

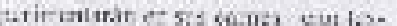
izlmetis t firmulsedeinse isciti-

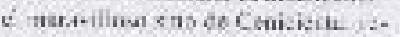

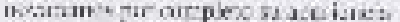
uni tian or as a ntric s...ith $\rightarrow$ b iber xey que sus suzists st

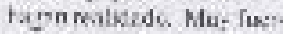

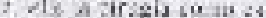

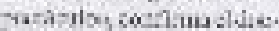
r wrorde lleailar r cuat. itin a $\rightarrow$ gentinsoderejo ike

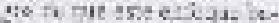

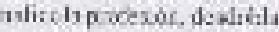

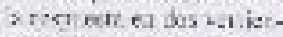
in: *.: Iun q.e 4 icualizit. sur -nizamas sith cL alat

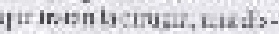
dipline if b todicate se firmethessexeydamesIfer in tuil negusto of pre- 


\section{Imagen 35:}

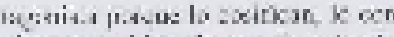

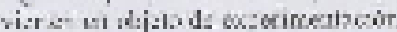

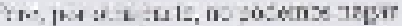

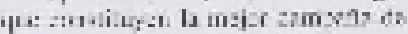

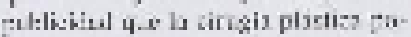

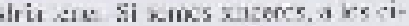

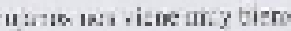

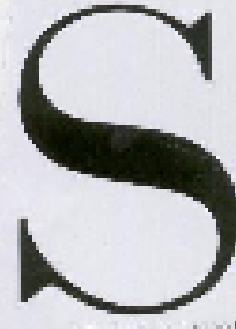

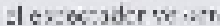
el picier coszams un por.zs sesal zyz un dic.ear.egiar el vin. crocienejorm tr pir: se besntyesn lus cetece butrom is

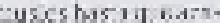
ou csaremoto in in isab is syes at

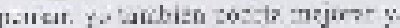

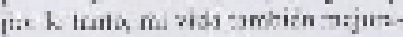

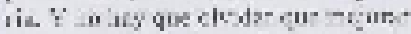

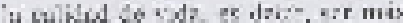

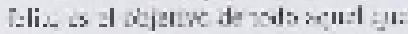

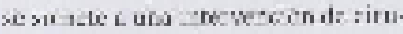
Situlislicce cicote.

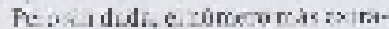

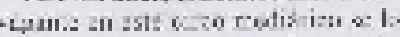

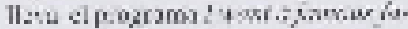

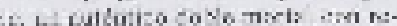

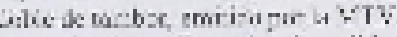

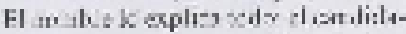

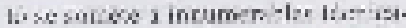

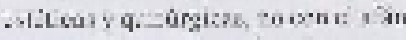

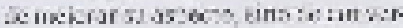

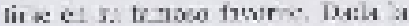

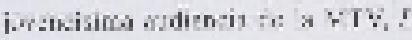

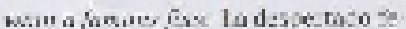

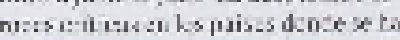

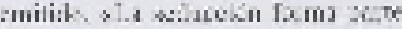

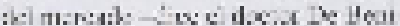

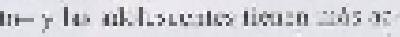

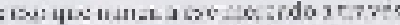

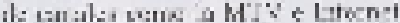
A besit de elhs atera sis propers

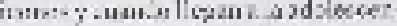
ira, unt als:t the fu-fts imir.3coen. z3

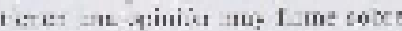

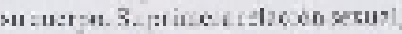

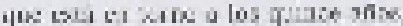
Aul:i:u inllo:-pa adess prejup o

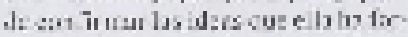

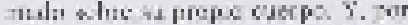

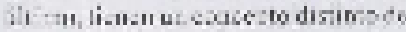

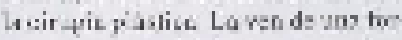

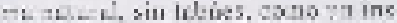

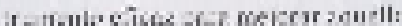

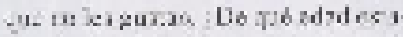

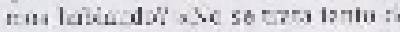

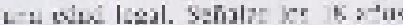
ali. su- bizh -c.c. roar, pere en :i-

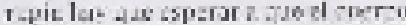

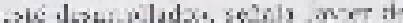

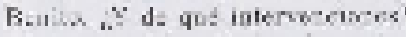

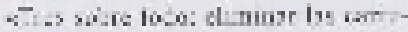

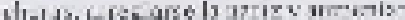

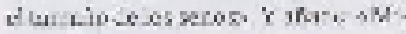

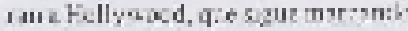
intcisu ies da selezi.

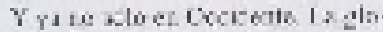

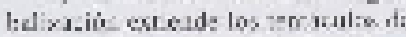

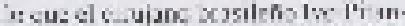

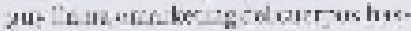

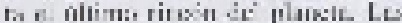

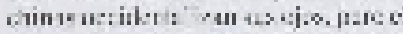
de lirssil ts ol : j:mr-l:tuatilus.n....

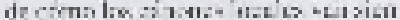

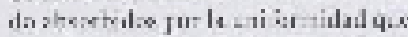

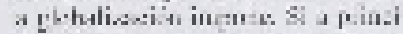
-ies d. ins sourek. les ir--avios de

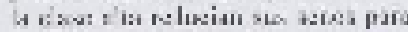
alfjuro: b: Ies adests lacjes, L - L. L. d:

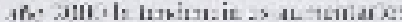

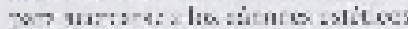

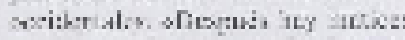

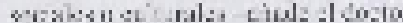

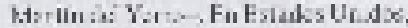

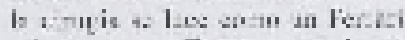

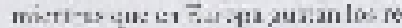

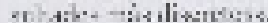

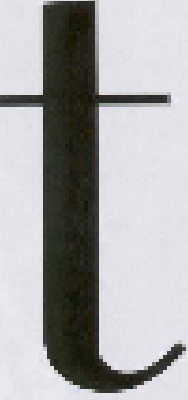

Gi:al.4a vero Has.

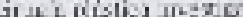

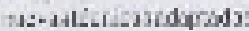

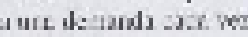

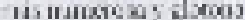

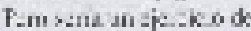
fo wilisal resporectok

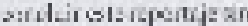
totudar i. lise surres - Ix Lu inerceocla d: -itucis pí̉z.se erran ii-esi denkes i ks d:

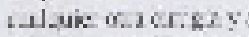

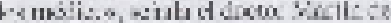

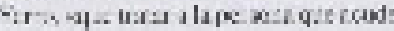

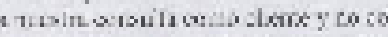

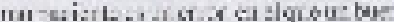

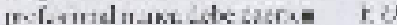

\section{tuxismo quimirgsico

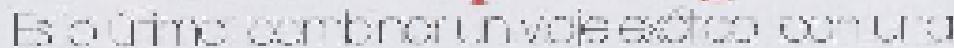

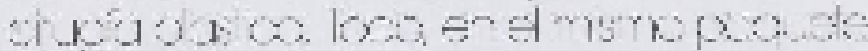

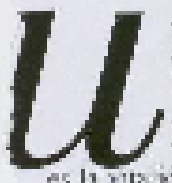

- masiranative

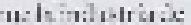
lo: $7 y$ isplistes sirasicst - 7 tos-

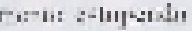
(1) cimoraziniuset nisisues-

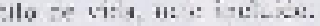
ion-uren I spafularisicts-

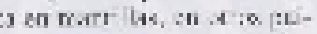

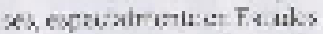

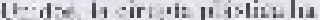
cenactisetu rall frozi.tiss tureress tholll ankite ton. are coll herst forilie a:s

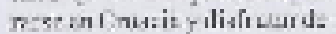

sus cociss, ap:arsis? an sc.ari antdiza ea suditriata.

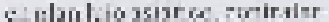
iII padece cocplota on litusdic que icouge $y$ b ilizi

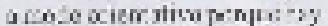

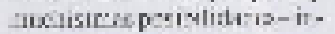
zer-cozibe q arzorits or urn

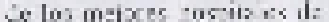
Banatok a se l'ukhot ras

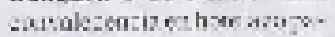

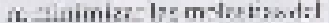
wsocezeris, ror ir aluils -11 acb: aces. तssuesufendelurarte to-als zelsn:is

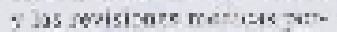

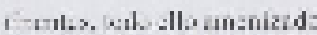
pw we i-ilal:a de wh cus

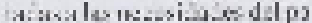

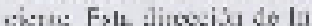

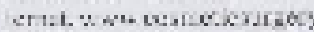

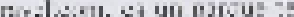

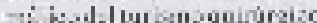
-y in sul. plistioc: xhezen

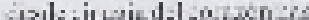

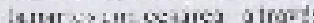

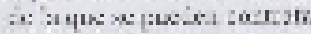

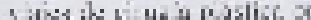

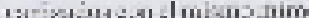

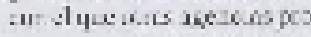

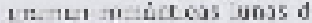
micl. Lua derioses mos the

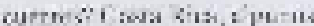

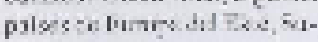

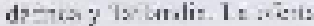

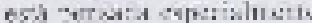

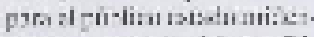

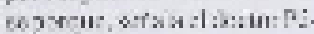

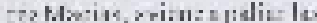

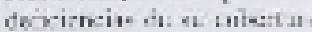

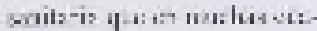

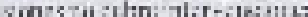
currir zises nimeicutalas :u

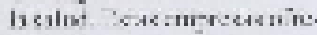

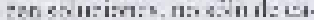

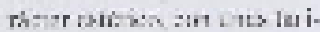

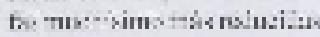

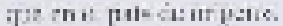


REVISTA DE LA SEECI

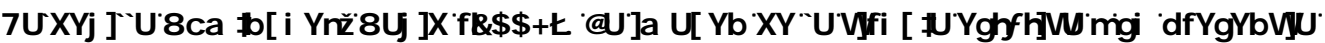

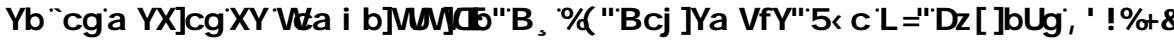
, 661 [U

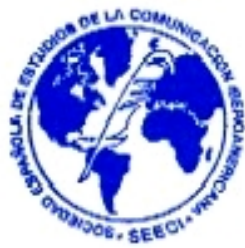

\section{Imagen 37:}

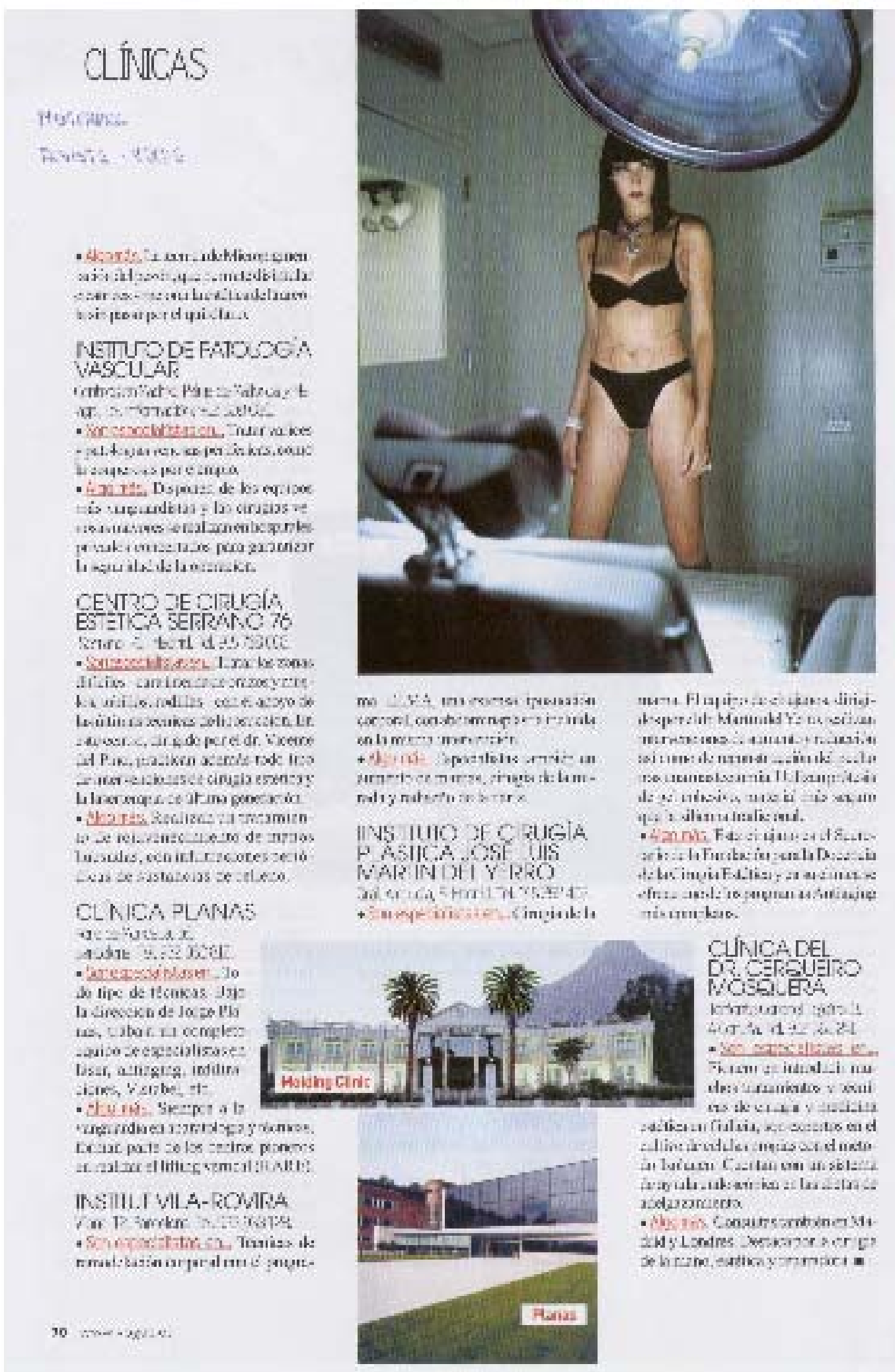




\section{Imagen 38:}

PRONONOGLF

\section{Últimas propuestas para DAR LUZ A TU BELLEZA}

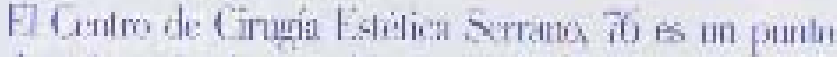

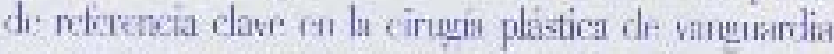

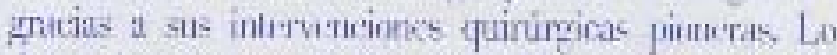

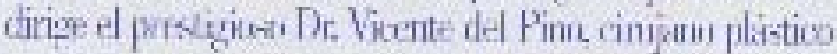
y reonstrus:ox yus: ha impulsado la aparicion de nuecas

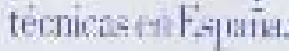

\footnotetext{
El ocobo ;es uta í ant para sumettrse a tma nperaxiinn sle tiruLia esteticu?

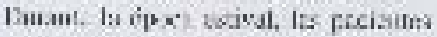
2. Lun dab cuentz de sals antar ias

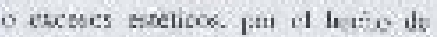
veste: pis: at plicy:s, wa bitimi o

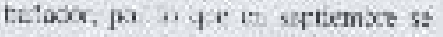

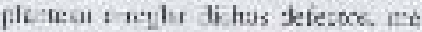

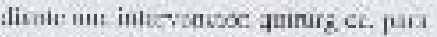

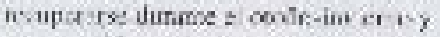

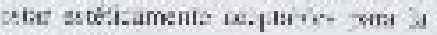
puminera.
}

ACinál en la iviraica mis eticna para eliminar ba grissa de la zana de les coklerax pluittvs y plernas?

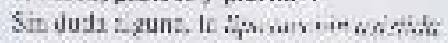

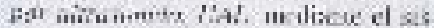
temo l.YWWIVIY are sec at verside

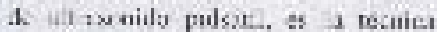
uk uas atgresies of mas efecr zu pasa :

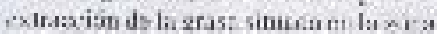

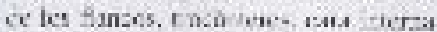

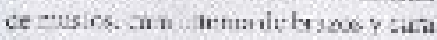
terincis a:fill:as

Para ivensefuir un vicztic planu, $\lfloor, 4$ utilixaria la misma temica"

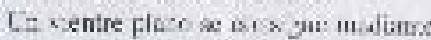

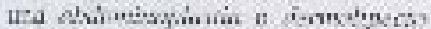

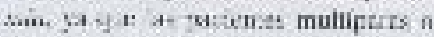

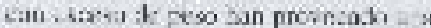

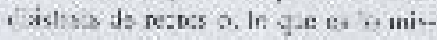
tex, und sesurazica d. A mun ulia urs

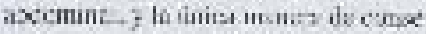

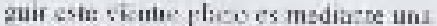

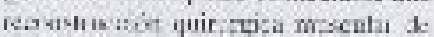
Ilista sune

Ltabbemis ife lns nu wes impdamies ms

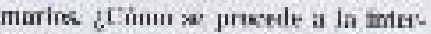

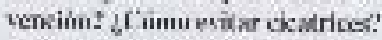

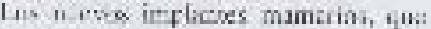

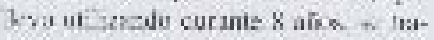

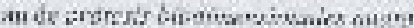

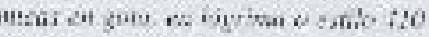

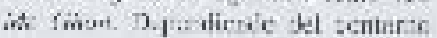

\section{Crinayutate he titimas} kenizs luxtrologicas y do. lis fonuulas misavanzulas. cidavecresilla indsencillo -ilisfacrolublat tus morailarle-ile bellezia

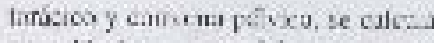

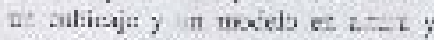

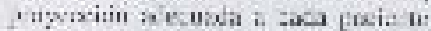
Sal : in. diexe hoes a'os a parialle

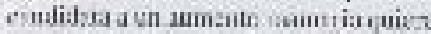

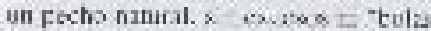

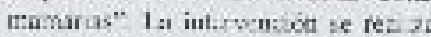
e mas a tes lavaborstixe dalas xat

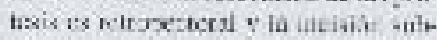

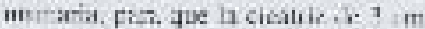

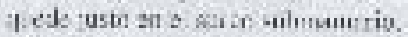

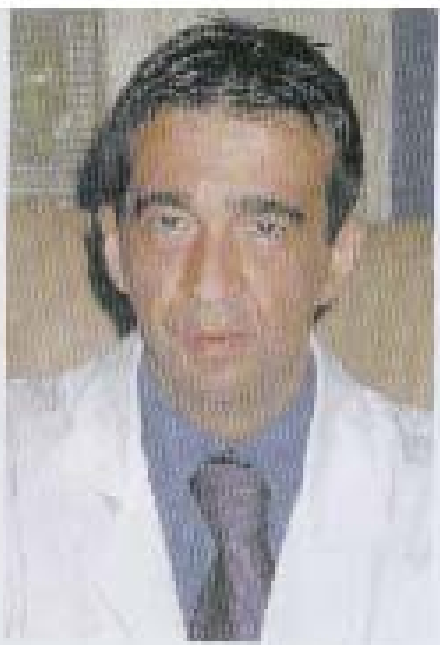

- Ohe sisterma nation en has tratianievilus factaks que lumsan is desapiricion de las arrugse?

thy en el nentaln; dixonlunent:, $m$ -

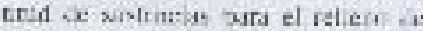

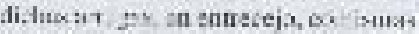

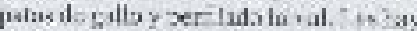

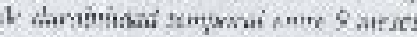

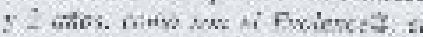
ifutrontion graw. i, especalment:

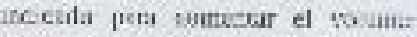

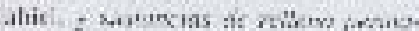

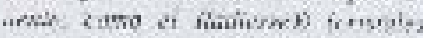

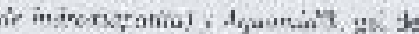

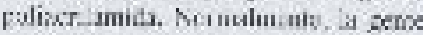
even s,a par 1. fine kexarals y las

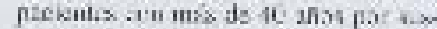

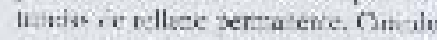

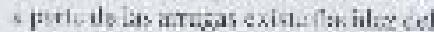
ctive infeion te IL : ra na utizames

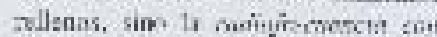

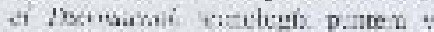

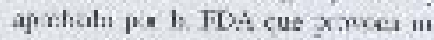

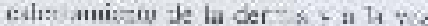

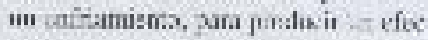

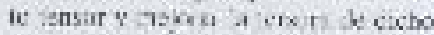

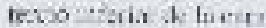

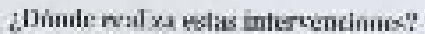

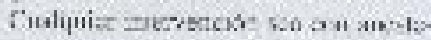

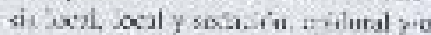

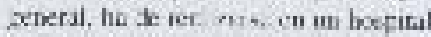

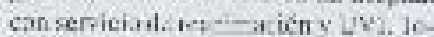
cat ut. st is iterwoncienes se relizan

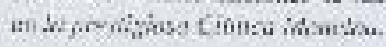

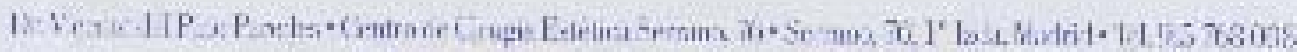

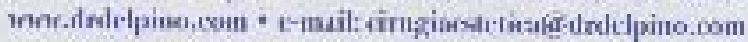


REVISTA DE LA SEECI

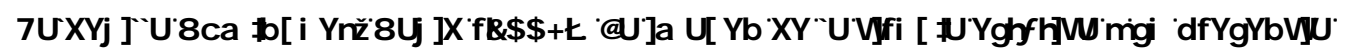

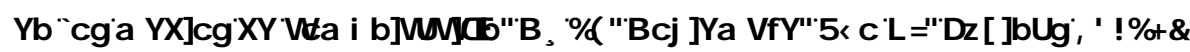

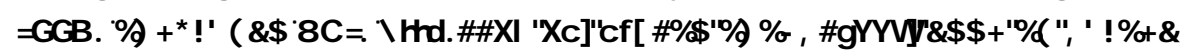

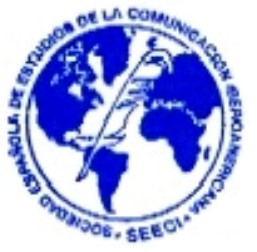

Imagen 39:

CRUAANOS P ÁSTOOS

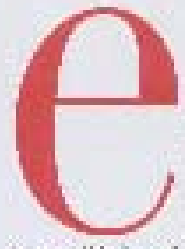

treicsentueti: ispersertej-in lippra, retiode Ir vivar.ren.e n:: $:$ presem n. neporod is

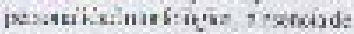

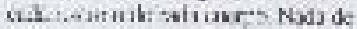

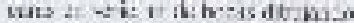
It iens.ario wamess deretsi

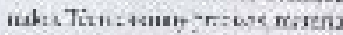

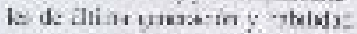

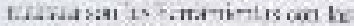

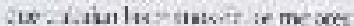
efecialstu.

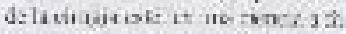

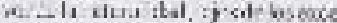
S.): to thitites imprehzs

InoPlontyy-dmax.

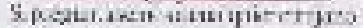

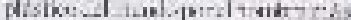

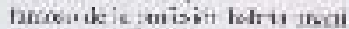

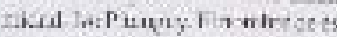

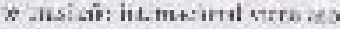

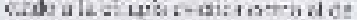

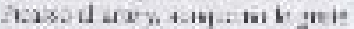

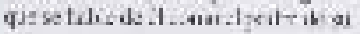

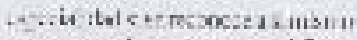

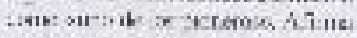

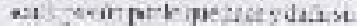

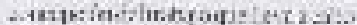

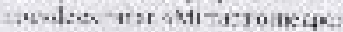

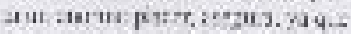

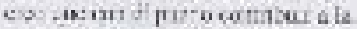

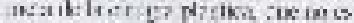

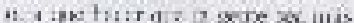

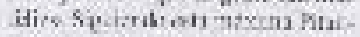

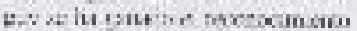

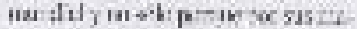

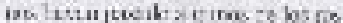

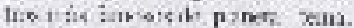

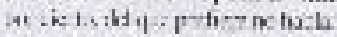

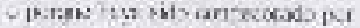

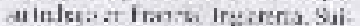

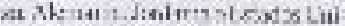

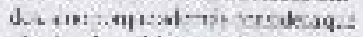

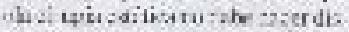

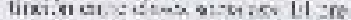

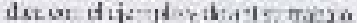

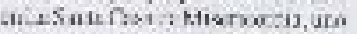

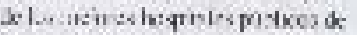

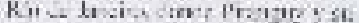

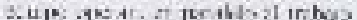

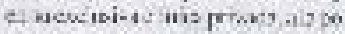

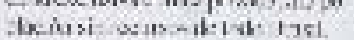

lodesentaston

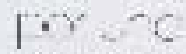

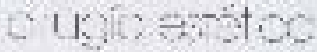

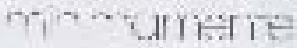

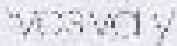

dows kntes

kitsmy

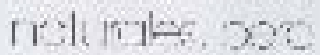

50:011ftex?

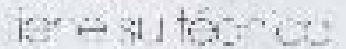

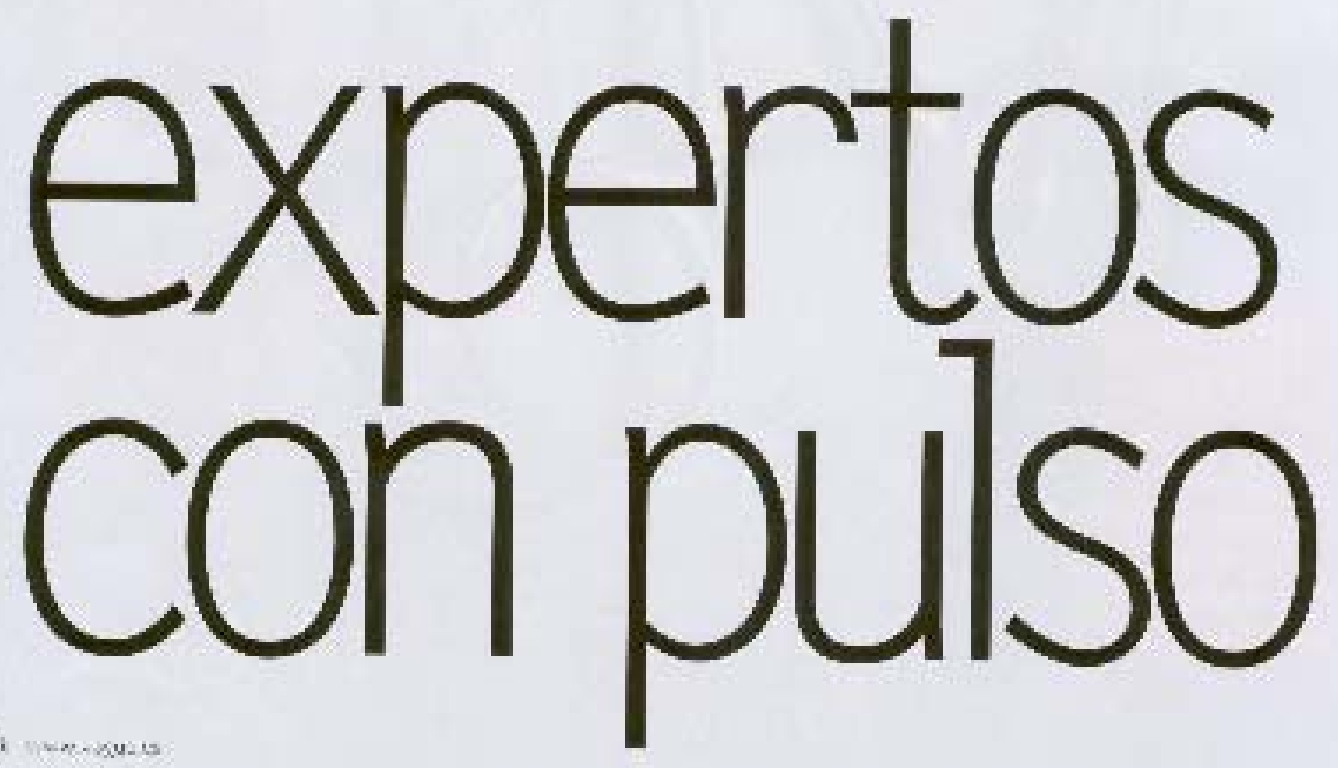


REVISTA DE LA SEECI

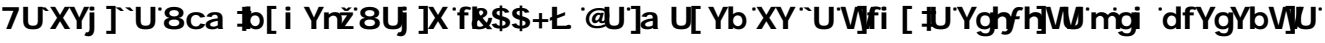

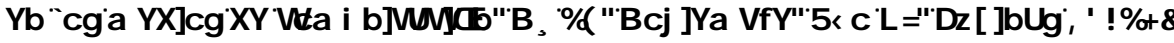

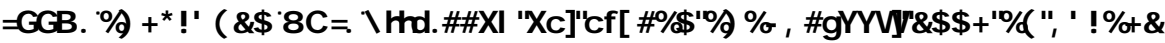

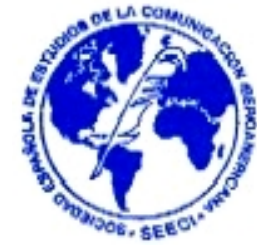

Imagen 40:

\section{en dimecto con... Pilangeny}

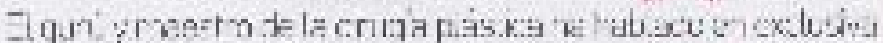

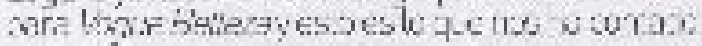

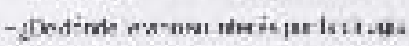

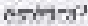

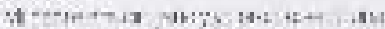

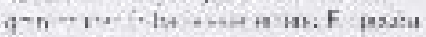

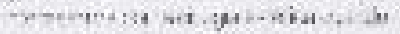

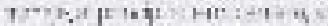

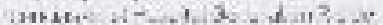

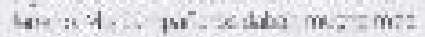

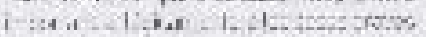

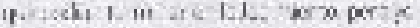

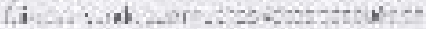

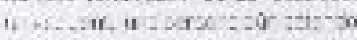

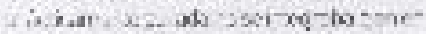

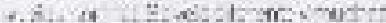

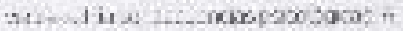

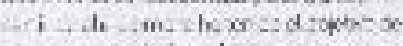

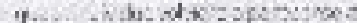

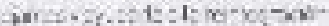

sug - poris aroos:

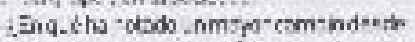

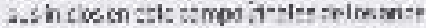

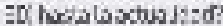

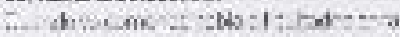

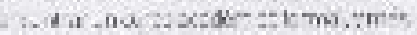

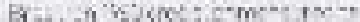

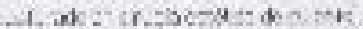

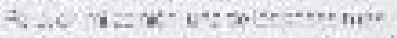

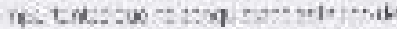

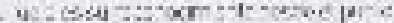

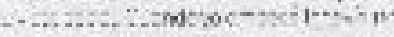

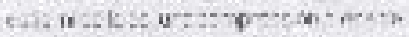

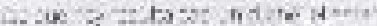

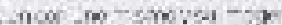

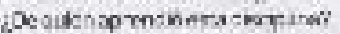

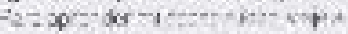

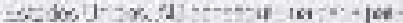

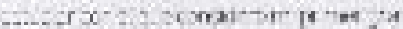

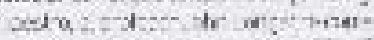

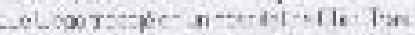

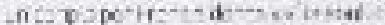

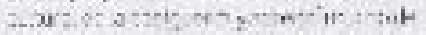

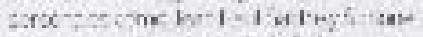

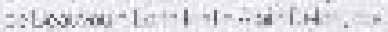

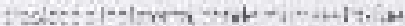

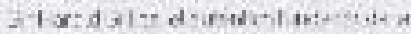

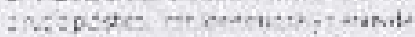

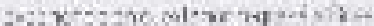

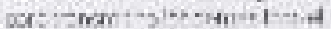

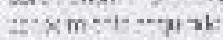

$-E^{-}$gudin et ha remut: $\rightarrow$ misile $3: 0$

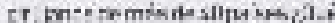

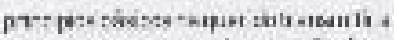

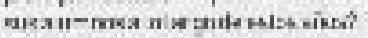

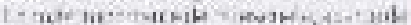

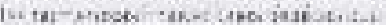

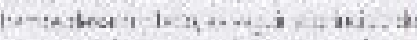

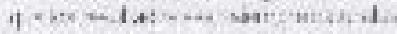

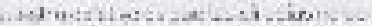

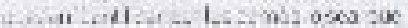

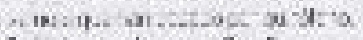
Cus niervionbresprefler?

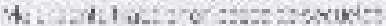

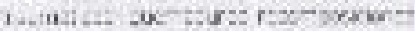

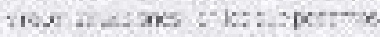

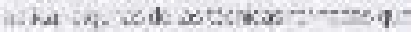

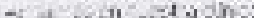

,Ous lpodz czecemocerzr zjo-sos?

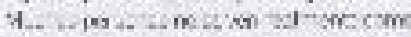

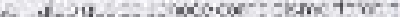

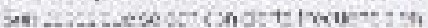

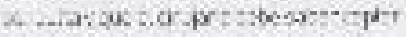

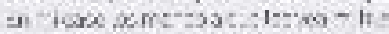

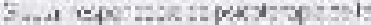

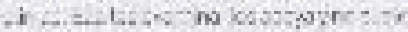

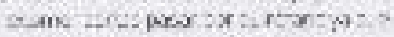

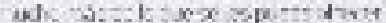

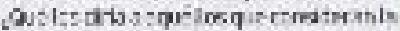

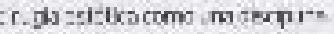

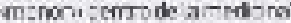

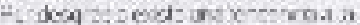

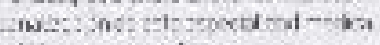

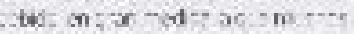

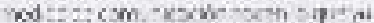

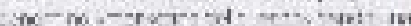

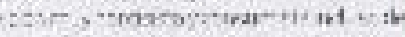

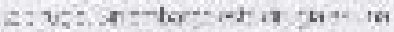

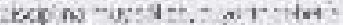

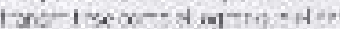

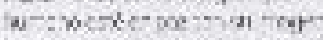

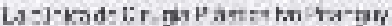

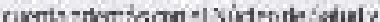

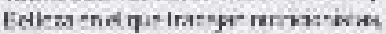

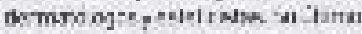

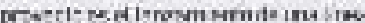

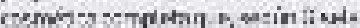

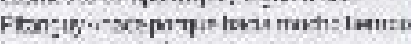

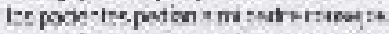

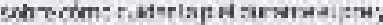

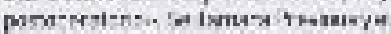

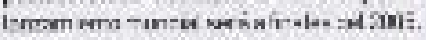

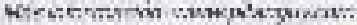

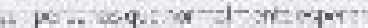

\section{L.rtg...ren-mi- Tar.ni=}

\section{- poDer amar}

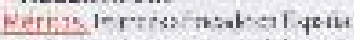

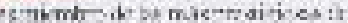

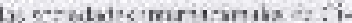

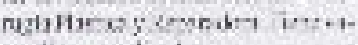
rixlitse pa-bisabs

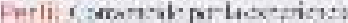

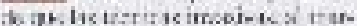

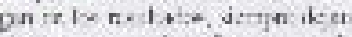

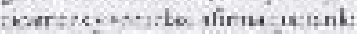

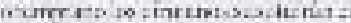

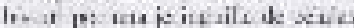

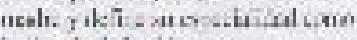
lacivis ablatis.

Eroviditidid. I. kera als de 8 alpes

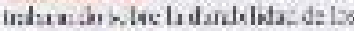

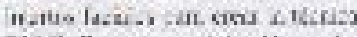
FA27:

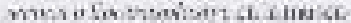

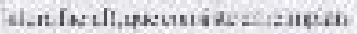

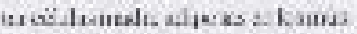

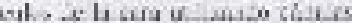

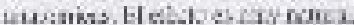

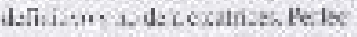

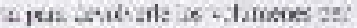
J6!. a t

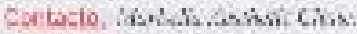

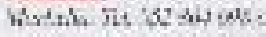

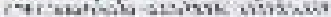

- J AVIER DEBENTTO

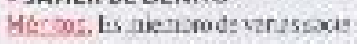

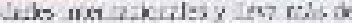

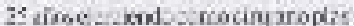

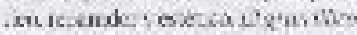

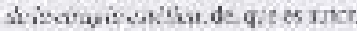

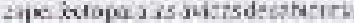
ucin casic waxistres

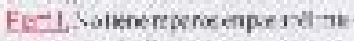

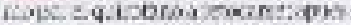

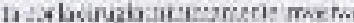

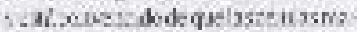
ae, 4 e pennsidn reerpdrar iews.s kspuads a zkanzes cor $\times$ jab :

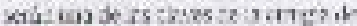
cutinge on migk kra

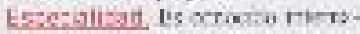

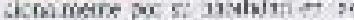

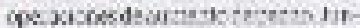

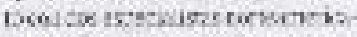

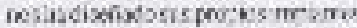

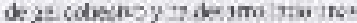

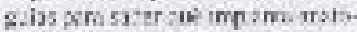

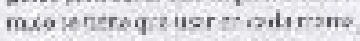

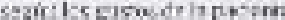




\section{Imagen 41:}

\section{CRLLLANOS PLASTTIOOS}

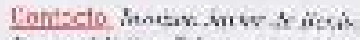

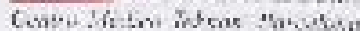
2it y:25092?

\section{- Mieuel chamasa}

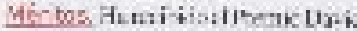

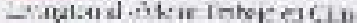

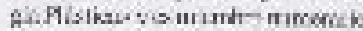

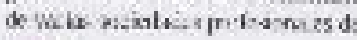
mestizik

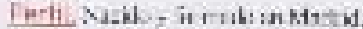

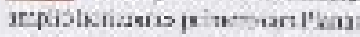

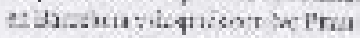

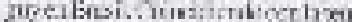

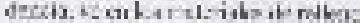

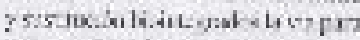

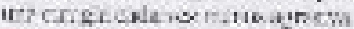

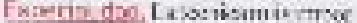

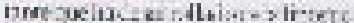

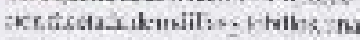

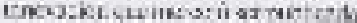

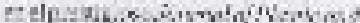

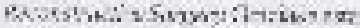

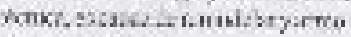
ins 75 pecous

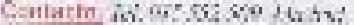

\section{- ANTUNIO DE LAFUENTE}

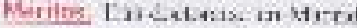

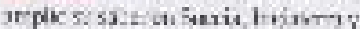

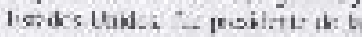

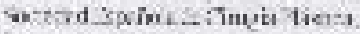

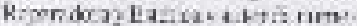

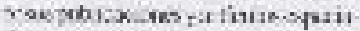

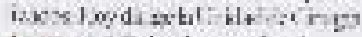
(b) instil R.ter los: 1::i-nt

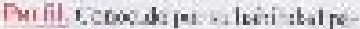

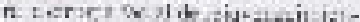

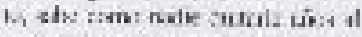
t.6.-.r.

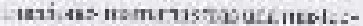

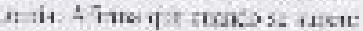

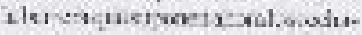

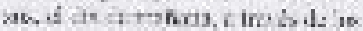

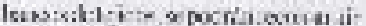

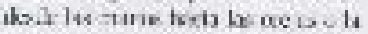
ie iv : k in noina

tescetalidad, (im experx a: เі.-

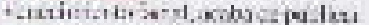

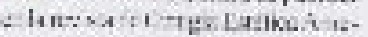

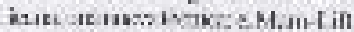
114.

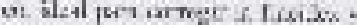

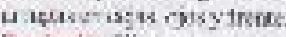

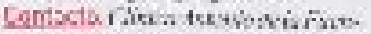

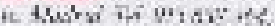

\section{en la lista}

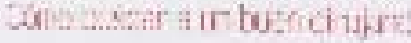

a

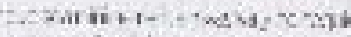

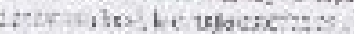

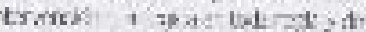

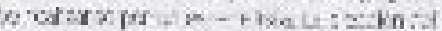

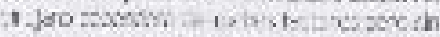

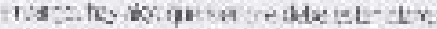

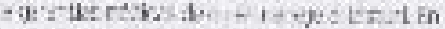

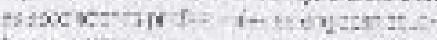

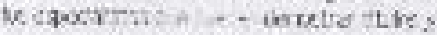

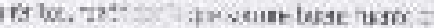

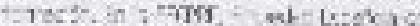

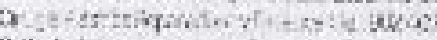

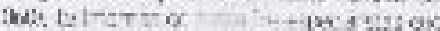

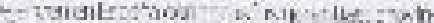

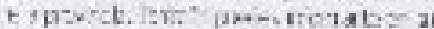

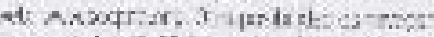

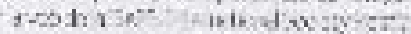

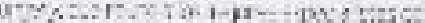
urde lazesination.

\section{- JULNOMILAN}

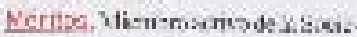

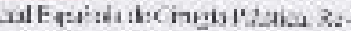

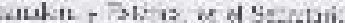
Gevadl-arfu-thain losetk $\mathrm{Di}$

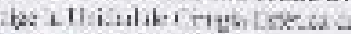

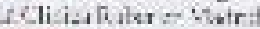

Perili Cin

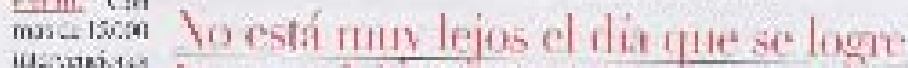

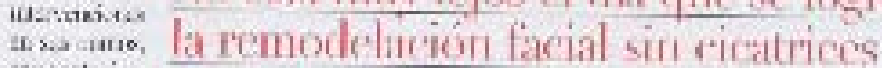
tiu alusis

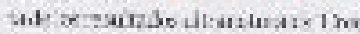

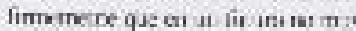
jirtudirdo.xespaials as vini

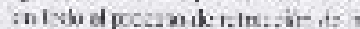

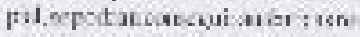

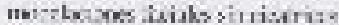

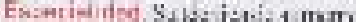

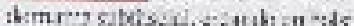

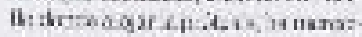

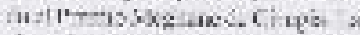

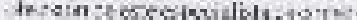

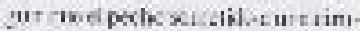

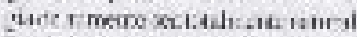

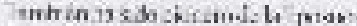
II:Ar?mons.

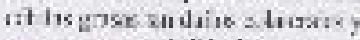

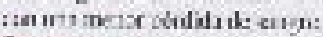

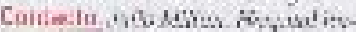

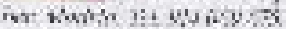

JAVIER MATO

ANSOFENA

dybers. Prosible at I

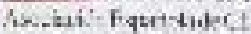

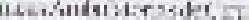
LL Fudi= Fein:a $\mathrm{Ke}$ [enal.n,akmistacis]

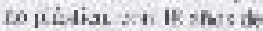

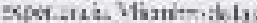

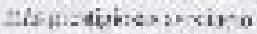
tasincubi.telesibres

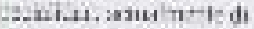

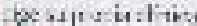

Berthl Cien thariknede

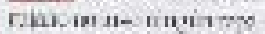

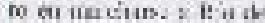

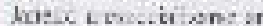

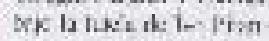
aus. He w the n os ovan tras: 141 - qus: blias co

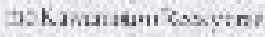
q.e Ikena a artan m

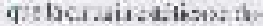
mess.ani $\gamma$ in mapt:

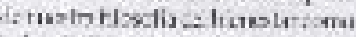

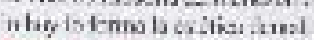

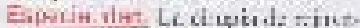

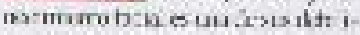

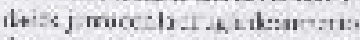

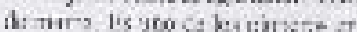

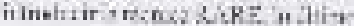

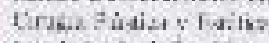

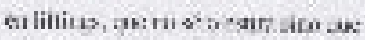

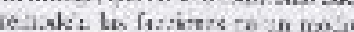
iov-is dis un

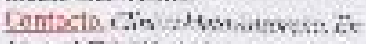

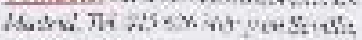
जi.

\section{- JUAN PENAS DOMINGUEZ}

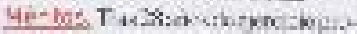

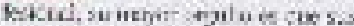

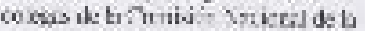

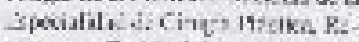

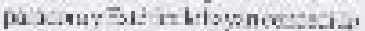

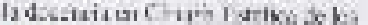

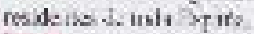

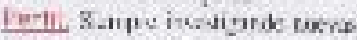

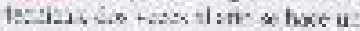

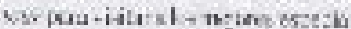
tsiasdal tutin atemritstas: + 


\section{Imagen 42:}

\section{CRIIANOS P ÁSTIOOS}

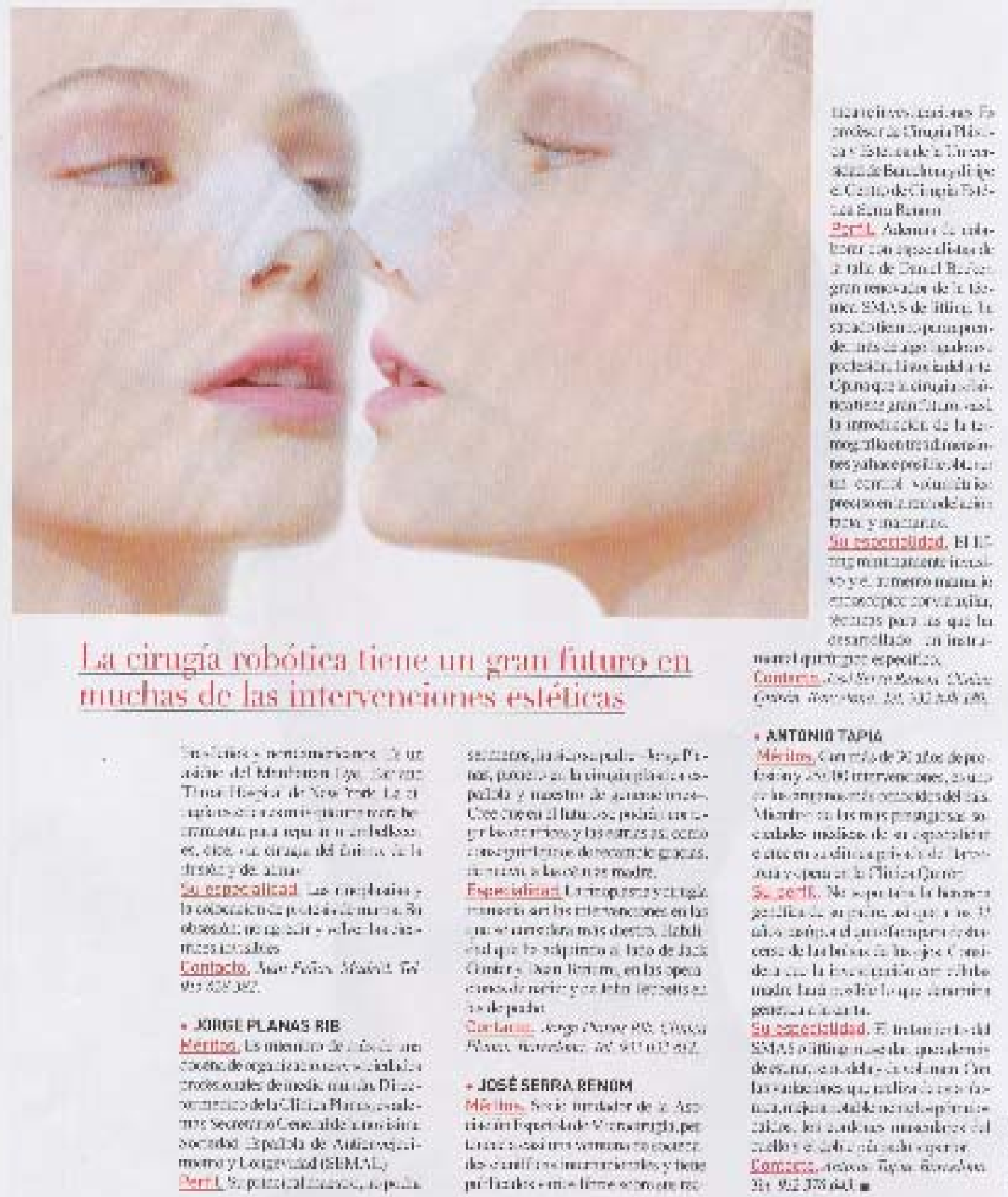


REVISTA DE LA SEECI

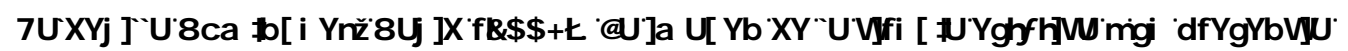

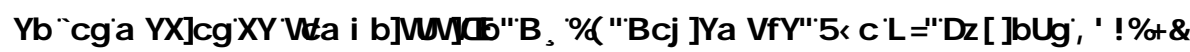

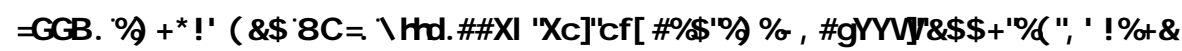

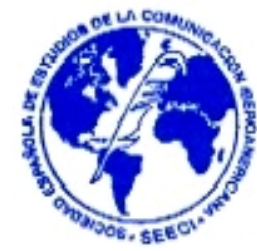

Imagen 43:
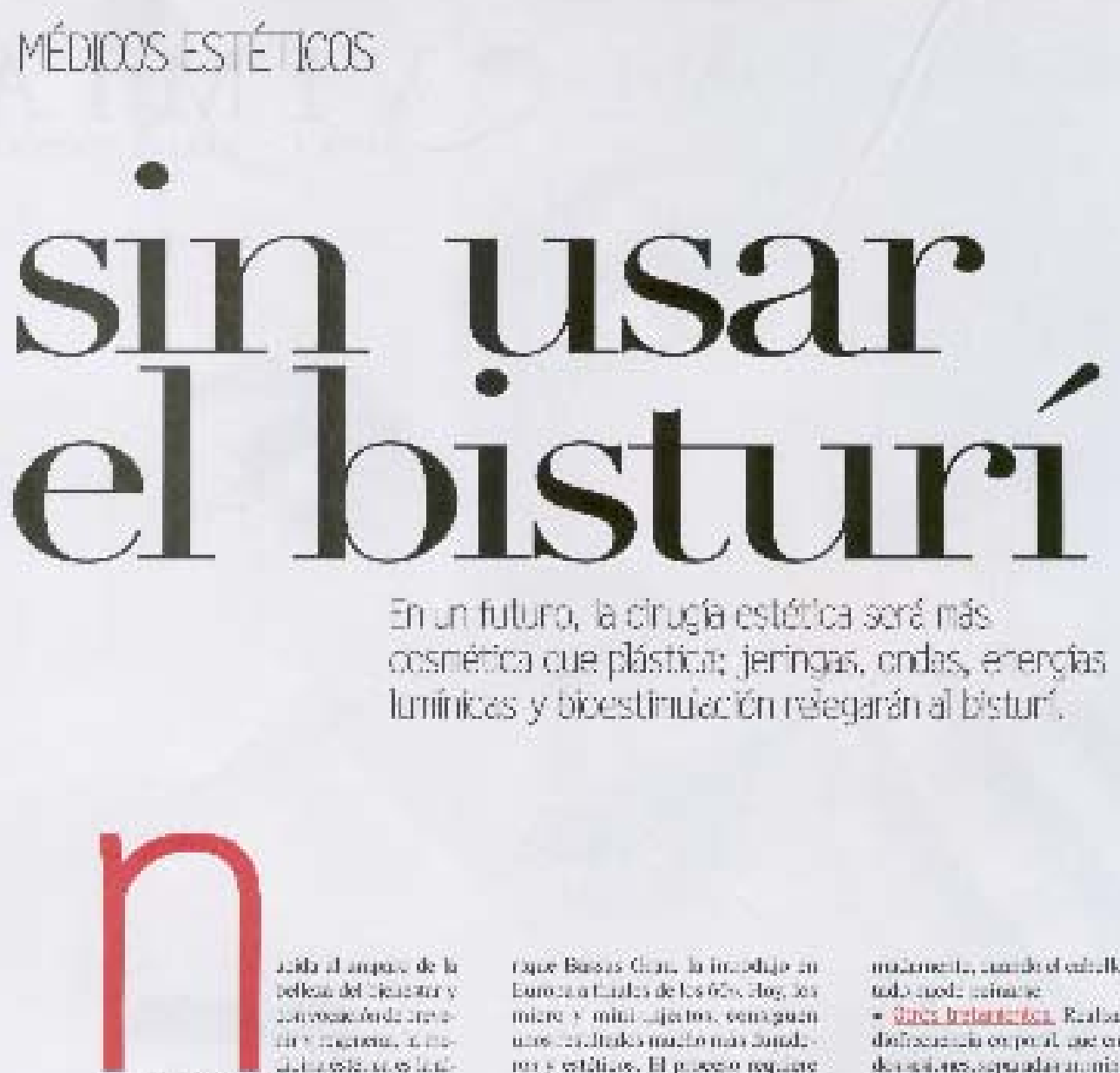

Libs d arites de th

ketken det-kisais

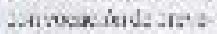

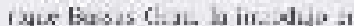

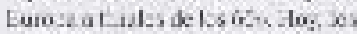

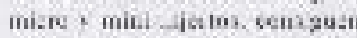

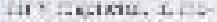

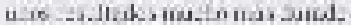

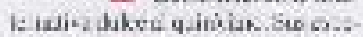

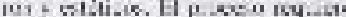

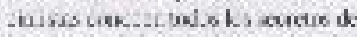

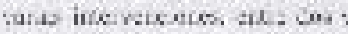

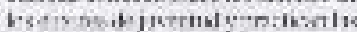

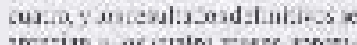

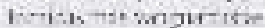

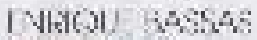

tull स: Aा) R

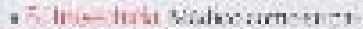

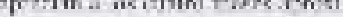

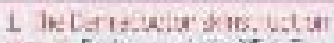

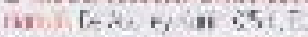

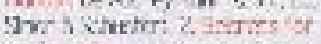

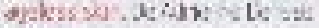

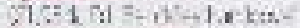

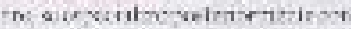

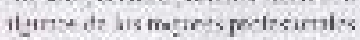

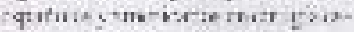

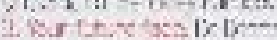

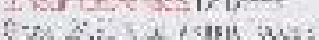

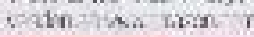

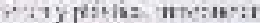

Cลง

n-itse ab vorgernlis

lis monts alsteril.

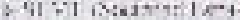

thers Viatian bitisa

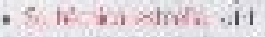

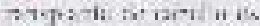

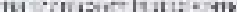

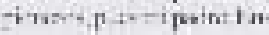
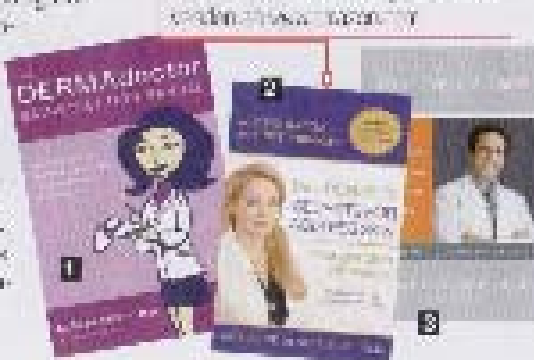

IIU-31k: 1-, - (w) - wod: - ariment

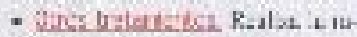

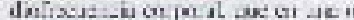

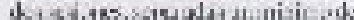

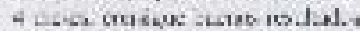

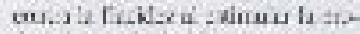

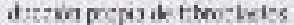

+6. las vighes 5 therrasen in hisyrs:s

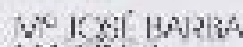
पैंस IN ?

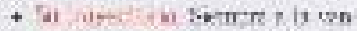

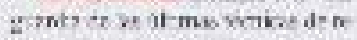

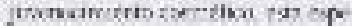

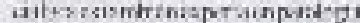

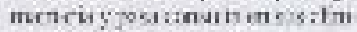

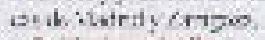

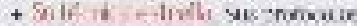

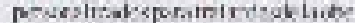

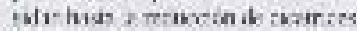

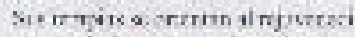
mars fo-in zarporalen :inges

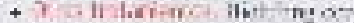

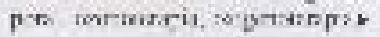


Imagen 44:

\section{MÉTICOS ESTÉ ITOOS}

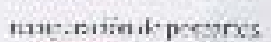

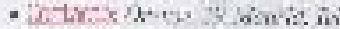

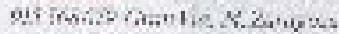

Thi ox, $24 \mathrm{~m}$ :

\section{MPTEREA GAV $=2$}

SAराE

- 31-erch len-gikd = anslibinus groumuns des

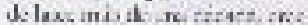
quz aesicolith : am: imnt

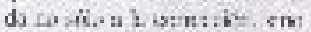

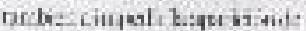
tyosefals ok tains...itaimu

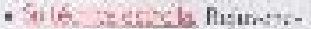
aseas liciulassiat. hust.

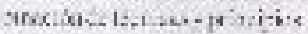

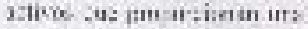

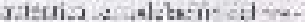

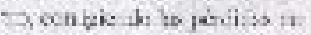

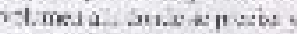

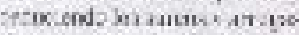

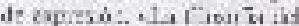
worpsire $x$ hestm.Insp:

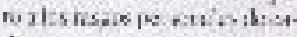

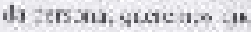
ractroc :2.kurs atsis -

proe de recan tists-ik:-

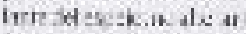

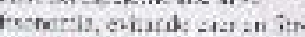
aiz: de iname

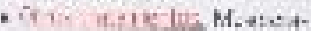

vainter roserearceasticial

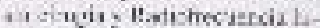
fris is walyocmeal c.2

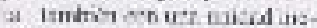
fis A-linenterer soo. der costuriato smavises cers

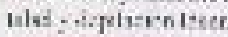

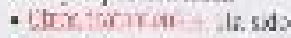
1.10 ab: bs prorerase: Iz in

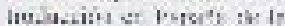
Dicalia to 7ar:

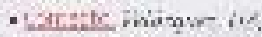

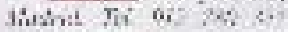

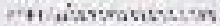

KLBOATSA_CNA DOEUKEO

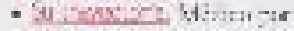

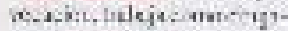

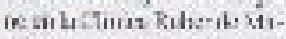
d.i. s a kic abli, tinilual ab:

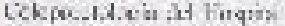
s) Cicnik 11 a is bumali-

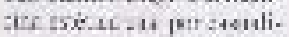

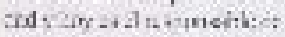

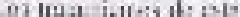
ta:-ivils-rule Tim. cue Fanus:

- Ankecirab F>

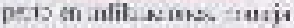

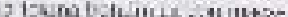

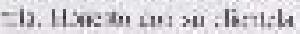

¿In buen esparalista? Teded whasmem. cam o teefonea a a Sorecad Escañola de Yadená y Ciructa Comślic (924 108400 )

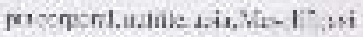
trmes micaks esicxishs

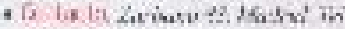
and ato on:

MOL MUR

जा $2 A C X X^{2}=$

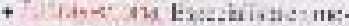

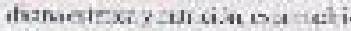

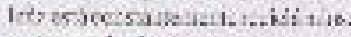
yomerode rowers piat-12s

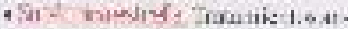

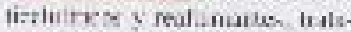

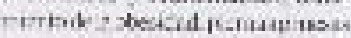

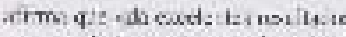

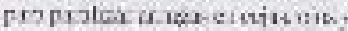

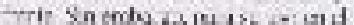

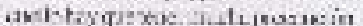

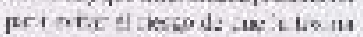

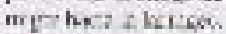

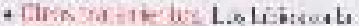

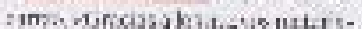

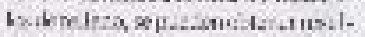

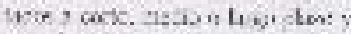

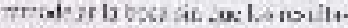
ciour retiostracs

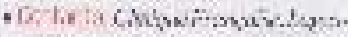

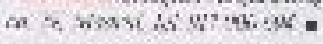

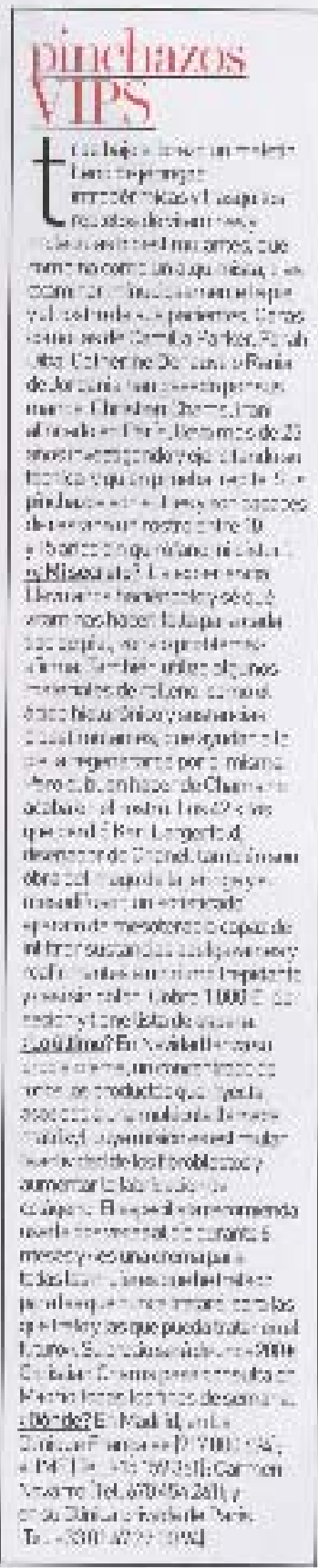


REVISTA DE LA SEECI

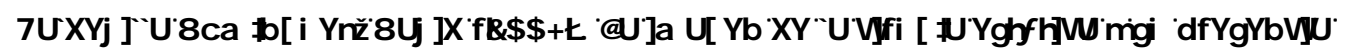

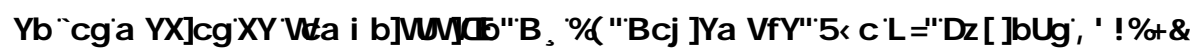

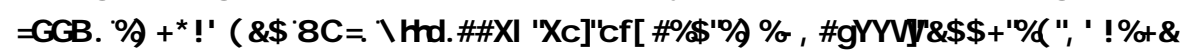

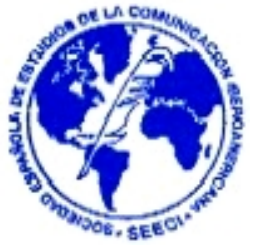

Imagen 45:

\section{DERMATÓ OGSS}

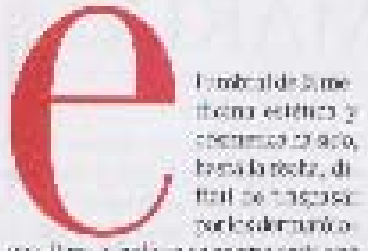

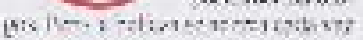

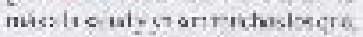

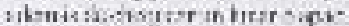

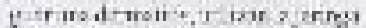

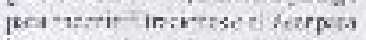

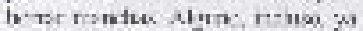

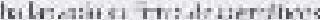

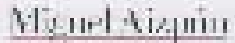

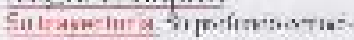

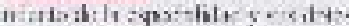

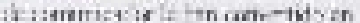

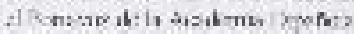

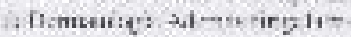

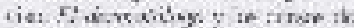

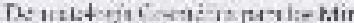
Cilaratictic

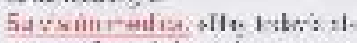
mas:

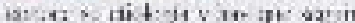

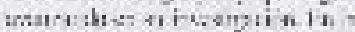

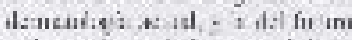

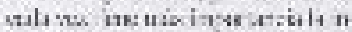
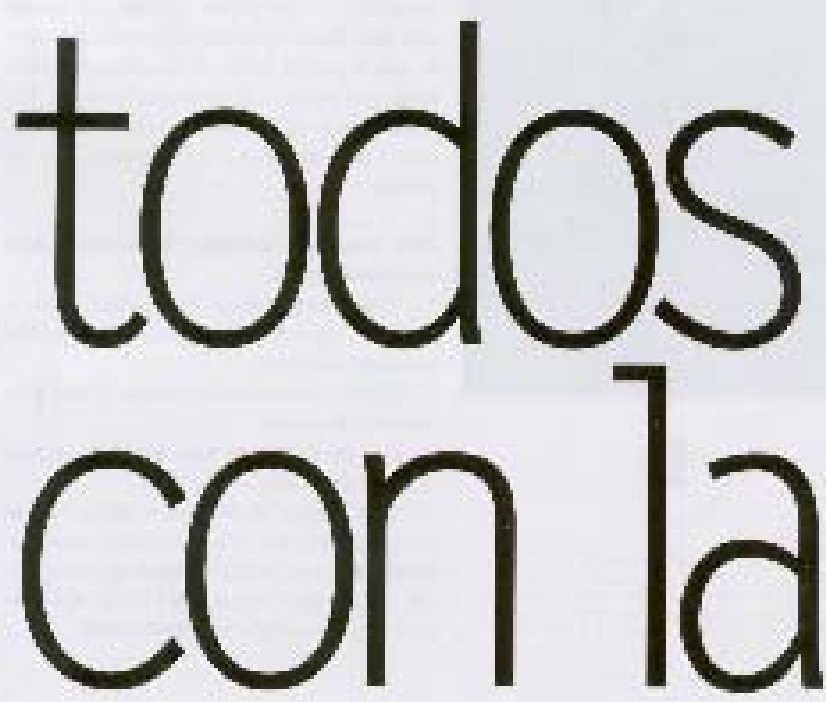

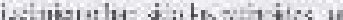

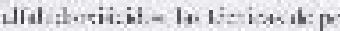

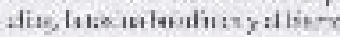

lianimoliant to

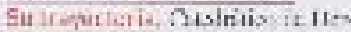

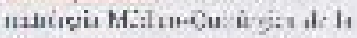

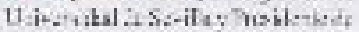

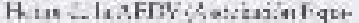

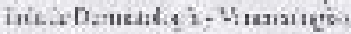

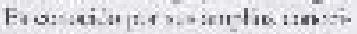

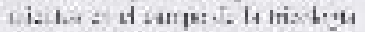

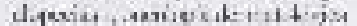

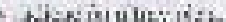

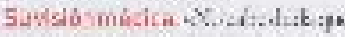

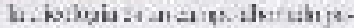
2 sf uf abith o thutaw

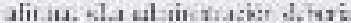

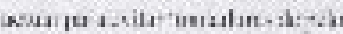

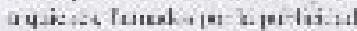

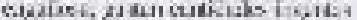

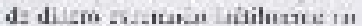
quasetrive

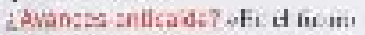

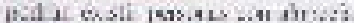

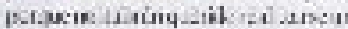

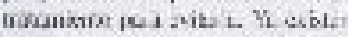

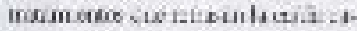

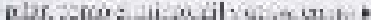

\section{Nalkes}

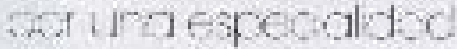

dente socies

o mowosona

siterit

culdetay , weterer.

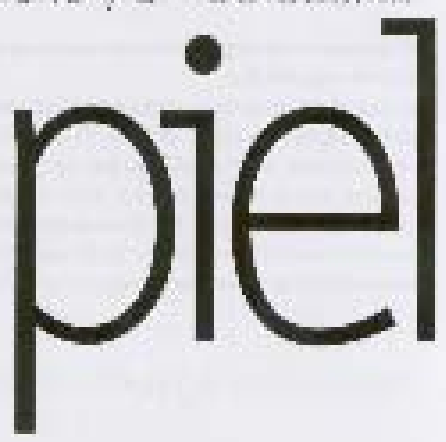


Imagen 46:

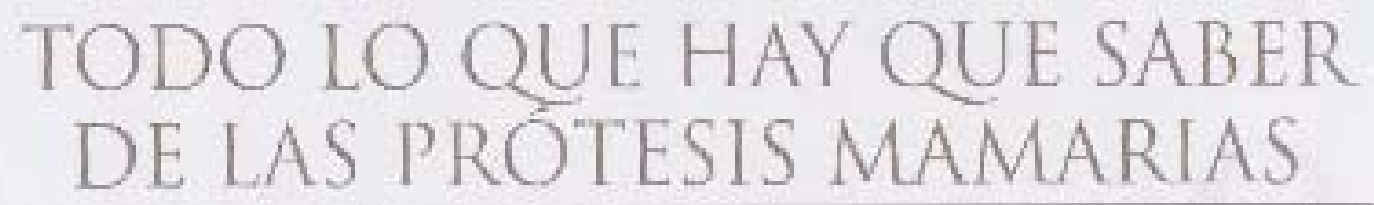

Cue yei fecuesoin we speran d perhs las mejoro epatides:

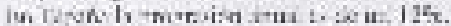

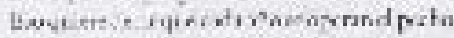

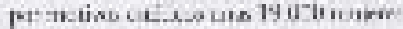

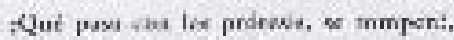
easker hay qoe efiliars?

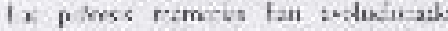

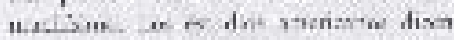

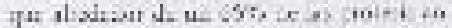

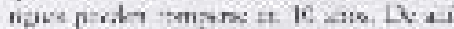

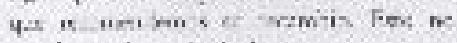

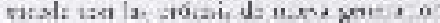

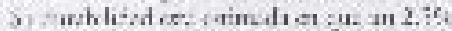

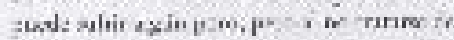

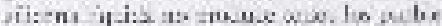

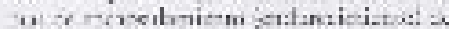
etenseyst albet on ar arves

fles quiem decir qus an sapura la pirj. tais de watus?

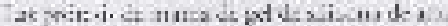

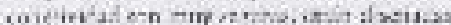

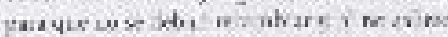

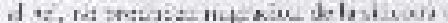

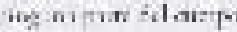

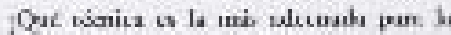
cedomo bio de la prinsoi munaria:

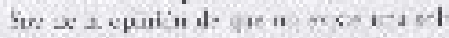

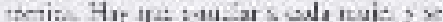

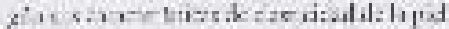

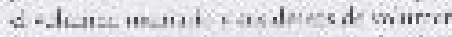

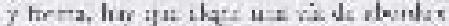

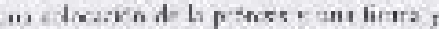

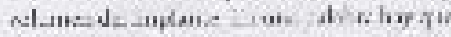

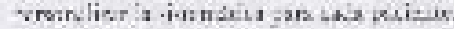

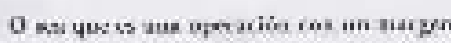
ath de equreilat

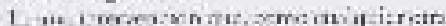

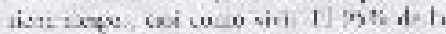

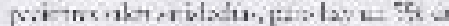

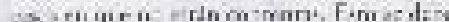

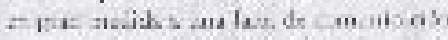

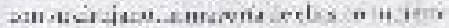

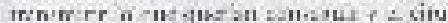

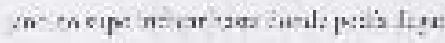
C.si us ta yucis anes anbitual

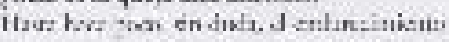

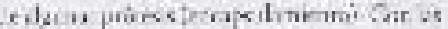

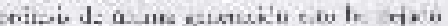

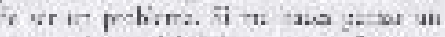
anv, $=1$. dile - ro w w m fircirm?

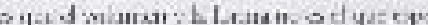
rakn strake was mo indian :je uinu

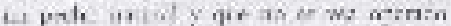

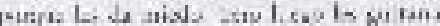

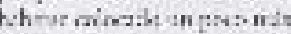

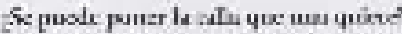

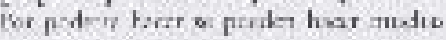
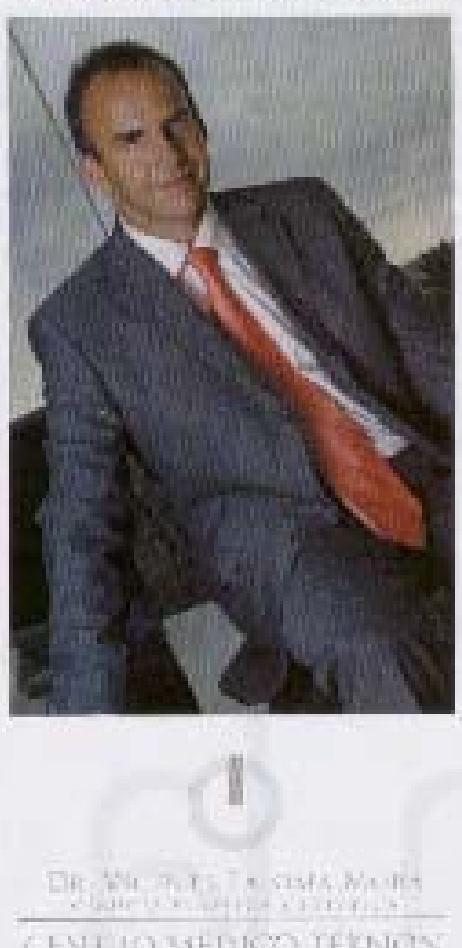

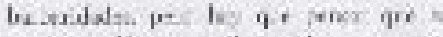

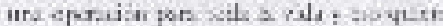

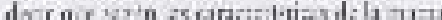

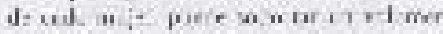

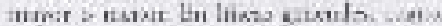
noreral moturs ris p-lirmas jakd.

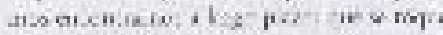
A r.tortedd i

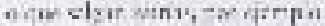

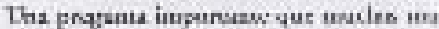

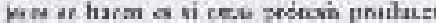
ubuse culosectat ocinos.s.

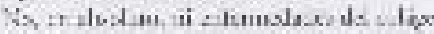

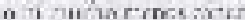

Ess quis: Latir qus al aguinisute ds u.

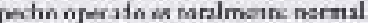

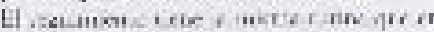

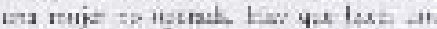

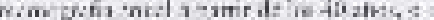

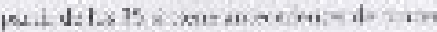

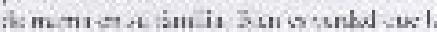

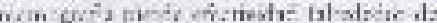

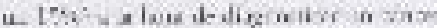

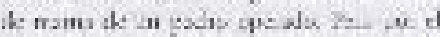

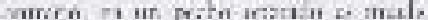

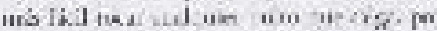

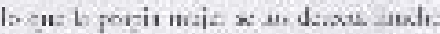

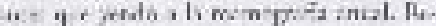

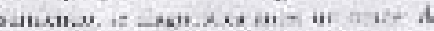

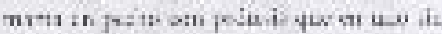
$\min \propto x$

Pera vermian, antasjas imponoasus yan inesuastermon

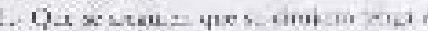

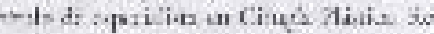

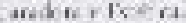

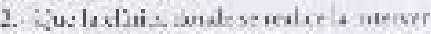
ca-erits alals.

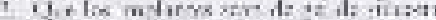

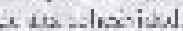

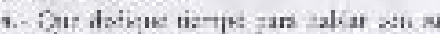

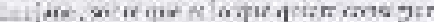

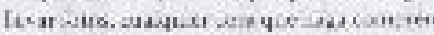

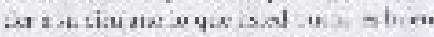

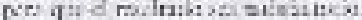


REVISTA DE LA SEECI

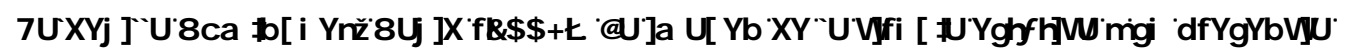

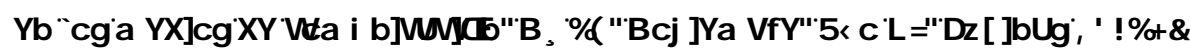

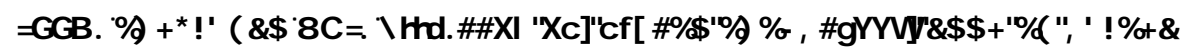

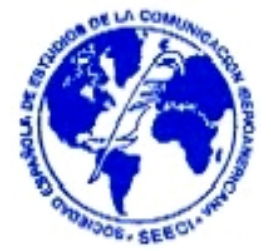

\section{Imagen 47:}

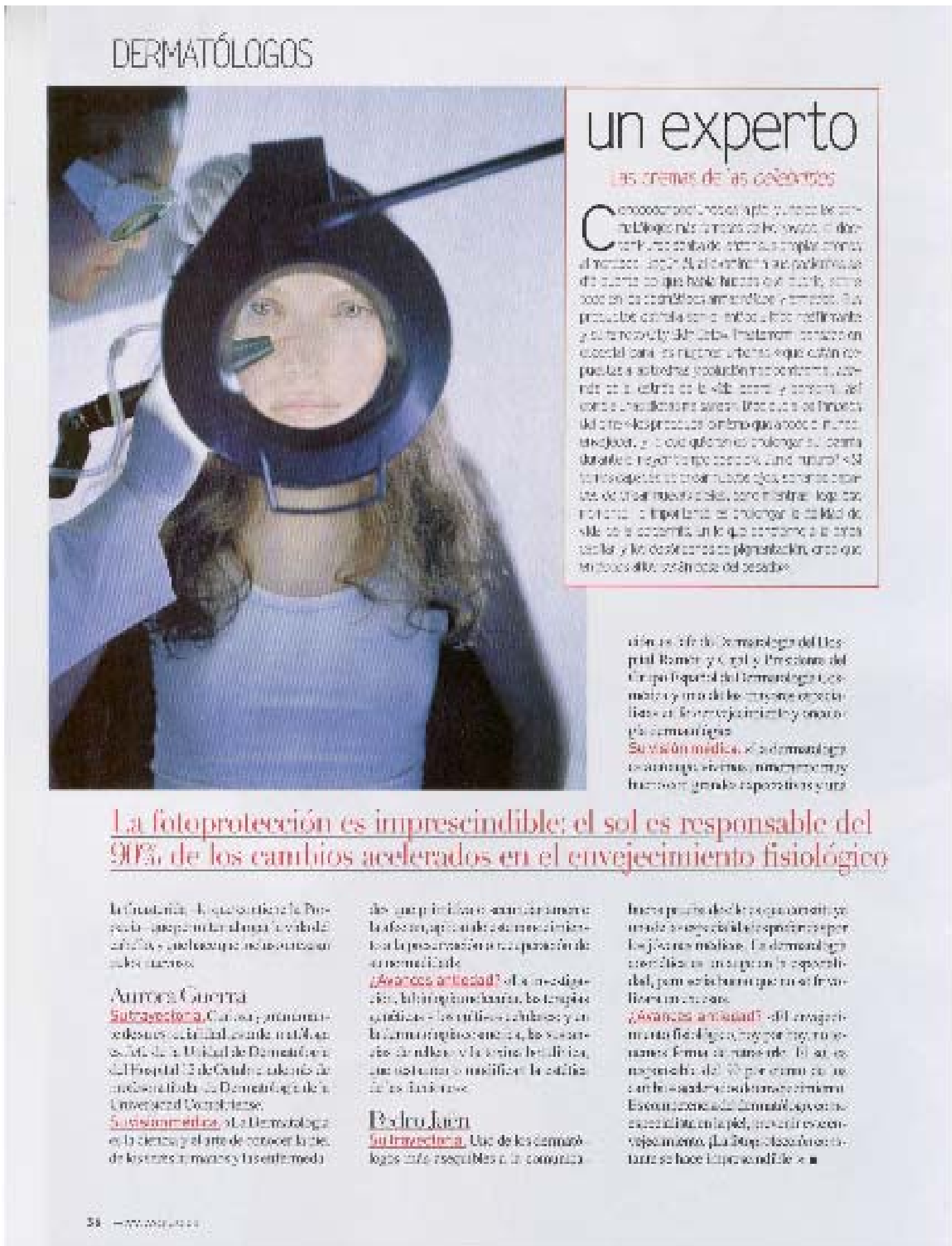




\section{Imagen 48:}

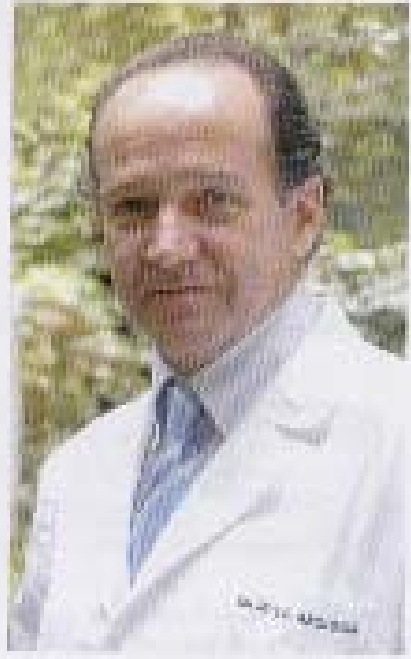

\section{"UNA BUENA IMAGEN TE ABRE MUCHAS PUERTAS"}

El doctor Javier Mato Ansorena, cirujano plástico, reparador y estético, lleva más de 20 anos en el ejercitio de una profesión que, segun sus palabras, "ayuda al paciente a reforzar la autoestima". Hemos querido aprovechar su dilatada experiencia para hablar con el y quenos informe de las novedades quese hanido incorporando en los últimos años.

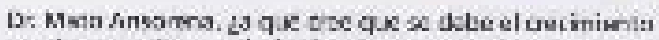

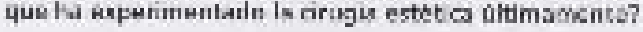

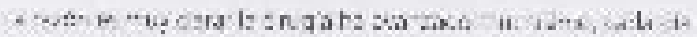

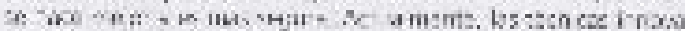

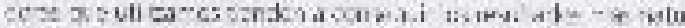

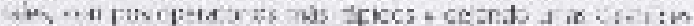

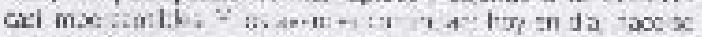

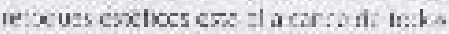

¿Que intervencián custucaria de tates las que se realzen en ill rlrica?

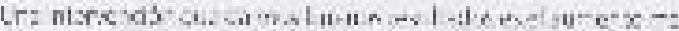

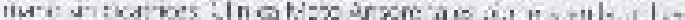

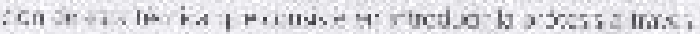

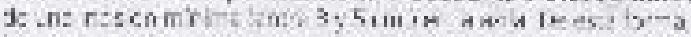

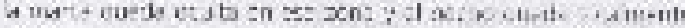

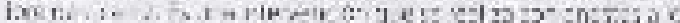

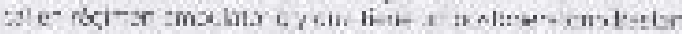

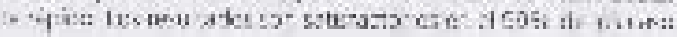

2Due soluciones ofrcce is Clinica Rata Ansermern pura les probinimes ite snhrepeso y grsed scimulada?

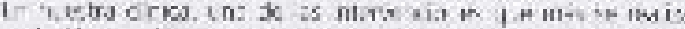

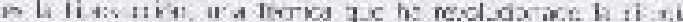

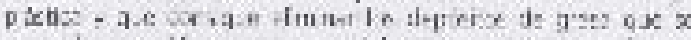

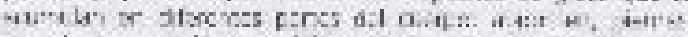

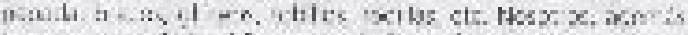

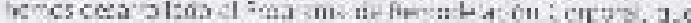

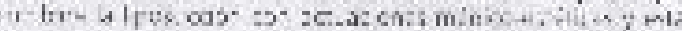

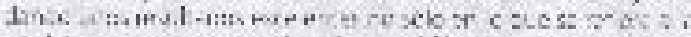

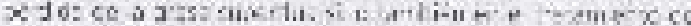

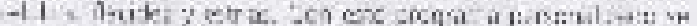

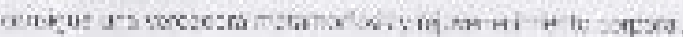
¿Como so censiyun huy un mjuranedmitrto radal natural?

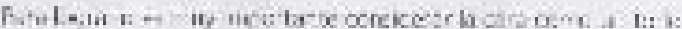

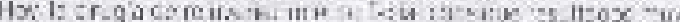

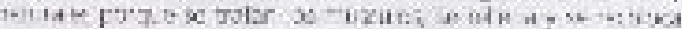

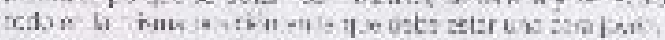

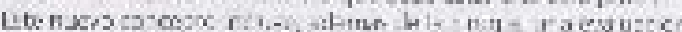

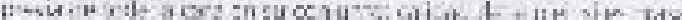

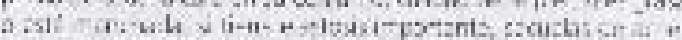

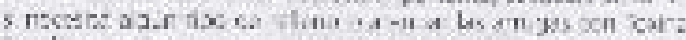

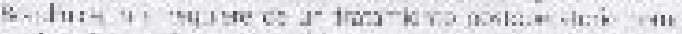

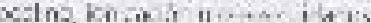

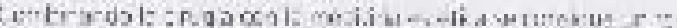

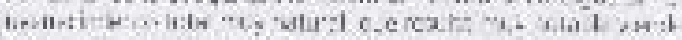

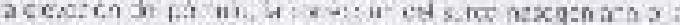

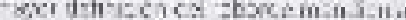

¿E la modicina estwika tumplemetaria to ta crugls?

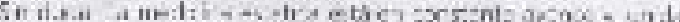

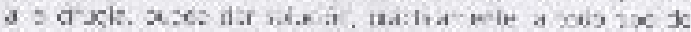

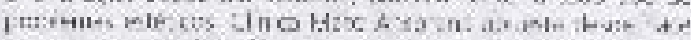

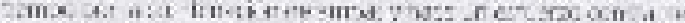

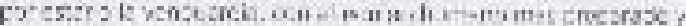

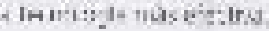

Por oitima. Doctor, de disties dunusisaid imantaras a resstru imagen!

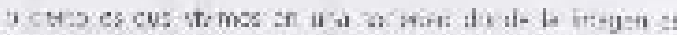

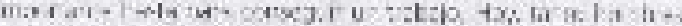

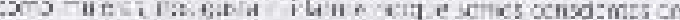

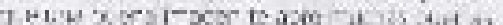

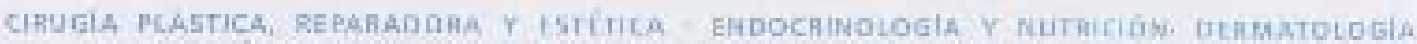

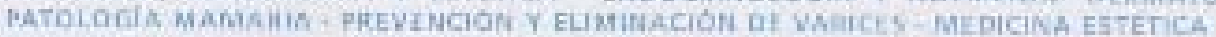

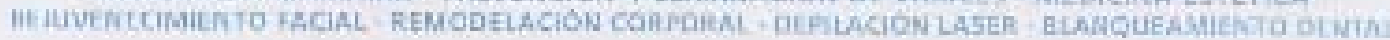

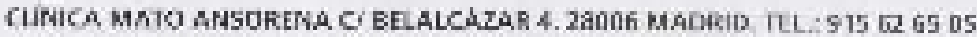
AVDA. SAN FCAMCISCO IAVER 19. 91005 SEVILA. TEL- 554 63 9199

wwo.mato-ansorena.com 


\section{Imagen 49:}

rnomowgeut

\section{CIRUGÍA ESTÉTICA PROGRAMA ANTIAGING}

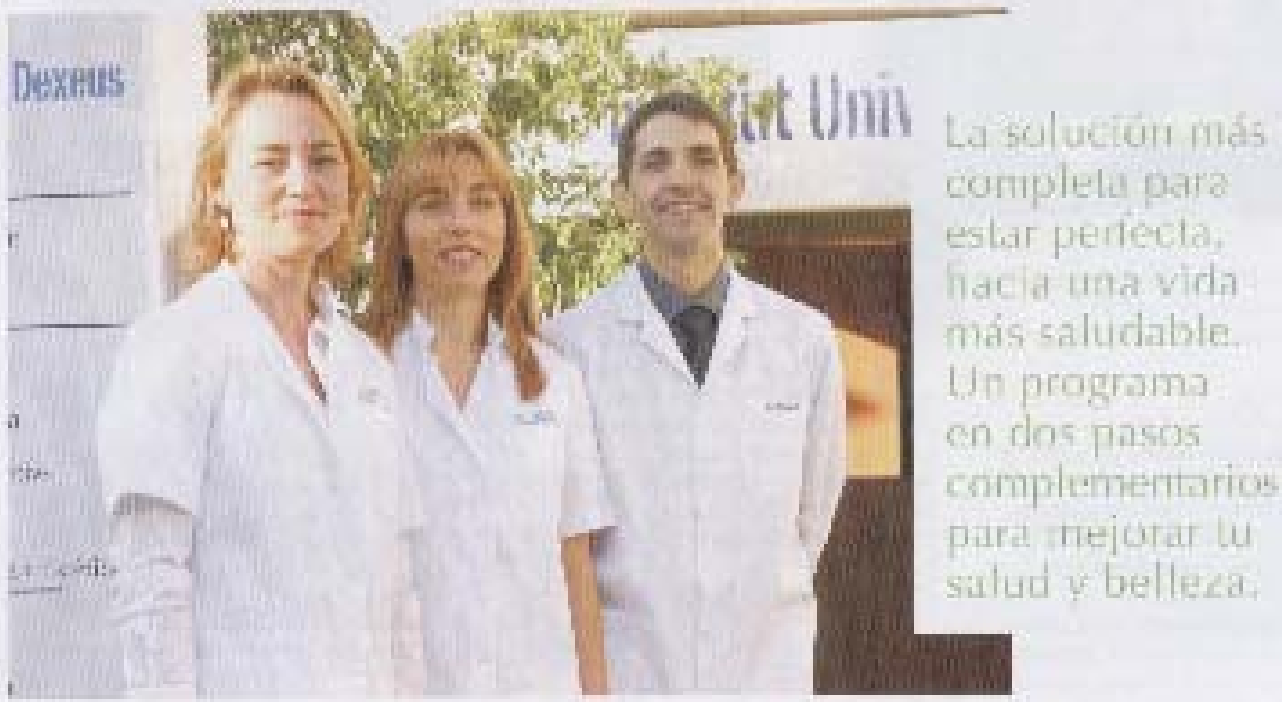

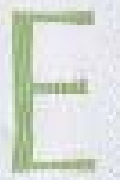

I prasighasa cire kno Dr. kscis Deniles +' rexalumzcivin can la Dra. Manxann i li IMa. Szhador $d: \mid$ Aatiagine Group Br. for piunetes do the lis.era ietua de motrourler a belleza. Su incrionds concepros se centra ro stâk $\alpha$ o 1 interverciones de sin ug estelicas gonfuales fiscarts a ink " -jous exteran de la parcane, sire hambién en en tarso sey jimit-al: a vasex de in protyrume prescanalizarlo dr: disgostico ? Una corkepeinary ahabal doda bolicza natis que

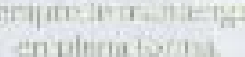
tratamientu antiaging, $\mathrm{DH}_{\mathrm{H}}$ pstc

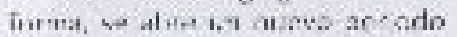
cen la lucha contra a tedad Foles

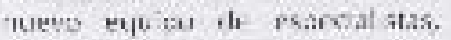

que cuenta cori ona armplia experiereis er foluzia plistica

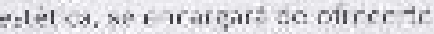
ins srilicion a tu motids Asi, el domor er medicina y Cirugis :

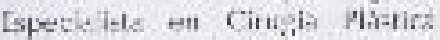
- Repraiartora lezue lievita, se ararga de la perte que equiere und incrve on yoi argice.

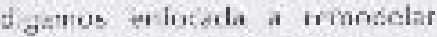
iliper o el roat no mientres las. dect::as pancalo y Salviten, $\mathrm{cm}$ in pistama antestad. facilan al ruartenimisntes de cores ceporat $r$ le kstua de mo armer jusen el argavisfo, z go da sosa nectuario dato el the to sida que leviluss in la artisalielad.
Ial programa se basa en cuafro punlus exenciales

L sual sis del rsicto te salud Cox

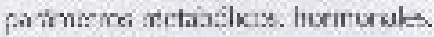
b. clqu nicus...

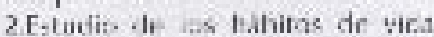
romo. Is artivilar tams, a mer:ata intectreal y rekual

3.Ansisiz vesde aria perspertist medisa ba la arfieidan ficicz aderueda en bast $=$ Jn estudio corticnestudur previto

4. Orienbacitu tar is una xata mas Qh irlihli, sepur Ire res altzdos d: rades los cat udins previes won un prisgrana sncarinado of resctom

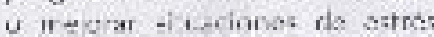
is ifallerique permitan mestablocer

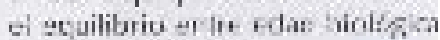
prolad rurmotopira. 
REVISTA DE LA SEECI

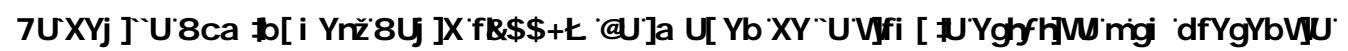

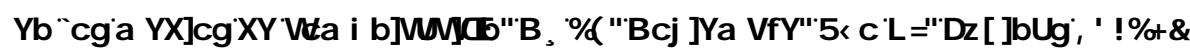

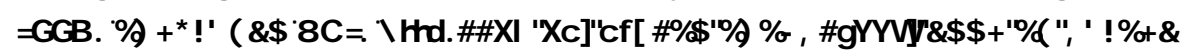

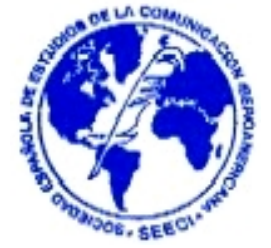

Imagen 50:
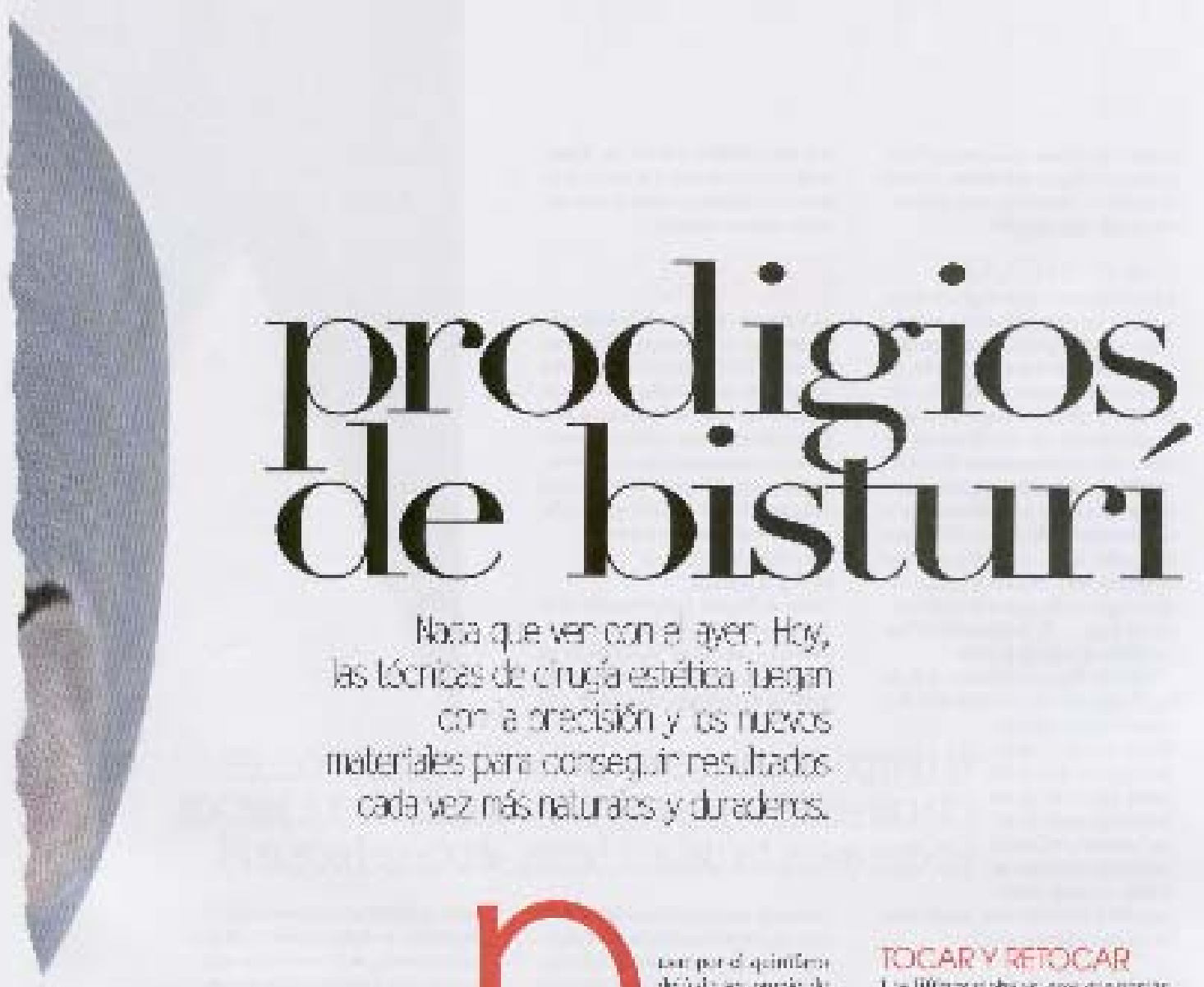

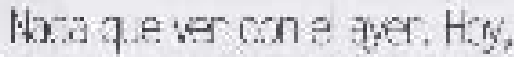

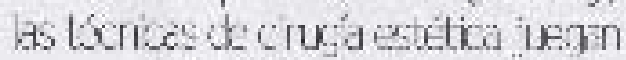

cor a racisikn y us luxios

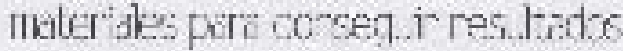
cada nez mas netudas y juadars.

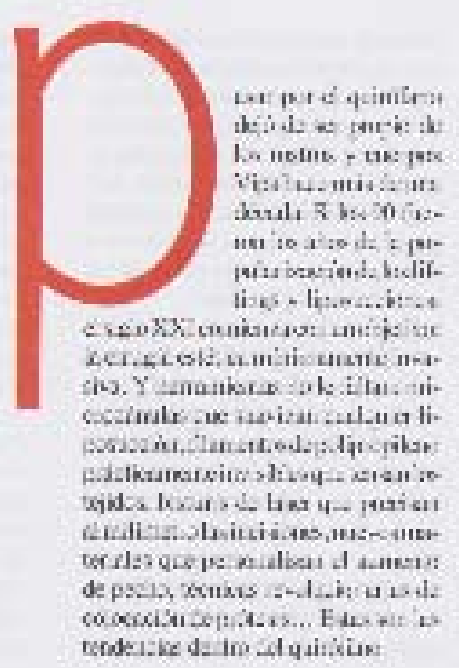

TOCARV FFTOCAR

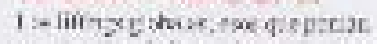

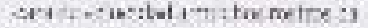

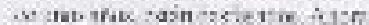

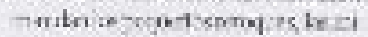

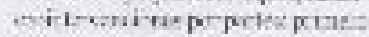

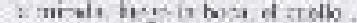

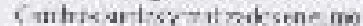

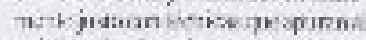

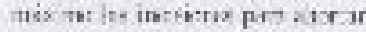

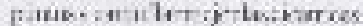

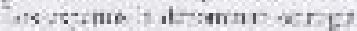

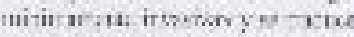

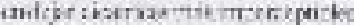

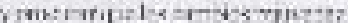
anport ram by prosyos

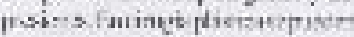

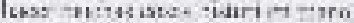

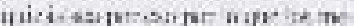

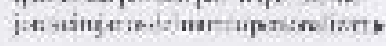


Imagen 51:

\section{CRUGÁA ESTÉTICA}

akitu: $r$ -

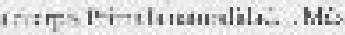

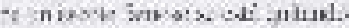

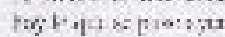

\section{CAMBIO DE CORTE}

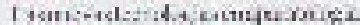

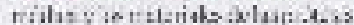

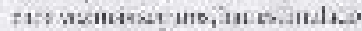

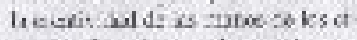

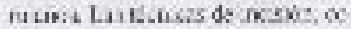

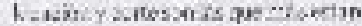

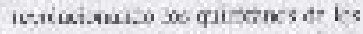

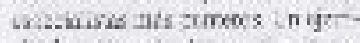

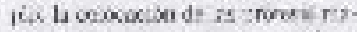

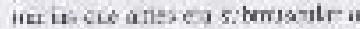

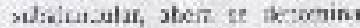

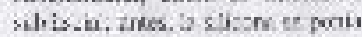

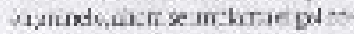

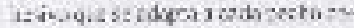

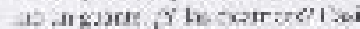
inistdes detura ce as sils

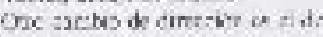

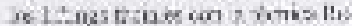
isreim Keocensm?

Ell:A, R.A.K.L, er: se seperos I vezot scrac cose us tors: izrsora, cortices:

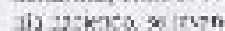

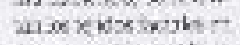
xardoo veroa. Ah

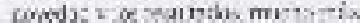
crouke $y=35$ yir twair:ts

\section{LA JNOK HACF}

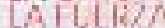

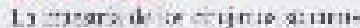

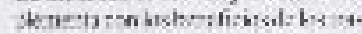

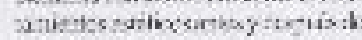

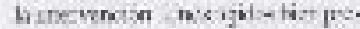

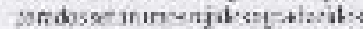

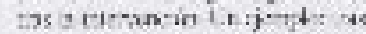

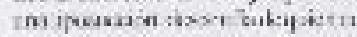

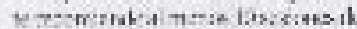

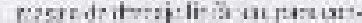

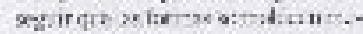
krylosechmoh run ua: if enti-

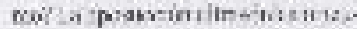

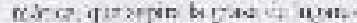

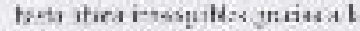

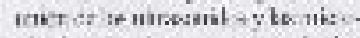

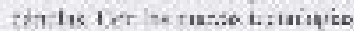

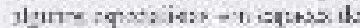

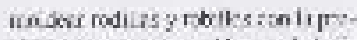

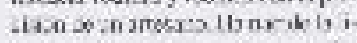

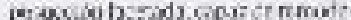

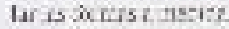

\section{TECDICAS ?}

VANGLAसओク

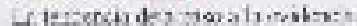

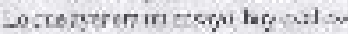

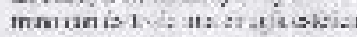

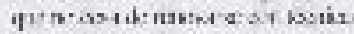

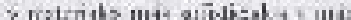

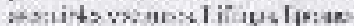

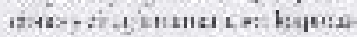

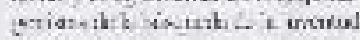

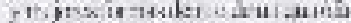

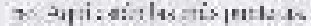
Iecricas that a, e

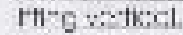

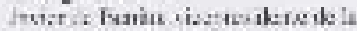

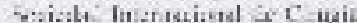

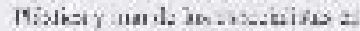

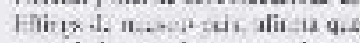

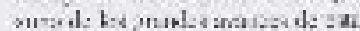

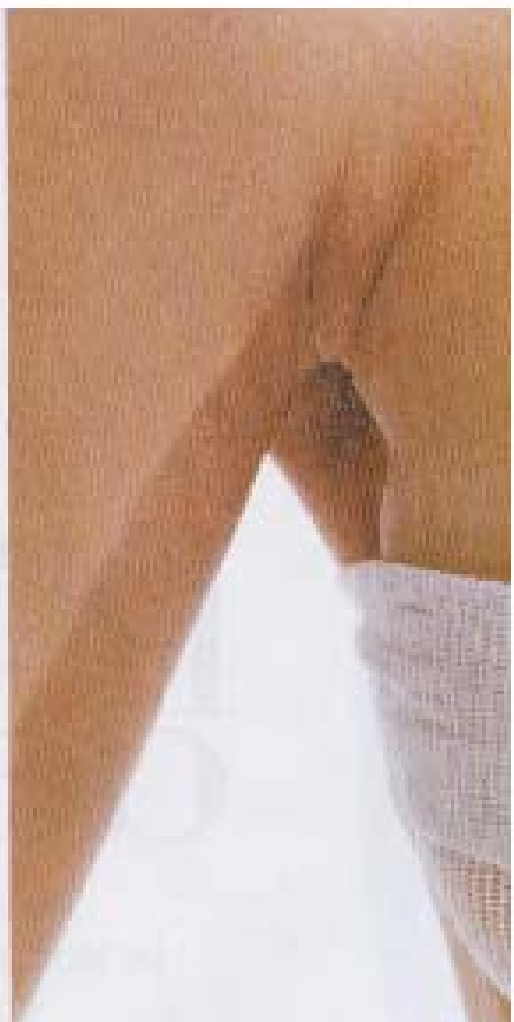

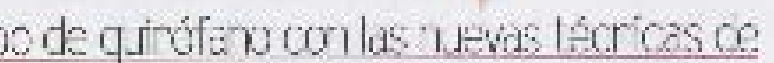
cirugía estétca se ha reducido resta en on trecos. Eartes tarcala 3 hows shora se vecen

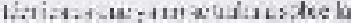

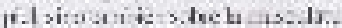

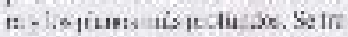

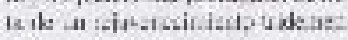

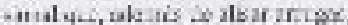

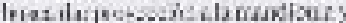

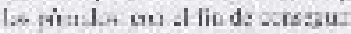

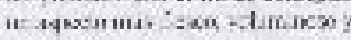

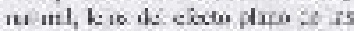

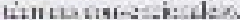

- Len,as Di, ila dietro ac alyos

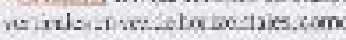

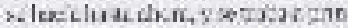

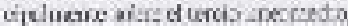

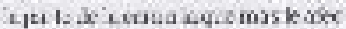

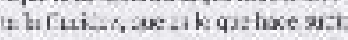

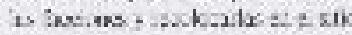
Az bus dies dines hetros pess:o det

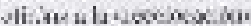

- zavgratra -iblices de k mol auswe incsinc. L ckosiz qust - dia ine atedk delasenzksan

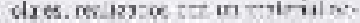

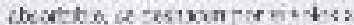

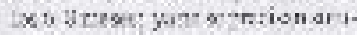
cospreter ie xible latema-

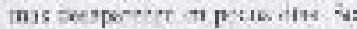

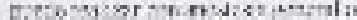

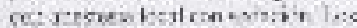

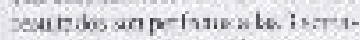

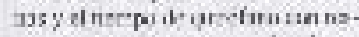

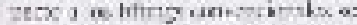

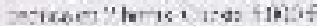

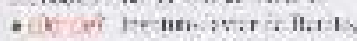

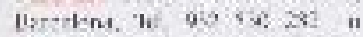
corverecid tetsrius:m s 5 in:

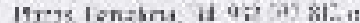

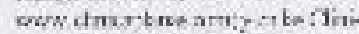

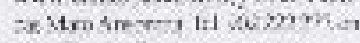
Aintniy vall?

hes tomentergen

nomonoty

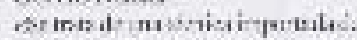
las texdics forti. Furáribs. 


\section{Imagen 54:}

\section{CRUG'ÁA ESTÉTICA}

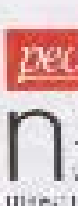
gechos wiez

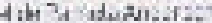
i wente revin: lo

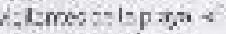

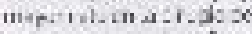

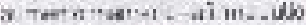

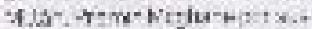

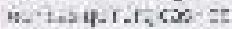

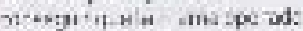

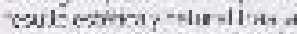

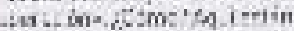
ats of: H: the th-onet:

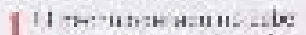

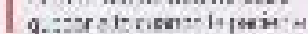

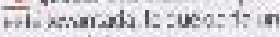
ninis:anls:a

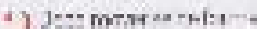
2 sidu.cuon:-1-

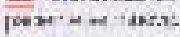

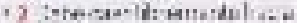

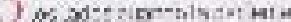
Hejhaseatas.

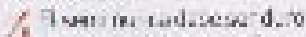

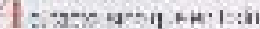

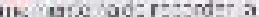

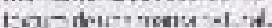

masrigile. F posiondesarde of 75

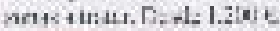

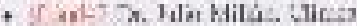
krh- Ta gic we fos Vudri.

ext.cescitude

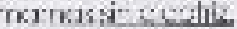

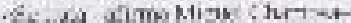

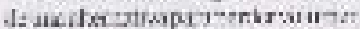

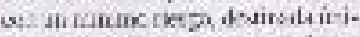
curerecpeciedes ncryon'shorn-

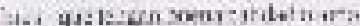

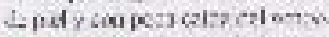

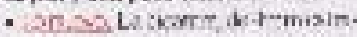
colisudzts snus:2 o od m-ilisen

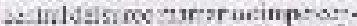
IR:e 2 b: poses moes sisili ja: $=\mathrm{b}$ thisa in toroude l' rorni:: - istak sepserer ibyerasines

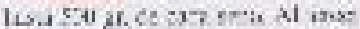

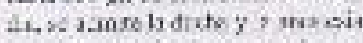

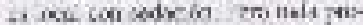

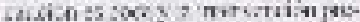

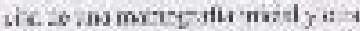

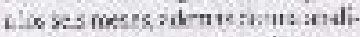

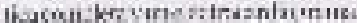

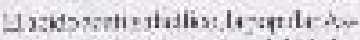

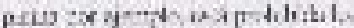

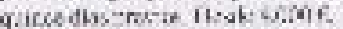

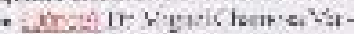

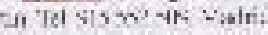
s.mentsare re:...c:

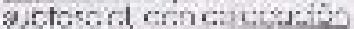

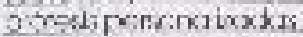

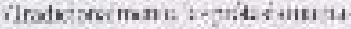

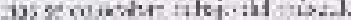

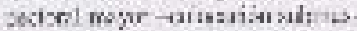

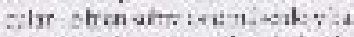

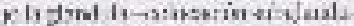

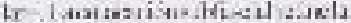
eronjest: los is titum an wit

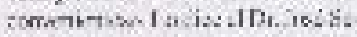

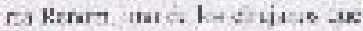

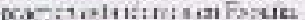

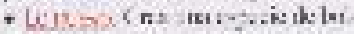

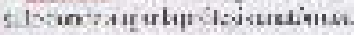

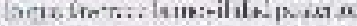

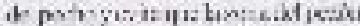

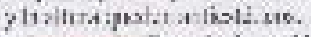

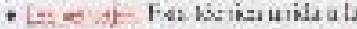

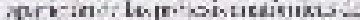

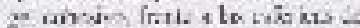

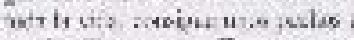

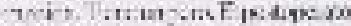

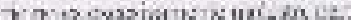

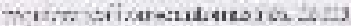

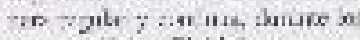

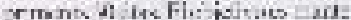
rarbinpi it.sil nel-idas a

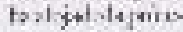

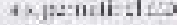

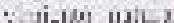
the ...ta: ivere

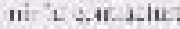

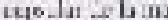
IIti Pic... Des: 3ive

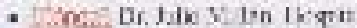

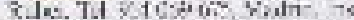

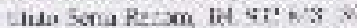

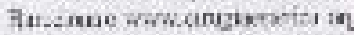

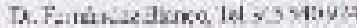
Merlik. D.Jueuskbetnde "tmt

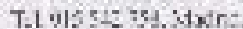

ili w funte entrestern for es zesosoces.

Deinew lecrict nt insmerte i

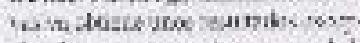

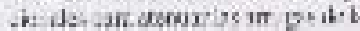

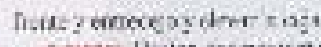

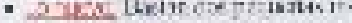

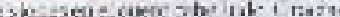

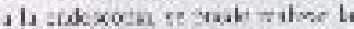

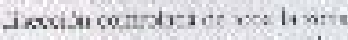
iscracso isdos bu vose y otsi.

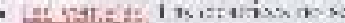

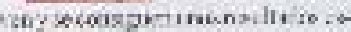

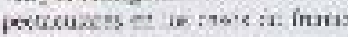

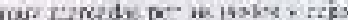

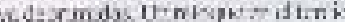

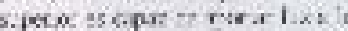

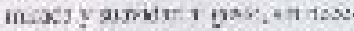

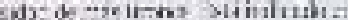

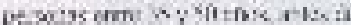

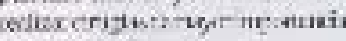
oxte 2 wots

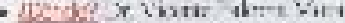

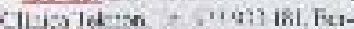

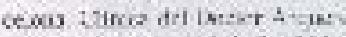

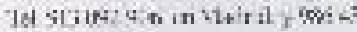
23 . an ine

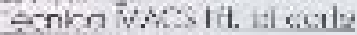
serts:anma

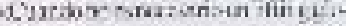

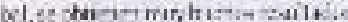

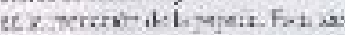
wesprenisentr e nitial ol -i

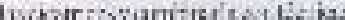

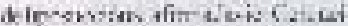

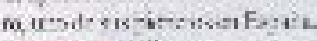

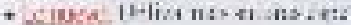

En loe Ltimos 25 afics, mis de dos os y merio de mujeres se

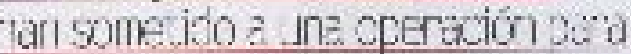
a nileriar el tamaño ce su zeclo

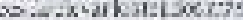

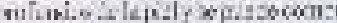

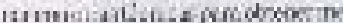
jontinsalines

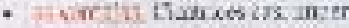

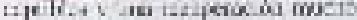

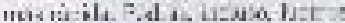

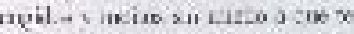

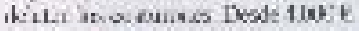
- Ir ari D luser cecoxima le

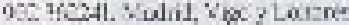

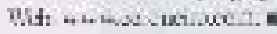


REVISTA DE LA SEECI

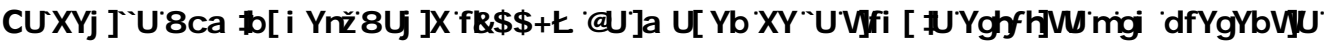

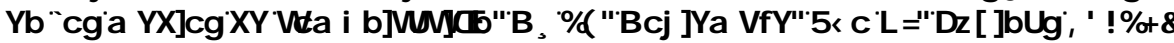

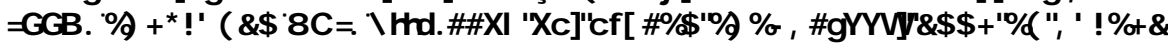
Q

Información sobre clínicas especializadas:

Imagen 36:

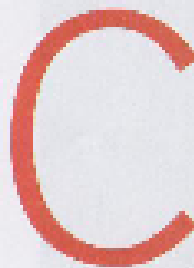

in:lise. At:ms.

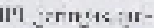
trones lsetio Tam:ate is It raisuyn:rige

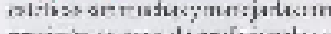

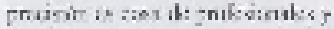

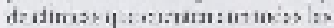
anciustalis:-ent istis

CI VIFA IrKXYX)

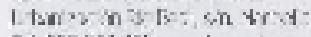

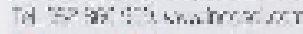

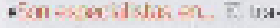

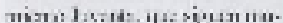

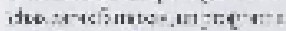

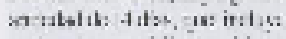
B.

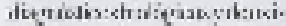

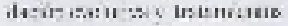

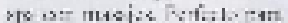

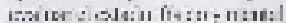

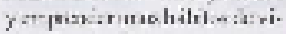

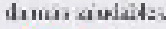

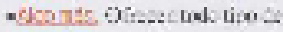

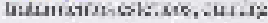

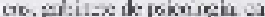

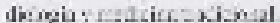

CLNCA DEFUVIE Tr: L:1: ish L 2 har:

I: Su.sekt

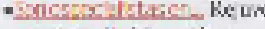

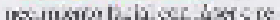

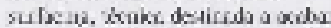

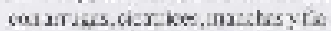

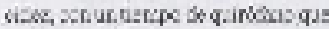

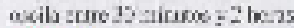

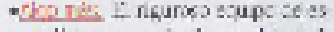

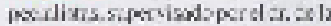

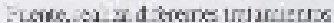
der.sde ker. fi.pdrizs, eatikc? re:crason, desst is eedennalogia - ici pas la cetalrs tosis Is rocas

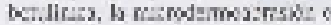

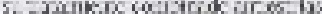

अOUVA OLVIC

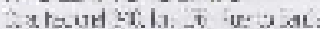

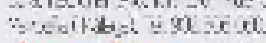

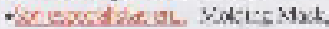

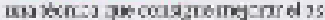

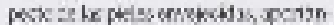

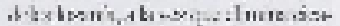

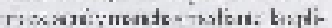

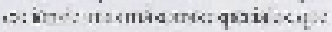

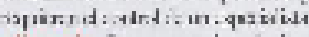
- tign Yes Mas: arso insastivas

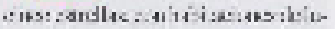

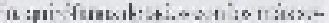

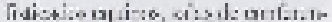

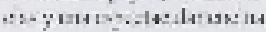

ELIVA TEKVOV

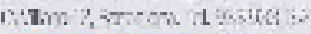

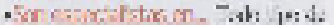

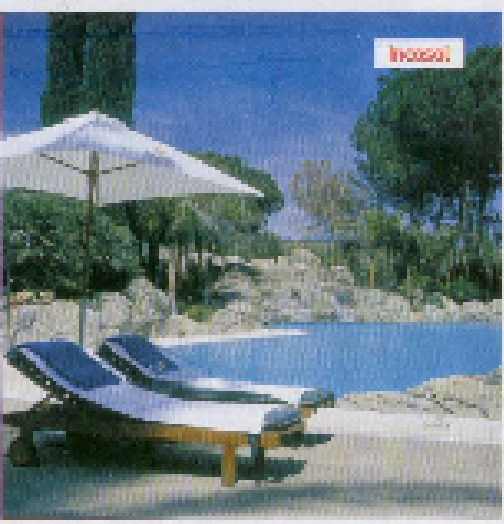

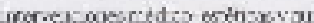
c.ecis Cermoin tuagra mere is netoxas laser vetion enre ks pyco.

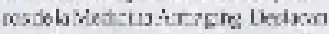

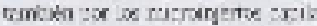

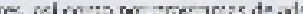

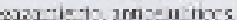

- Junde Liserendexca ig yor tases seresejund cel mones:

CNIX)MEICOC DXinis.

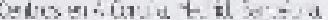

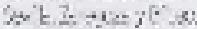

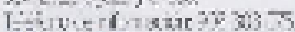

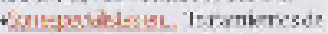
medicnsy ikerackis uries,

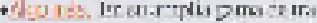

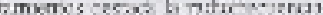

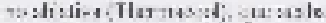
or : $r_{1}$ ible it: is -id.

IVSTILTO CE WEDICIN. ESTET: $\because E$

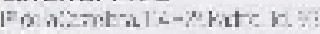
$1+x+2$

- Ler mperitistitien Furvilalda

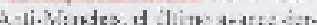

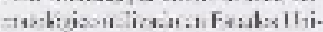

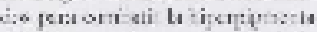

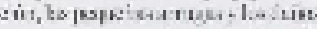

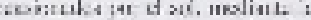

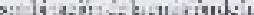

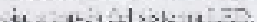

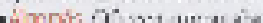

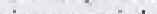

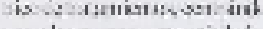

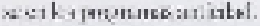

MEDCNA Y CIRLCAA

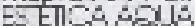

rino mens:- rat $\therefore: 14: 241$.

- Sensuscistase Lex ir.

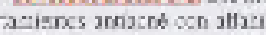

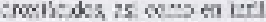
exkins !remo:zlysole da 13

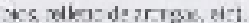

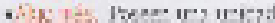
a conjis acretike y ots d

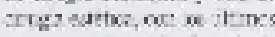
Juzasecizporowgz? retr

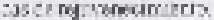

CUNIQUL IRANC.NS

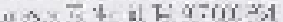

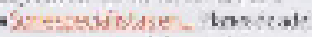
pormanes modtitor tirs me.

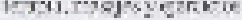

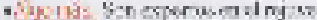
the cotod-rokestm

C:NIXMII xcoknoto MakC

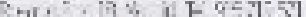

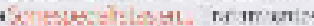

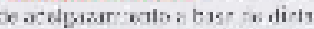

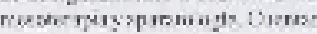

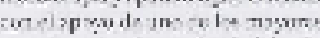

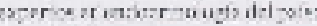
1.7ute starsa 


\section{REVISTA DE LA SEECI}

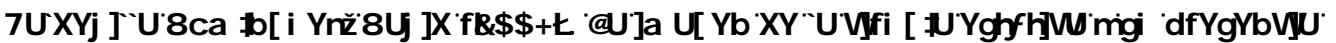

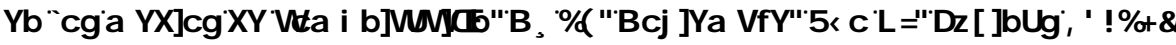

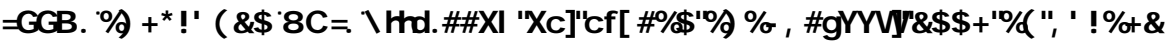

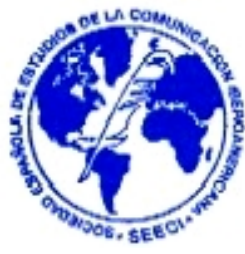

Un ejemplo de campaña contraria a las intervenciones de cirugía estética, proponiendo soluciones alternativas al bisturí (se nota la influencia de las empresas de cosmética, muy buenas clientas de este tipo de revistas mediante contratación de publicidad):

Imagen 52:

\section{TRATAMIENTOS MÉICO-ESTÉTICOS}

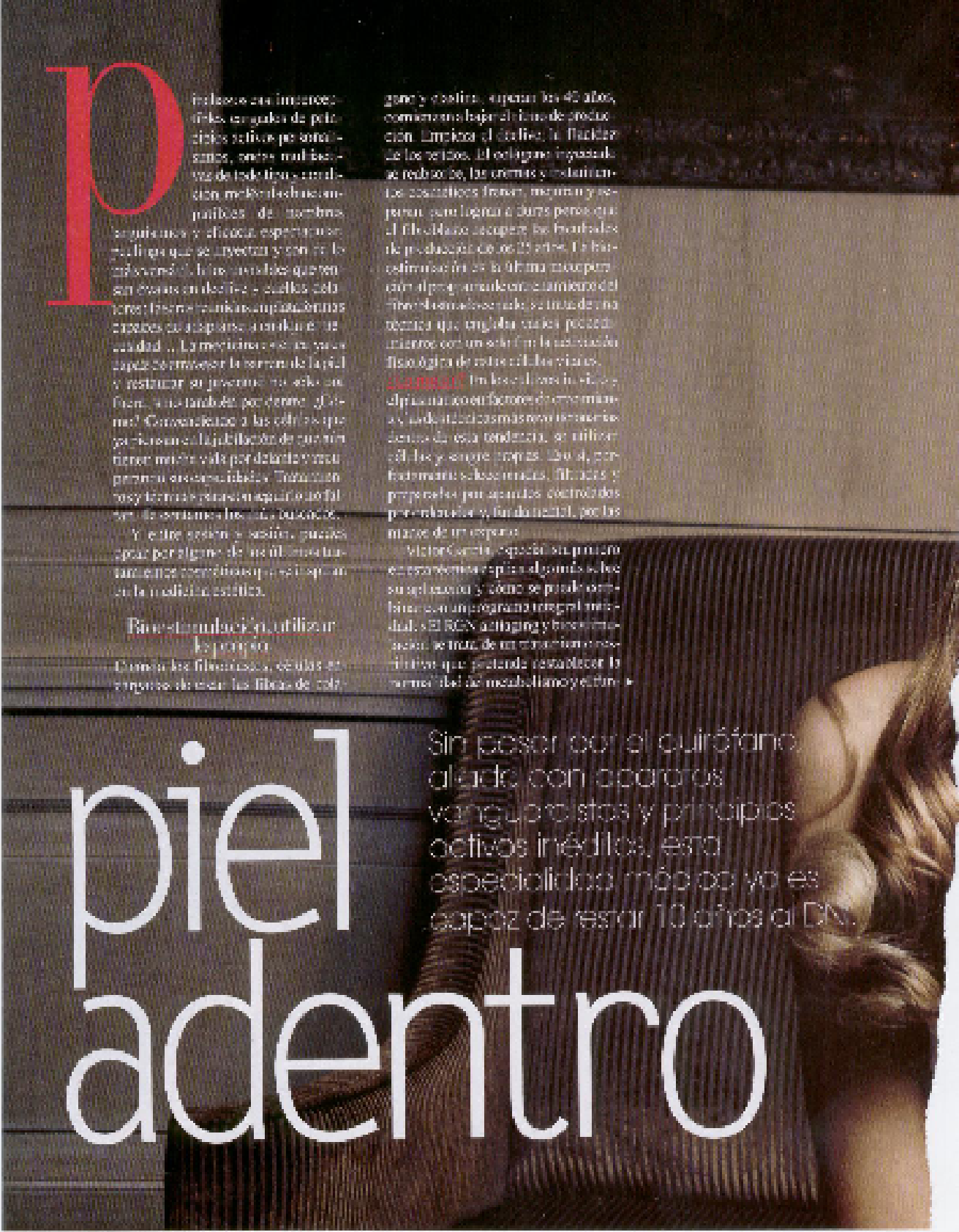


REVISTA DE LA SEECI

Caldevilla Domínguez, David (2007): La imagen de la cirugía estética y su presencia

en los medios de comunicación. No 14. Noviembre. Año XI. Páginas 83-172

ISSN: 1576-3420 DOI: http://dx.doi.org/10.15198/seeci.2007.14.83-172

\section{Imagen 53:}

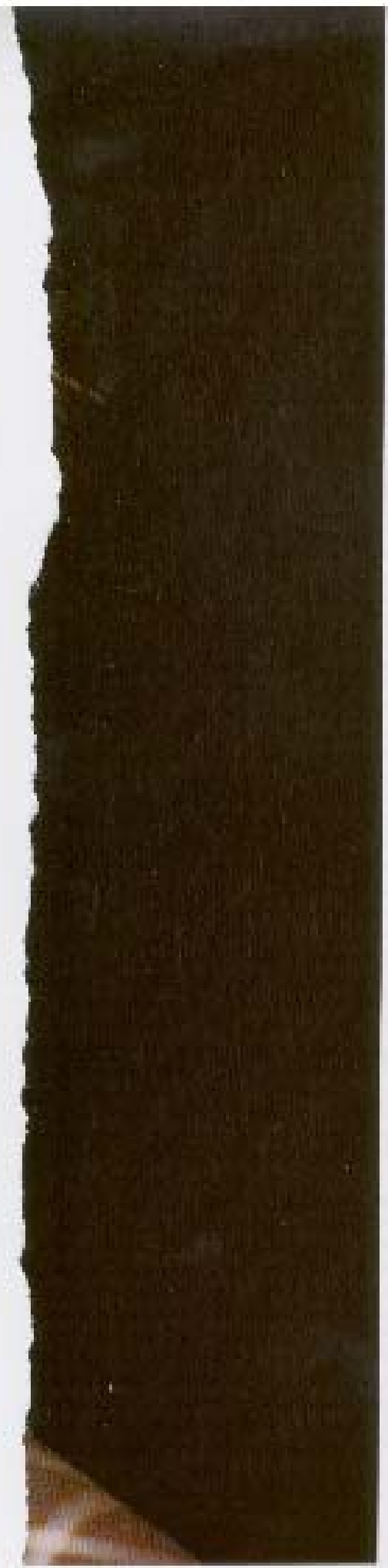

\section{CRIGIAESIÉIICA}

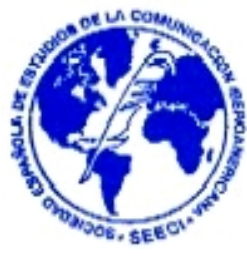

ermz, cir.jace pen nesedesatima.

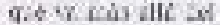
lirus councition. wasecoritioside itchocs ix bicision incerezritioic.

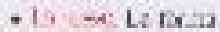

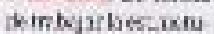
n mascierthose q2 I-s reuts a s seca

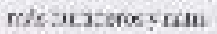
mish indercis, is in $37-13-4 \times 2=0$ tow tum misule al risme semes; zoese rithateso

- linseriata Itses

truirmizaces cerreperitequah merpericionstios?

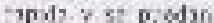
om-virariksn-rios? enlsmentinese: ela er comer max metwer Ixres. nodeser poecsoolot bater mostwit

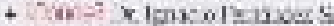

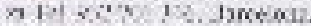
lsorbo ge mikron Crss ga 7.terso

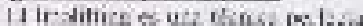

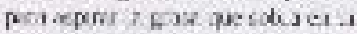

Hés alá ce as arandesonariones de cin fáa est tica en la act ridad vancan los poquorios netorues

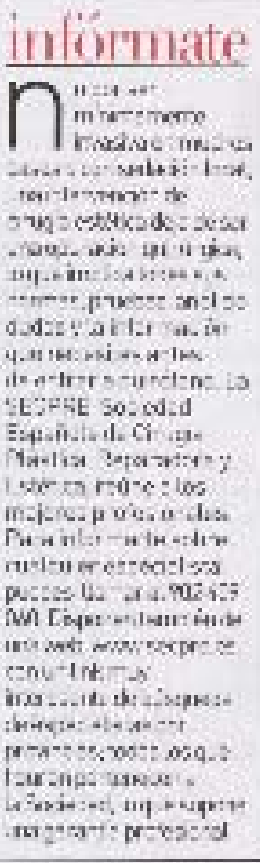

an:mes. An seres? anestre oct ta $3 x$

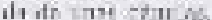
jor e- wo y times acraistarts zano fribis orazevitae - Izintrirtilaga

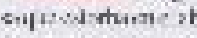

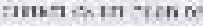

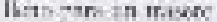

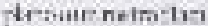
3. Ientinuraprs Arulnicar th was y cuisailas, njisto: s'tenen-sibruest tohisenistymier riscocomats an tpu Alitions aran-e r-ancermpior cukes zirba s loce sroventingan is

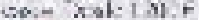

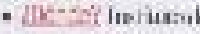
erien:atafirs?

acortenzin.

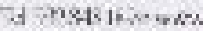
singis:d:tazsen:

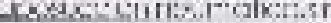

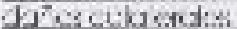

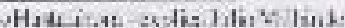

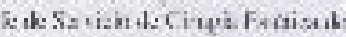

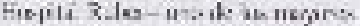

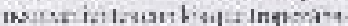

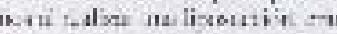
Ledarue setaznl.

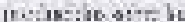

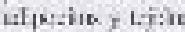
situse - sin $2-1+1+4$ -ri:-wrsing witis Aescilt-is -4ex a iazer co

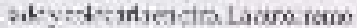

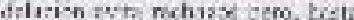

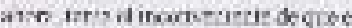
$m * h=s m-;$ trs proirisids.ase

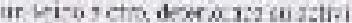

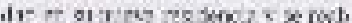

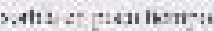

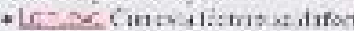

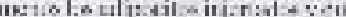

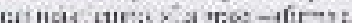

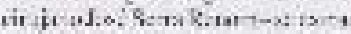
usliate hespratibin as oje $\mathrm{n}$.

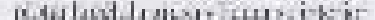

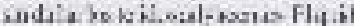

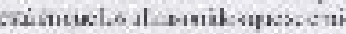

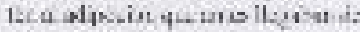

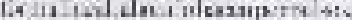

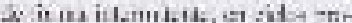

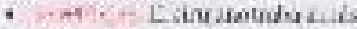
rlunt y se prese a licic lis:u

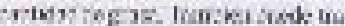
ogranswesmassjer. Wiaks?...

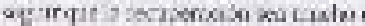
प्रatsiss perelesposialsis 
Tras todo el proceso de recolección de imágenes de publicidad sobre la cirugía estética, la conclusión principal es que es un tema que está muy presente en la sociedad y en todos los medios de comunicación, tanto convencionales como no convencionales gracias a sus constantes campañas publicitarias y reportajes recurrentes en casi todos los Medios de Comunicación para Masas. Asimismo se ha contrastado que estos medios se posicionan en general a favor de la cirugía y de su utilización controlada por expertos. Incluso se ha emitido algún reportaje especial sobre los riesgos del turismo de bisturí en países como Brasil y Colombia.

Los puntos fuertes de la campaña de imagen de las Clínicas se basan en:

- Dan solución a una necesidad.

- En algunos casos se pueden evitar problemas psicológicos, como los complejos, entre otros.

- Mediante publicidad continua y transparente se está intentando dar una idea de normalidad a la sociedad.

- Cada vez son más los medios de comunicación en los que se promocionan, tanto convencionales, como no convencionales.

- Su mensaje va enfocado a ayudar a personas con casos extremos de necesidad.

- Mejoran la imagen de las personas.

Los puntos de ataque a sus postulados se centran en:

- Mucha presencia en anuncios de modelos con físico espectacular desviando la realidad.

- Es bastante cara.

- Puede provocar la muerte.

- Existencia de clínicas ilegales que pueden afectar negativamente a la imagen del resto de clínicas.

- Cada vez es más la gente joven que se opera por influencias exteriores, o por conseguir los cánones de belleza. 
- Poca información sobre el riesgo de la cirugía.

- Pueden provocar deformaciones físicas si no se trata con cuidado, y especialización.

- Se prometen resultados (a veces milagrosos) que muchas veces no se consiguen.

La imagen de la Cirugía Estética es hoy un tema recurrente en la sociedad, presentando tantos detractores como seguidores. El hecho de que el bombardeo publicitario sea amplio supone que el dinero que se mueve es mucho y por ello el interés de los prescriptores de negocio.

Esta investigación pretendió plantear un 'Usted está aquí' como paso previo para poder comprender mejor el funcionamiento mercantil de una industrial que actúa como un lobby (junto a las farmacéuticas) dentro del campo médico.

Esperamos haber contribuido a su mayor y mejor conocimiento desde el punto de vista del análisis de su comunicación persuasiva.

$$
\text { NÍHIL ÓBSTAT . IMPRIMÁTUR }
$$

\section{Bibliografía}

CALDEVILLA DOMÍNGUEZ, David (2006): Campaña de imagen sobre la Cirugía Estética. Visión Net. Madrid.

ABC: $\underline{w w w . a b c . e s}$

DIARIO QUÉ: $\underline{\text { www.que.es }}$ 
EL MUNDO:

EL PAÍS: Ww.elpais.com

LA RAZÓN: Www.larazon.es

LA VANGUARDIA: Wwavanguardia.com

CADENA COPE: WW.cope.es

CADENA SER: W.cadenaser.com

CADENA SER: Programa especial sobre la cirugía estética Www.cadenaser.com/archivo/buscando.html?query $=$ cirugia\%20 estetica\&sitio $=\&$ formato $=\mathrm{T}, \mathrm{A}$ \&donde=\&medio= csr\&seleccionaDia $=\&$ seleccionaMes $=\&$ SeleccionAnyo=\&seleccionaDiaH asta $=\&$ seleccionaMesHasta $=\&$ seleccionaAnyoHasta $=\&$ fechaultimos $=$ \&order $=\&$ keyword $=\& d$ ecPage $=10 \&$ docStart $=11$

ONDA CERO: WW.ondacero.es

RADIO NACIONAL DE ESPAÑA:-wWw.rtve.es/radio

ANTENA 3: WWw.antena3.com

LA CUATRO: WWW.cuatro.com

TELE 5: Ww.telecinco.es

TELEMADRID:

TELEVISIÓN ESPAÑOLA: 